\title{
Activation and Deactivation of Neutral Palladium(II) Phosphinesulfonato Polymerization Catalysts
}

\author{
Thomas Rünzi, $^{\dagger}$ Ulrich Tritschler, ${ }^{\dagger}$ Philipp Roesle, ${ }^{\dagger}$ Inigo Göttker-Schnetmann, ${ }^{\dagger}$ Heiko M. Möller, ${ }^{\dagger}$ \\ Lucia Caporaso, ${ }^{* \dagger}$ Albert Poater, ${ }^{\$}$ Luigi Cavallo, ${ }^{\perp}$, and Stefan Mecking ${ }^{* \dagger}$ \\ ${ }^{\dagger}$ Department of Chemistry, University of Konstanz, 78464 Konstanz, Germany \\ ${ }^{ \pm}$Department of Chemistry, University of Salerno, Via Ponte Don Melillo, 84084-Fisciano (SA), Italy \\ ${ }^{\S}$ Institut de Química Computacional, Department de Química, Universitat de Girona, Campus de Montilivi, E-17071 Girona, Spain \\ ${ }^{\perp}$ Chemical and Life Sciences and Engineering, Kaust Catalysis Center, King Abdullah University of Science and Technology, \\ Thuwal 23955-6900, Saudi Arabia
}

ABSTRACT: ${ }^{13} \mathrm{C}$-Labeled ethylene polymerization (pre)catalysts $\left[K^{2} \cdot(\text { anisyl })_{2} P, \mathrm{O}\right] \mathrm{Pd}\left({ }^{13} \mathrm{CH}_{3}\right)(\mathrm{L})\left({ }^{1{ }^{13}} \mathrm{CH}_{3} \cdot \mathrm{L}\right)(\mathrm{L}=$ pyridine, dmso) based on di (2-anisyl)phosphine benzenesul. fonate were used to assess the degree of incorporation of ${ }^{13} \mathrm{CH}_{3}$ groups into the formed polyethylenes. Polymerizations of variable reaction time reveal that ca. $60-85 \%$ of the ${ }^{13} \mathrm{C}$. label is found in the polymer after already 1 min polymerization time, which provides evidence that the pre-equilibra. tion between the catalyst precursor $1-{ }^{13} \mathrm{CH}_{3}-\mathrm{L}$ and the active

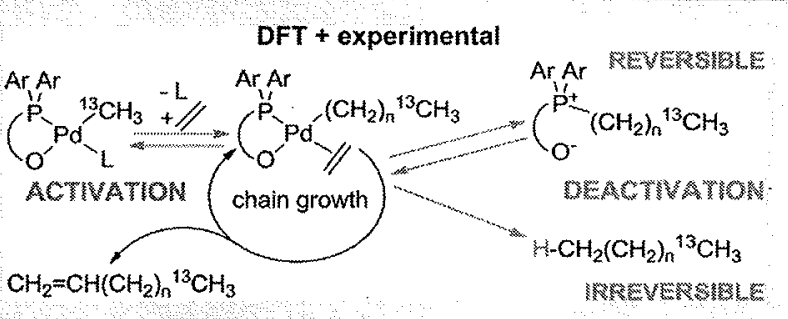
species $1{ }^{13} \mathrm{CH}_{3}$-(ethylene) is fast with respect to chain growth. The fraction of $1^{13} \mathrm{CH}_{3}-\mathrm{L}$ that initiates chain growth is likely higher than the $60-85 \%$ determined from the ${ }^{13} \mathrm{C}$-labeled polymer chain ends since (a) chain walking results in in-chain incorporation of the ${ }^{13} \mathrm{C}$-label, (b) irreversible catalyst deactivation by formation of saturated (and partially volatile) alkanes diminishes the amount of ${ }^{13} \mathrm{CH}_{3}$ groups incorporated into the polymer, and (c) palladium-bound ${ }^{13} \mathrm{CH}_{3}$ groups, and more general palladium bound alkyl (polymeryl) chains, partially transfer to phosphorus by reductive elimination. NMR and ESI-MS analyses of thermolysis reactions of $1-{ }^{13} \mathrm{CH}_{3} \mathrm{~L}$ provide evidence that a mixture of phosphonium salts $\left({ }^{13} \mathrm{CH}_{3}\right)_{x} \mathrm{P}^{+}(\text {aryl })_{4-x}(2-7)$ is formed in the absence of ethylene. In addition, isolation and characterization of the mixed bis(chelate) palladium complex $\left[\mathrm{K}^{2}\right.$-(anisyl) $\left.{ }_{2} \mathrm{P}, \mathrm{O}\right] \mathrm{Pd}\left[\mathrm{x}^{2}\right.$-(anisyl) $\left.\left({ }^{13} \mathrm{CH}_{3}\right) \mathrm{P}, \mathrm{O}\right](11)$ by NMR and $\mathrm{X}$-ray diffraction analyses from these mixtures indicate that oxidative addition of phosphonium salts to palladium $(0)$ species is also operative. The scrambling of palladium-bound carbyls and phosphorus-bound aryls is also relevant under NMR, as well as preparative reactor polymerization conditions exemplified by the X-ray diffraction analysis of $\left[\kappa^{2}-(\right.$ anisyl $\left.){ }_{2} P, O\right] P d\left[\kappa^{2}-(\right.$ anisyl $\left.)\left(\mathrm{CH}_{2} \mathrm{CH}_{3}\right) \mathrm{P}, \mathrm{O}\right](12)$ and $\left[\kappa^{2}-\left(\right.\right.$ anisyl) $\left.{ }_{2} \mathrm{P}, \mathrm{O}\right] \mathrm{Pd}$ $\left[\kappa^{2}\right.$-(anisyl) $\left.\left(\left(\mathrm{CH}_{2}\right)_{3} \mathrm{CH}_{3}\right) P, O\right](13)$ isolated from pressure reactor polymerization experiments. In addition, ESI-MS analyses of reactor polymerization filtrates indicate the presence of (odd-and even-numbered alkyl)(anisyl)phosphine sulfonates (14) and their respective phosphine oxides (15). Furthermore, 2-(vinyl)anisole was detected in NMR tube and reactor polymerizations, which results from ethylene insertion into a palladium -anisyl bond and concomitant $\beta$-hydride elimination. In addition to these scrambling reactions, formation of alkanes or fully saturated polymer chains, bis(chelate)palladium complexes $\left[\kappa^{2}-P, O\right]_{2} P d$, and palladium black was identified as an irreversible catalyst deactivation pathway. This deactivation proceeds by reaction of palladium alkyl complexes with palladium hydride complexes $\left[K^{2}-P, O\right] P d(H)(L)$ or by reaction with the free ligand $H[P, O]$ generated by reductive elimination from $\left[\kappa^{2}-P, O\right] \mathrm{Pd}(\mathrm{H})(\mathrm{L})$. The model hydride complex $1-\mathrm{H}-\mathrm{P}^{t} \mathrm{Bu}_{3}$ has been synthesized in order to establish whether $1-\mathrm{H}-\mathrm{P}^{\prime} \mathrm{Bu}_{3}$ or $\mathrm{H}[\mathrm{P}, \mathrm{O}]$ is responsible for the irreversible catalyst deactivation. However, upon reaction with $\mathrm{I}^{\left({ }^{(3)} \mathrm{CH}_{3}-\mathrm{L} \text { or }\right.}$ 1- $\mathrm{CH}_{2} \mathrm{CH}_{3}-\mathrm{PPh}_{3}$, both 1-H-P $\mathrm{Bu}_{3}$ and $\mathrm{H}[\mathrm{P}, \mathrm{O}]$ result in formation of methane or ethane, even though $\mathrm{H}[\mathrm{P}, \mathrm{O}]$ reacts faster than 1-H.P ${ }^{t} \mathrm{Bu}_{3}$. DFT calculations show that reductive elimination to form $\mathrm{H}[\mathrm{P}, \mathrm{O}]$ and (alkyl) $[\mathrm{P}, \mathrm{O}]$ from $1-\mathrm{H} /\left(\right.$ alkyl)-Pt $\mathrm{Pu}_{3}$ is kinetically accessible, as is the oxidative readdition of the $\mathrm{P}-\mathrm{H}$ bond of $\mathrm{H}[\mathrm{P}, \mathrm{O}]$ and the $\mathrm{P}$-anisyl bond of (alkyl) $[\mathrm{P}, \mathrm{O}]$ to $\left[\mathrm{Pd}\left(\mathrm{P}^{t} \mathrm{Bu}_{3}\right)_{2}\right]$. These calculations also indicate that for a reaction sequence comprising reductive elimination of $\mathrm{H}[\mathrm{P}, \mathrm{O}]$ from 1-H.P $\mathrm{Bu}_{3}$ and reaction of $\mathrm{H}[\mathrm{P}, \mathrm{O}]$ with $1-\mathrm{CH}_{3}-\mathrm{P}^{t} \mathrm{Bu}_{3}, 1-\mathrm{CH}_{3}$ dmso, or $1-\mathrm{CH}_{2} \mathrm{CH}_{3}-\mathrm{PPh}_{3}$ to form methane or ethane, the ratelimiting step is reductive elimination of $\mathrm{H}[\mathrm{P}, \mathrm{O}]$ with a barrier of $124 \mathrm{~kJ} \mathrm{~mol}^{-1}$ However, a second reaction coordinate was found for the reaction of $1-\mathrm{H}-\mathrm{P}^{t} \mathrm{Bu}_{3}$ with $1-\mathrm{CH}_{3}-\mathrm{P}^{t} \mathrm{Bu}_{3}$ or $1-\mathrm{CH}_{3}$-dmso, which evolves into bimetallic transition-state geometries with a nearly linear $\mathrm{H}-\left(\mathrm{CH}_{3}\right)-\mathrm{Pd}$ alignment and which exhibits a barrier of 131 or $95 \mathrm{~kJ} \mathrm{~mol}^{-1}$ for the formation of methane. 


\section{INTRODUCTION}

Catalytic polymerizations of olefins are practiced on a large scale. However, an insertion polymerization of polar vinyl monomer is a long-standing challenge. ${ }^{1,2}$ Major advances were achieved recently by the finding that neutral $\kappa^{2}-P, O$-phosphinesulfonato palladium(II) complexes (cf. 1-L) promote the formation of linear copolymers of ethylene with a broad scope of polar monomers including not only acrylates, ${ }^{3}$ but also acrylonitrile, ${ }^{4}$ vinylacetate, ${ }^{5}$ vinylftuoride, ${ }^{6}$ allylic monomers, ${ }^{7}$ acrylic acid, ${ }^{8}$ and acrylamides $^{9}$ and also catalyze insertion homooligomerization of acrylates. ${ }^{10,11}$

Many features of the catalytic chain growth in these (co)polymerizations have been revealed by detailed experimental and theoretical investigations, 12 and a fairly comprehensive mechanistic picture exists. Polar monomers $\left(\mathrm{CH}_{2}=\mathrm{CHX}\right)$ reduce polymerization rates by chelating coordination of the growing polymeryl chain via functional groups $(\mathrm{X})$ of a last or penultimate incorporated repeat unit. For many polar monomers $\kappa$-X coordination of free monomer can also block coordination sites required for $\pi$-coordination of monomer and chain growth. These and other features observed are all reversible, and they slow down but do not shut down chain growth.

No irreversible steps have been reported to occur in polymerizations with these catalysts, although the importance of any such steps for polymer synthesis, catalyst development, and also mechanistic analyses is obvious. It appears that this unique class of catalysts is considered to be essentially stable during polymerization. Intimately related to issues of irreversible deactivation is the efficiency of activation of the catalyst precursor employed. A knowledge of the portion of metal sites that actually enter the catalytic cycle as an active species is essential in order to analyze decomposition pathways of the latter.

We now report on the identification and in-depth analyses of various reversible and irreversible deactivation reactions that occur extensively in polymerizations and have long-ranging implications, and provide a detailed analysis of catalyst precursor activation as a prerequisite for a comprehensive picture.

\section{RESULTS AND DISCUSSION}

Methyl complexes 1- $\mathrm{CH}_{3}-\mathrm{L}$ have been employed frequently as well-defined catalyst precursors (Chart 1). ${ }^{4-10,12}$ Activation

Chart 1. Natural Abundance and ${ }^{13} \mathrm{C}$-Enriched Complexes $1-{ }^{13} \mathrm{CH}_{3}-\mathrm{L}$
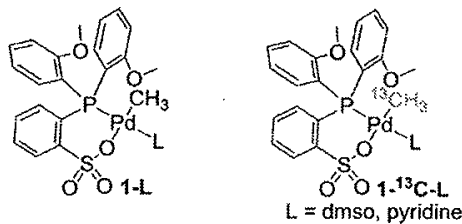

occurs by displacement of the monodentate ligand $\mathrm{L}$ by ethylene monomer and insertion in the resulting olefin complex 1- $\mathrm{CH}_{3}-$ (ethylene). Closely related to this activation pre-equilibrium $\left(K_{e q}\right)$, the growing active species 1- $\left(\mathrm{CH}_{2}\right)_{2 n} \mathrm{CH}_{3}$-(ethylene) can be in equilibrium with a dormant state due to competitive binding of the olefin and the ligand $L$ introduced with the catalyst precursor $\left(K_{\text {eq }}^{\prime}\right.$ in eq 1$)$.

Assuming these competitive binding equilibria to be fast, this overall scenario should result in a saturation kinetic behavior of the polymerization reaction. That is, with increasing ethylene

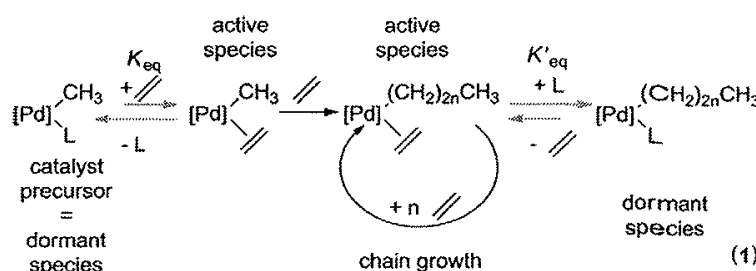

concentration, the overall rate of polymer formation should asymptotically approach a maximum value that corresponds to the equilibria being entirely in favor of the olefin complexes. Indeed, such saturation kinetic behavior was observed for 1- $\mathrm{CH}_{3}-\mathrm{L}$ at $p$ (ethylene) $>5-10$ bar $(\mathrm{L}=\mathrm{dmso})$ or $>15$ bar ( $\mathrm{L}=$ pyridine) in 30 and 60 min polymerization runs. ${ }^{10}$ However, the assessment of a rapid equilibration of $1-\mathrm{CH}_{3}-\mathrm{L}$ and $1-\mathrm{CH}_{3}-$ (ethylene) with respect to chain growth was never made. Moreover, the picture outlined in eq 1 suggests that precatalysts 1- $\mathrm{CH}_{3}-\mathrm{L}$ quantitatively participate in the polymerization reaction and that no other competitive reaction pathways exist by which fractions of $1-\mathrm{CH}_{3}-\mathrm{L}$ or $1-\left(\mathrm{CH}_{2}\right)_{2 n} \mathrm{CH}_{3}-\mathrm{L}$ may be excluded from forming polymer.

Activation of Precatalysts under Preparative Polymerization Conditions and Overall Incorporation of ${ }^{13} \mathrm{C}$ Label in the Formed Polymer. In a first approach to elucidate these issues ${ }^{13} \mathrm{C}$-labeled precatalysts $1{ }^{13} \mathrm{CH}_{3}-\mathrm{L}(\mathrm{L}=$ dmso, pyridine) were synthesized (for experimental details see Supporting Information). These complexes were employed for ethylene polymerizations with variable reaction times $(1-10 \mathrm{~min}$ $150-450 \mu \mathrm{M}$ precatalyst, 5 bar ethylene, $333-363 \mathrm{~K}$ ) to determine the fraction of ${ }^{13} \mathrm{C}$-labeled methyl groups incorporated from the precatalyst $1-{ }^{13} \mathrm{CH}_{3}-\mathrm{L}$ into the $\mathrm{Sl}$ end groups of the isolated polymer (Figure 1 shows an exemplified ${ }^{13} \mathrm{C}$ NMR spectrum including end group definitions).

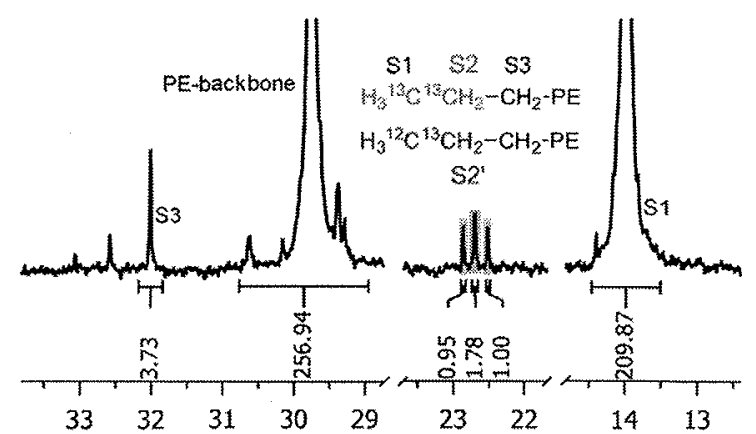

Figure 1. S1, S2, and S3 region of the ${ }^{13} \mathrm{C}$ NMR spectrum (inverse gated decoupled, $403 \mathrm{~K}_{2} \mathrm{C}_{2} \mathrm{D}_{2} \mathrm{Cl}_{4}$ ) of polyethylene (Table 1, entry 7 ) obtained with 1-13 $\mathrm{CH}_{3}$-pyr (54 TON ethylene, ca. 0.9 chain transfers per active $\left.{ }_{1-}{ }^{13} \mathrm{CH}_{3}-\mathrm{pyr}\right)$ in a pressure reactor polymerization experiment.

A higher sensitivity in these experiments was achieved by increasing the concentration of the catalyst precursor, $\left[1{ }^{13} \mathrm{CH}_{3}-\mathrm{L}\right]$, and by decreasing the ethylene concentration as well as the polymerization time and temperature in comparison to standard polymerization conditions (which are typically $20-50 \mu \mathrm{M}, 40$ bar ethylene, $363 \mathrm{~K}, 30 \mathrm{~min}$ polymerization time), ${ }^{10}$ thus limiting the absolute turnover number per overall palladium. ${ }^{13}$ Aliquots of the polyethylenes thus obtained were subjected to quantitative ${ }^{13} \mathrm{C}$ NMR analysis, ${ }^{14}$ and the fraction of ${ }^{13} \mathrm{C}$-labeled $\mathrm{CH}_{3}$ end groups incorporated into the polymer was determined by comparing the overall backbone integral with the $S 1$ and $S 2$ end group integrals, 
Table 1. Ethylene Polymerization Conducted with ${ }^{13} \mathrm{C}$-Labeled Complexes $1-{ }^{13} \mathrm{CH}_{3}-\mathrm{L}$

\begin{tabular}{|c|c|c|c|c|c|c|c|c|c|c|c|}
\hline entry & $\begin{array}{l}\text { catalyst } \\
\text { precursor }\end{array}$ & (K) & [min] & rield & TON & Branclies & $\begin{array}{l}\text { no. of chain } \\
\text { transfers? }\end{array}$ & $\mathrm{M}_{\mathrm{n}}^{\mathrm{s}}\left[10_{\mathrm{NMR}}^{3} \mathrm{~mol}^{\prime}\right]$ & 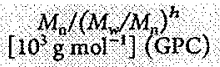 & inc $[ \pm 5 \%]$ & olefinto \\
\hline $1^{n}$ & $1-{ }^{13} \mathrm{CH}_{3}-\mathrm{dmso}$ & 333 & 1 & 138 & 328 & 1.0 & 4.2 & 2.8 & $9 /(1.6)$ & 69 & $1: 10$ \\
\hline $2^{a}$ & ${ }_{1}{ }^{13} \mathrm{CH}_{3}$-dmso & 333 & 3 & 165 & 393 & 0.9 & 5.0 & 3.3 & n,d. & 59 & $1: 6$ \\
\hline $3^{a}$ & ${ }_{1-}^{13} \mathrm{CH}_{3}$-dmso & 333 & 10 & 273 & 650 & 1 & 5.1 & 5.3 & $11 /(2)$ & 59 & $1: 8$ \\
\hline $4^{b}$ & ${ }_{1-}{ }^{13} \mathrm{CH}_{3}$-dmso & 333 & 1 & 199 & 158 & 1.4 & 2.8 & 2.0 & n.d. & 71 & $1: 10$ \\
\hline $5^{a}$ & $1-^{13} \mathrm{CH}_{3}$-dmso & 343 & 1 & 231 & $\$ 50$ & 2 & 10.5 & 3.4 & $10 /(2)$ & 41 & $1 ; 8$ \\
\hline $6^{a^{2}}$ & $1-{ }^{13} \mathrm{CH}_{3}$-dmso & 353 & I & 253 & 601 & 4.5 & 15.1 & 2.7 & $7 /(2.1)$ & 41 & $1: 3$ \\
\hline $7^{b}$ & ${ }_{1-}{ }^{13} \mathrm{CH}_{3}-\mathrm{pyr}$ & 333 & 1 & 68 & 54 & 0.7 & 0.9 & 1.7 & $1.6 /(1.2)$ & 86 & 1:8 \\
\hline $8^{c}$ & $1{ }^{13} \mathrm{CH}_{3}-\mathrm{pyr}$ & 343 & I & 151 & 180 & 1.2 & 1.8 & 2.9 & $5.3 /(1.3)$ & 76 & 1:6 \\
\hline $9^{a}$ & ${ }_{1-}{ }^{k 3} \mathrm{CH}_{3}-\mathrm{pyr}$ & 353 & 1 & 144 & 343 & 2.8 & 4.1 & 2.9 & $7 /(1.7)$ & 72 & $1: 6$ \\
\hline $10^{a}$ & ${ }_{1-}{ }^{13} \mathrm{CH}_{3}-\mathrm{pyr}$ & 353 & 3 & 232 & 552 & 2.8 & 4.3 & 4.3 & n.d. & 73 & $1: 6$ \\
\hline $11^{a}$ & ${ }_{1-{ }^{13}} \mathrm{CH}_{3}-\mathrm{pyr}$ & 353 & 10 & 484 & 1153 & 2.7 & 4.7 & 8.1 & $10 /(2)$ & 72 & $1: 4$ \\
\hline
\end{tabular}

${ }^{a}$ Polymerization conducted with $15 \mu \mathrm{mol}$ of $1{ }^{13} \mathrm{CH}_{3}-\mathrm{L}$ in $100 \mathrm{~mL}$ of toluene at 5 bar ethylene pressure. ${ }^{b}$ Polymerization conducted with $45 \mu \mathrm{mol}$ of $1{ }^{13} \mathrm{CH}_{3}-\mathrm{L}$ in $100 \mathrm{~mL}$ of toluene at $S$ bar ethylene pressure. ${ }^{\circ}$ Polymerization conducted with $30 \mu \mathrm{mol}$ of $1{ }^{13} \mathrm{CH}_{3}-\mathrm{L}$ in $100 \mathrm{~mL}$ of toluene at 5 bar ethylene pressure. ${ }^{d} \mathrm{Mol}$ ethylene converted per mol precatalyst. ${ }^{e}$ Methyl branches per 1000 carbon atoms, determined in $\mathrm{C}_{2} \mathrm{D}_{2} \mathrm{Cl}_{4}$ solution at $403 \mathrm{~K}$ in inverse gated decoupled experiments with a relaxation delay of $>7 \mathrm{~s}$. ${ }^{f}$ Determined by comparing the $\left({ }^{13} \mathrm{C}\right) \mathrm{S} 1\left({ }^{13} \mathrm{C}\right) \mathrm{S} 2$ and the $\left({ }^{12} \mathrm{C}\right) \mathrm{S} 1\left({ }^{13} \mathrm{C}\right) \mathrm{S} 2$ signal in inverse gated decoupled experiments with a relaxation delay of $>7 \mathrm{~s} .{ }^{g}$ Determined by the ratio of $\mathrm{S} 1$ end groups:remaining PE signals. ${ }^{h}$ Determined by high-temperature GPC in trichlorobenzene at $403 \mathrm{~K}$ vs linear PE standards. ${ }^{i}$ Fraction of polymer-incorporated ${ }^{13} \mathrm{CH}_{3}$ groups from $1-{ }^{13} \mathrm{CH}_{3}-\mathrm{L}$ determined by ${ }^{13} \mathrm{C}$ NMR spectroscopy; for details see SI. ${ }^{j}$ Determined by ${ }^{13} \mathrm{C}$ NMR spectroscopy by comparing the integrals of allylic and $\mathrm{S} 2$ signals in inverse gated decoupled experiments with a relaxation delay of $7 \mathrm{~s}$.

assuming that the ${ }^{13} \mathrm{C}$-label was exclusively incorporated in the $\mathrm{S} 1$ end groups. These data were corrected for additional occurring $\mathrm{SI}$ and $\mathrm{S}^{\prime}$ end groups (containing natural abundance ${ }^{13} \mathrm{C}$ ) resulting from chain transfer reactions during these polymerization experiments. A distinction of $S 2$ end groups in the vicinity of ${ }^{12} \mathrm{C}$ - or ${ }^{13} \mathrm{C}$-labeled $\mathrm{S} 1$ groups, respectively, can be made, since $\mathrm{S}^{\prime}$ end groups formed after chain transfer do not exhibit the characteristic ${ }^{1} J_{\mathrm{CC}}=34.8 \mathrm{~Hz}$ that is observed for $\$ 2$ end groups adjacent to the ${ }^{13} \mathrm{C}$-enriched $\mathrm{S} 1$ group (signals between 22 and $23 \mathrm{ppm}$ in Figure 1; for a detailed description see Supporting Information).

This distinction in turn allows for an estimation of the number of chain transfers per $1{ }^{13} \mathrm{CH}_{3}-\mathrm{L}$. Chain transfer numbers per $1{ }^{13} \mathrm{CH}_{3}-\mathrm{L}$ determined in this fashion increase with increasing polymerization temperature and are in the range of $\mathrm{ca} .1$ to 5 using $1{ }^{13} \mathrm{CH}_{3}$-pyr and in the range of 3 to 15 using $1{ }^{13} \mathrm{CH}_{3^{-}}$ dmso (Table 1 , column 8).

All fractional incorporations of ${ }^{13} \mathrm{CH}_{3}$-labeled groups into the isolated polymers even after only $1 \mathrm{~min}$ polymerization time are consistently $>55 \%$ for $1{ }^{13} \mathrm{CH}_{3}$-dmso (Table 1 , entries $1-4$ ) at $333 \mathrm{~K}$ polymerization temperature and reach ca. $85 \%$ for $1-{ }^{13} \mathrm{CH}_{3}$-pyr (Table 1, entry 7). They decrease with increasing polymerization temperature within the error limits (Table 1 , entries 4-6 and 7-9) and do not increase with polymerization time (Table 1, entries $1-3$ and 9-11). These data indicate that (a) the pre-equilibration of $1-{ }^{13} \mathrm{CH}_{3}-\mathrm{L}$ and $1-{ }^{13} \mathrm{CH}_{3}$-(ethylene) according to eq 1 is indeed rapid as compared to chain growth, and (b) side reactions triggered by increasing the polymerization temperature decrease the observed $\mathrm{S} 1$ incorporation of ${ }^{13} \mathrm{C}$-label in to the isolated polymer.

Turnover numbers do not increase linearly with time (entries $1-3$ and 9-11, columns 4 and 6) and decrease with increasing [precatalyst], e.g., from $150 \mu \mathrm{M}$ to $450 \mu \mathrm{M}$ (entries 1 and 4 ). This indicates that deactivation of catalytically active species occurs to a relevant extent and may account for the observation that the ${ }^{13} \mathrm{C}$-label is not incorporated completely into the isolated polymer, despite the rapid pre-equilibration of $1{ }^{13} \mathrm{CH}_{3}-\mathrm{L}$ and $1{ }^{13} \mathrm{CH}_{3}$-(ethylene). ${ }^{15}$ The finding that increasing chain transfer numbers also correlate with decreasing incorporation of ${ }^{13} \mathrm{C}$-label into the polymer (Table 1 , columns 8 and 11 ) points to the chain transfer being directly linked to the deactivation of the catalytically active species.

We also note that the isolated polymers exhibit ratios of unsaturated groups to aliphatic end groups that, if corrected for methyl branches and internal olefins, significantly deviate from the expected 1:1 ratio (Table 1, last column). While an incomplete ${ }^{13} \mathrm{C}$ relaxation of olefinic ${ }^{13} \mathrm{C}$ resonances and possibly also polymer chains still attached to palladium may contribute to this observed deviation of olefinic:aliphatic end group ratios, we believe that part of the polymer consists of fully saturated chains, which will also contribute to deviating ratios of olefinic:aliphatic end group signals. Evidence that supports this assumption will be presented in the following sections.

Activation of Precatalysts under NMR-Tube Conditions and Position of Incorporated ${ }^{13} \mathrm{C}$-Label in the Polymer Chains. Triggered by the observed catalyst deactivation and indication for the formation of fully saturated polymers, NMR monitoring of the reaction of ${ }^{13} \mathrm{C}$-labeled complexes ${ }_{1}-{ }^{13} \mathrm{CH}_{3}$-pyr and $1{ }^{3} \mathrm{CH}_{3}$-dmso with ethylene in pressure-stable J. Young NMR tubes was conducted: In thf- $d_{8}$ solution (dried over sodium-potassium alloy) ${ }_{1}^{13} \mathrm{CH}_{3}$-pyr $\left(6.6 \mathrm{mmol} \mathrm{L}^{-1}\right)$ reacts only very slowly with ethylene (initial concentration [ethylene] $]_{0}=\mathrm{ca} .46 \mathrm{mmol} \mathrm{L} \mathrm{L}^{-1}, 7$ equiv) even at elevated temperature, and consumption of ca. 6.5 equiv of ethylene requires heating to $378 \mathrm{~K}$ for ca. $7 \mathrm{~h}$. At this point the initially introduced $1-{ }^{3} \mathrm{CH}_{3}$-pyr is totally consumed, as jugded by ${ }^{\mathrm{I}} \mathrm{H}$ NMR spectroscopy. Traces of palladium black were visible, and no further polymerization takes place upon repeated addition of ethylene and heating to $378 \mathrm{~K}$. However, only an estimated ca. $65 \%$ of the initial $1-{ }^{3} \mathrm{CH}_{3}$-pyr had initiated a polymer chain, as judged by additional resonances between $\delta=13.5$ and $11.5 \mathrm{ppm}$ in the ${ }^{13} \mathrm{C}$ NMR spectrum, accounting for ca. $35 \%$ of the introduced ${ }^{13} \mathrm{C}$-label. ${ }^{16}$ These signals are split into a doublet of doublets with $J=\mathrm{ca} .35 \mathrm{~Hz}$ (and $J=3 \mathrm{~Hz}$ ) at 150 and $100 \mathrm{MHz}$. While the observed $J=35 \mathrm{~Hz}$ are suggestive of ${ }^{1} J_{\mathrm{CC}}$ couplings, ${ }^{17}$ upon ${ }^{31} \mathrm{p}$-decoupling all these signals collapsed into singlets (Figure 2). In addition they were identified as isotopomeric enriched ${ }^{13} \mathrm{CH}_{3}$ groups by phase-sensitive ${ }^{1} \mathrm{H},{ }^{13} \mathrm{C}$ gHSQC in combination with ${ }^{1} \mathrm{H},{ }^{31} \mathrm{P}$ gHMBC and ${ }^{1} \mathrm{H},{ }^{31} \mathrm{P}\left\{{ }^{13} \mathrm{C}\right\}$ gHMBC experiments with no further correlation in ${ }^{1} \mathrm{H}_{1}^{13} \mathrm{C}$ gHMBC 


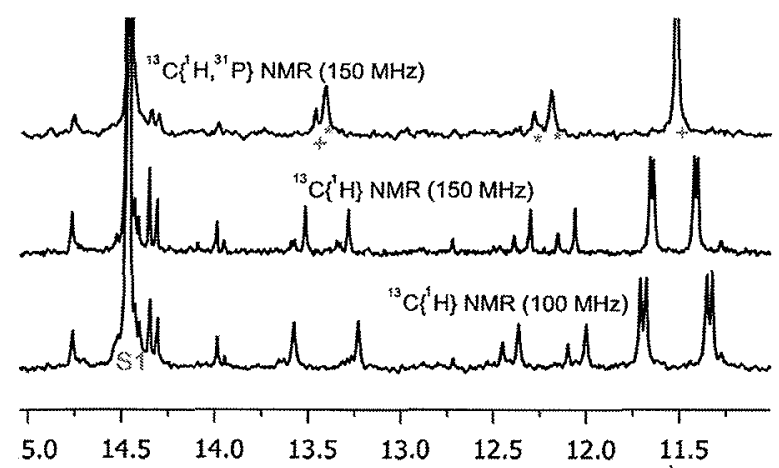

Figure $2 .{ }^{13} \mathrm{C}$ NMR methyl region of an oligomer sample obtained with 1. ${ }^{13} \mathrm{CH}_{3}$-pyr after $7 \mathrm{~h}$ at $378 \mathrm{~K}$, with 7 equiv of $\mathrm{C}_{2} \mathrm{H}_{4}$ in a NMR-tube experiment. Signals marked (*) were assigned to $\left({ }^{13} \mathrm{CH}_{3}\right)$-phosphine palladium complexes. Signals marked $(+)$ were assigned to $\left({ }^{13} \mathrm{CH}_{3}\right)$ phosphine palladium complexes containing one additional phosphine ligand (vide infra, Scheme 2 and Figure 4).

experiments (see SI). Thus, a substantial part of the ${ }^{13} \mathrm{C}$-labeled $\mathrm{CH}_{3}$ groups in these experiments is transferred to phosphoruscontaining species.

The identity of these species will be discussed later, as the ${ }^{13} \mathrm{C}$ NMR spectrum of this ${ }^{13} \mathrm{C}$-enriched sample also proves most informative with respect to the formed oligomers vis à vis the control experiment with natural abundance 1- $\mathrm{CH}_{3}$-pyr: First of all we have noticed a much better signal-to-noise ratio $(\mathrm{S} / \mathrm{N})$ for the ${ }^{13} \mathrm{C}$-enriched sample not just for the ${ }^{13} \mathrm{C}$-enriched $\mathrm{S} 1$ signal at $\delta=14.47 \mathrm{ppm}$, but for many other resonances attributable to products obtained by chain growth. However, an increased S/N was not observed for the identified signals of cis- and trans-but-2ene, which are formed after $\beta$-hydride elimination and insertion of ethylene into palladium hydride species $\left[\kappa^{2}-\mathrm{P}, \mathrm{O}\right] \mathrm{Pd}(\mathrm{H})$ under NMR polymerization conditions (and therefore contain no ${ }^{13} \mathrm{C}$-label introduced by $1-{ }^{13} \mathrm{CH}_{3}$, Figure 3).

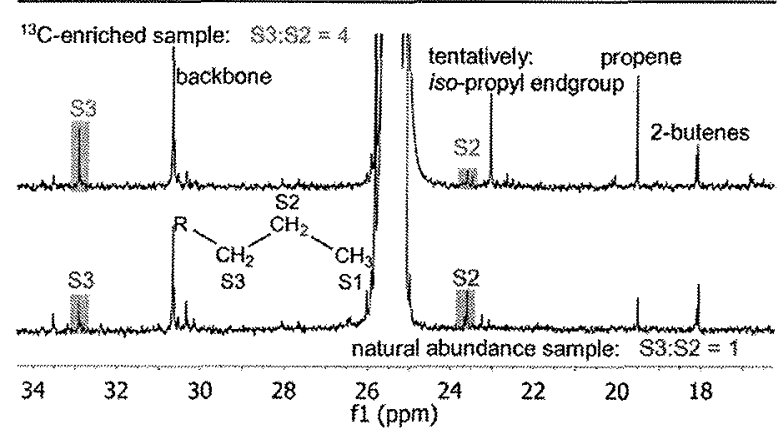

Figure 3. S3, S2, and methyl branch ${ }^{13} \mathrm{C}$ NMR region of ethylene oligomers obtained with ${ }^{1}{ }^{13} \mathrm{CH}_{3}-\mathrm{pyr}$ (top line) and $1-\mathrm{CH}_{3}-\mathrm{pyr}$ (bottom line).

Even more striking, substantial amounts of propylene were identified in both samples with virtually identical integral ratios of terminal methylidene (116.0 ppm)-to-methyl signals (19.52 ppm) of $0.8: 1$ in each case (see SI), while the internal methine carbon is hardly detectable. Since propylene can be formed only by ethylene insertion into $1-{ }^{13} \mathrm{CH}_{3}$ (1- $\mathrm{CH}_{3}$, respectively) and concomitant $\beta$-hydride elimination, the observed $0.8: 1$ ratio of methylidene:methyl resonances in the case of the ${ }^{13} \mathrm{C}$-labeled precatalyst $1-{ }^{13} \mathrm{CH}_{3}-\mathrm{pyr}$ is indicative of a rapid chain-walking reaction (i.e., $\beta$-hydride elimination and reinsertion with opposite regiochemistry) along the growing chain, which exchanges ${ }^{13} \mathrm{C}$-label between these two groups and is competitive to chain growth. This chain-walking process along the growing chain results in dissipation of the initially introduced ${ }^{13} \mathrm{C}$-label at the chain terminus into every other position of a linear chain or, if methyl branching takes place, even into a methyl branch (Scheme 1).

A deeper analysis of the labeled oligomers obtained from ${ }_{1-}{ }^{13} \mathrm{CH}_{3}$-pyr in the NMR-tube experiment supports that chain walking is operative in a polymerization-active palladium species. A ratio of S3:S2 end groups of ca. 4:1 was found, whereas a S3:S2 ratio of 1:1 was obtained starting from unlabeled $1-\mathrm{CH}_{3}-$ pyr. That is, some of the ${ }^{13} \mathrm{C}$-label is indeed incorporated at the $\mathrm{S} 3$ position, resulting in increased $\mathrm{S} 3$ integrals. With respect to methyl branches we find an intensive ${ }^{13} \mathrm{C}$ signal at $\delta 23.04 \mathrm{ppm}$, which is correlated via ${ }^{1} J_{\mathrm{CH}}$ to an obscured signal at $0.88 \mathrm{ppm}$ in the ${ }^{1} \mathrm{H}$ NMR spectrum and which is tentatively assigned to a ${ }^{13} \mathrm{C}$-enriched isopropyl end group. With respect to the isopropyl end groups however, we note that that they may also form after 1,2-insertion of 1-olefins into $1-{ }^{13} \mathrm{CH}_{3}$ and extensive chain walking through a tertiary carbon center (Scheme 1 and Figure 3$){ }^{18}$

Overall, the increased signal-to-noise ratio for many resonances attributable to ethylene enchainment products obtained with $1-^{13} \mathrm{CH}_{3}$-pyr vis à vis unlabeled 1- $\mathrm{CH}_{3}$-pyr clearly supports that these catalysts can undergo chain-walking on the same time scale as chain growth, particularly at low ethylene concentration and high temperature.

This chain-walking process, which was also observed on a preparative scale as jugded by low but clearly quantifiable degrees of branching (Table 1, column 7: Me branches) and which is also supported by other studies, ${ }^{19}$ will apparently lower the calculated fraction of ${ }^{13} \mathrm{C}$-label (Table 1 , column 11) introduced into the polymer, as exclusively ${ }^{13} \mathrm{C}$-labeled $\mathrm{S} 1$ positions have been considered. However, while chain-walking contributes to an apparently lowered ${ }^{13} \mathrm{C}$ incorporation into the polymer at low ethylene concentration and high temperature, the formation of ${ }^{13} \mathrm{C}$-labeled phosphorus-containing side products results in a fraction of the ${ }^{13} \mathrm{C}$-label not being incorporated at all into the polymer. $^{20}$

Furthermore, the formation of volatile saturated alkanes constitutes another reaction path by which ${ }^{13} \mathrm{C}$-label is prevented from incorporation into the formed polymer in the above NMR experiments: We have unambiguously observed ${ }^{13} \mathrm{C}$-enriched ${ }^{13} \mathrm{CH}_{4}$ identified by a doublet with ${ }^{1} J_{\mathrm{CH}}=125.6 \mathrm{~Hz}$ at $\delta$ $0.185 \mathrm{ppm}$ in the ${ }^{1} \mathrm{H}$ NMR spectrum, which is correlated via ${ }^{1} J_{\mathrm{CH}}$ (phase-sensitive gHSQC) to a carbon signal with evennumbered hydrogen substitution at $\delta-4.675 \mathrm{ppm}$ in the ${ }^{13} \mathrm{C}$ NMR spectrum.

In agreement with this assignment, the respective natural abundance methane formed by using $1-\mathrm{CH}_{3}-\mathrm{pyr}$ exhibits a singlet in the ${ }^{1} \mathrm{H}$ NMR spectrum at $\delta 0.184 \mathrm{ppm}^{21}$ In addition to ${ }^{13} \mathrm{C}$-enriched) methane a triplet at $\delta 1.118 \mathrm{ppm}$, i.e., downfield from usually observed methyl end groups, or methyl branching at ca. $0.85 \mathrm{ppm}$ was observed, which is coupled to a multiplet at $1.329 \mathrm{ppm}$ partially obscured by the methylene backbone signal of the formed oligomers (for details, see SI). We have assigned these signals to propane after incremental addition of a genuine sample of propane to these samples. Incremental addition of ethane to these samples also revealed that natural carbon abundance ethane identified by a singlet at $\delta=0.851$ forms during these in situ NMR experiments.

Scrambling of the Growing Alkyl Chain into the Phosphine Ligand. With respect to the phosphorus species 
Scheme 1. Insertion and Chain Walking Reactions Explaining the Dissipation of ${ }^{13} \mathrm{C}$-Label into Every Other Position of Linear Chains and into Branches Observed with $1{ }^{13} \mathrm{CH}_{3}-\mathrm{pyr}^{a}$

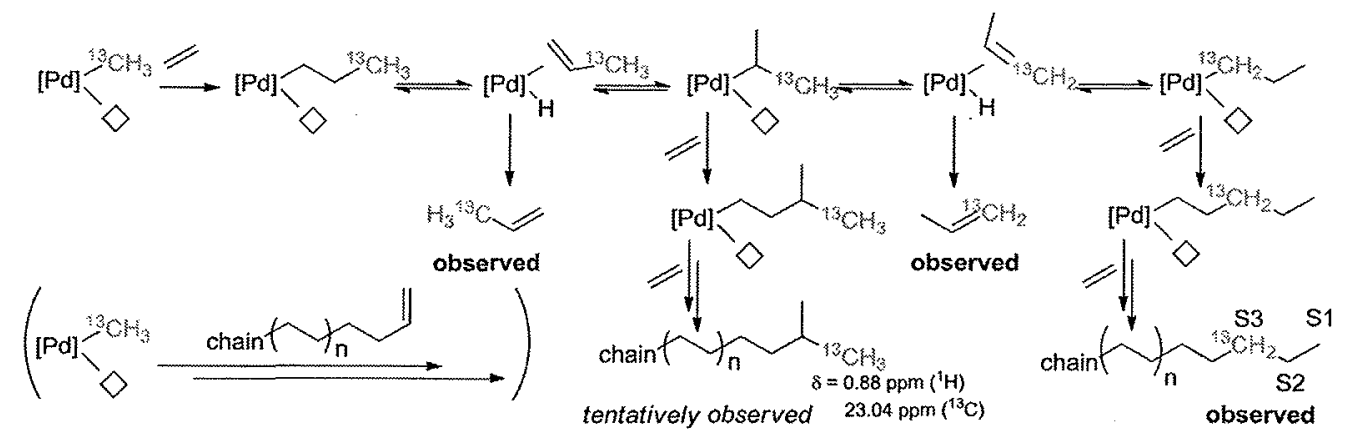

${ }^{a}$ In parentheses: alternative formation of ${ }^{13} \mathrm{C}$-enriched isopropyl end groups after 1,2-insertion of 1-olefins into ${ }^{1-}{ }^{13} \mathrm{CH}_{3}$.

Scheme 2. Phosphonium Salts and Methylphosphine Complexes by Thermolysis of $1{ }^{13} \mathrm{CH}_{3}-\mathrm{L}$ in thf- $d_{8}$ at $378 \mathrm{~K}$

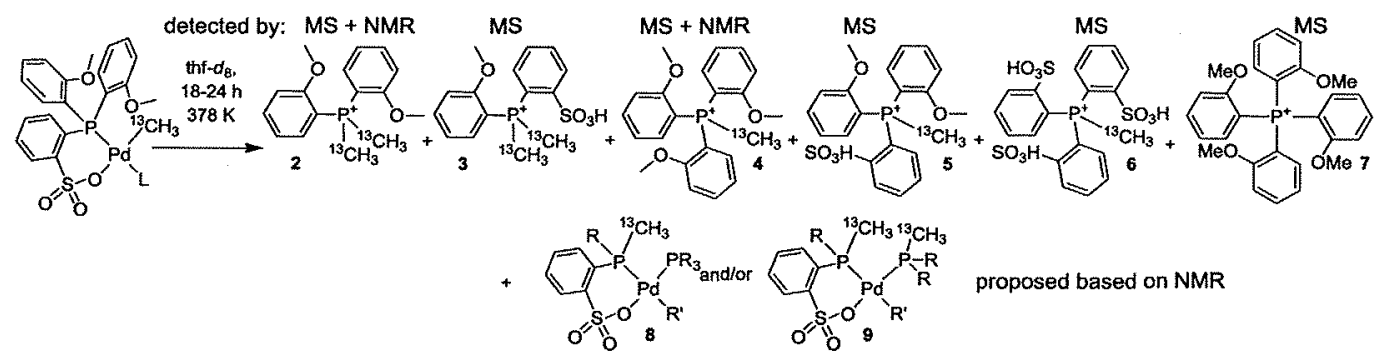

containing the ${ }^{13} \mathrm{CH}_{3}$-label (vide supra, Figure 2), several NMR spectroscopic and mass spectrometric observations led to the conclusion that these ${ }^{13} \mathrm{C}$-labeled species correspond to palladium complexes of ${ }^{13} \mathrm{C}$-labeled methylphosphines and not to palladium- ${ }^{13} \mathrm{CH}_{3}$ complexes, which implies that an exchange of aryl substituents on phosphorus and the palladium-bound ${ }^{13} \mathrm{CH}_{3}$ group takes place (Scheme 2 and Scheme 3): ${ }^{22}$ (a) the

Scheme 3. Exchange of Palladium-Bound Carbyls with Phosphorus-Bound Carbyls by Reductive Elimination and Oxidative Addition, and Formation of 2-Vinylanisole

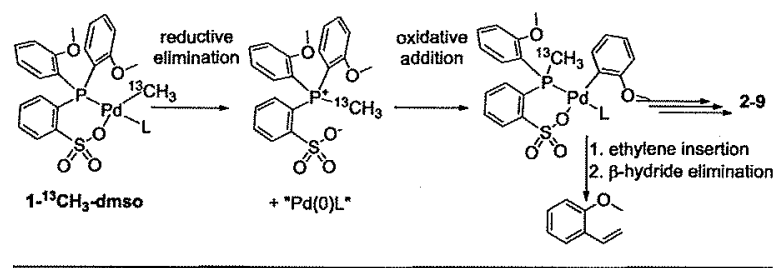

observed $J_{\mathrm{PC}}=35 \mathrm{~Hz}$ is neither in the range of a typical ${ }^{2} J_{\mathrm{PC}}$, trans as observed in several diphosphine palladium methyl complexes (ca. $70-120 \mathrm{~Hz})^{23}$ nor in the range of typically observed ${ }^{2} J_{\mathrm{PC}}$, cis in related phosphinesulfonato palladium methyl complexes (ca. $0-7 \mathrm{~Hz}) .{ }^{24}$ (b) ${ }^{1} \mathrm{H}$ chemical shifts of the observed ${ }^{13} \mathrm{CH}_{3}$ groups (ca. $0.85-1.9 \mathrm{ppm}$ ) are not in the range of typical palladium methyl complexes (typically -2 to $+0.85 \mathrm{ppm}$ ). (c) Traces of 2-vinylanisole were detected by ${ }^{1} \mathrm{H}$ - and ${ }^{1} \mathrm{H},{ }^{1} \mathrm{H}$-gCOSY NMR experiments (see SI), which are likely formed by ethylene insertion into a palladium-(2-anisyl) complex followed by $\beta$-hydride elimination. (d) Mass spectrometric analysis of the obtained sample after heating ${ }^{1}{ }^{13} \mathrm{CH}_{3}$-pyr with 7 equiv of ethylene for $7 \mathrm{~h}$ at $378 \mathrm{~K}$ revealed the presence of quaternary phosphonium cations $\left({ }^{13} \mathrm{CH}_{3}\right)_{x} \mathrm{P}^{+}(\text {anisyl })_{4-x}(x=1,2) 2$ and 4 by ESI-MS and MALDI (Scheme 2, for details, see SI). (e) Despite the reported stability of $1-\mathrm{CH}_{3}-\mathrm{L},{ }^{25}$ thermolysis of $1-{ }^{13} \mathrm{CH}_{3}-\mathrm{pyr}$ and $1{ }^{13} \mathrm{CH}_{3}$-dmso in the- $d_{8}$ for $18-24 \mathrm{~h}$ at $378 \mathrm{~K}$ also in the absence of ethylene results in formation of quaternary phosphonium salts. However, in addition to 2 and 4, tetra(anisyl)phosphonium 7 is also detected by mass spectrometry. (f) The ${ }^{13} \mathrm{C}$ NMR spectrum of these samples obtained in the absence of ethylene contains several ${ }^{31} \mathrm{P}$-coupled signals between $\delta=15$ and $8.5 \mathrm{ppm}$ with ${ }^{1} J_{\mathrm{pC}} \approx 54-62 \mathrm{~Hz}$ typical for methyl phosphonium cations which are correlated to doublets of doublets with ${ }^{1} J_{\mathrm{CH}} \approx 135 \mathrm{~Hz}$ and ${ }^{2} J_{\mathrm{PH}} \approx 15 \mathrm{~Hz}$ in the ${ }^{1} \mathrm{H}$ NMR spectra. Comparison with independently prepared, but unlabeled 2 and 4 clearly indicates the formation of ${ }^{13} \mathrm{C}$-labeled 2 and 4 in the aforementioned experiments starting from $1-{ }^{13} \mathrm{CH}_{3}-\mathrm{L}$ at $378 \mathrm{~K}$ (g) Thermolysis of $1{ }^{12} \mathrm{CH}_{3}$-pyr and $1-^{12} \mathrm{CH}_{3}$-dmso in dioxane for $18-24 \mathrm{~h}$ at $395 \mathrm{~K}$ yields the full range of phosphonium salts 2-7 as observed by ESI-MS.

In addition to phosphonium salts, the ${ }^{13} \mathrm{C}$-labeled samples obtained by thermolysis of $1-{ }^{13} \mathrm{CH}_{3}-\mathrm{dmso}$ in thf- $d_{8}$ for $18-24 \mathrm{~h}$ at $378 \mathrm{~K}$ also contain substantial amounts of the main ${ }^{13} \mathrm{C}$-labeled side product observed under NMR-tube polymerization conditions. It is characterized by a doublet of doublets at $\delta=$ $11.51 \mathrm{ppm}$ with $J_{\mathrm{pC}}=35$ and $3 \mathrm{~Hz}$ (see Figure 2), which is assigned to a palladium diphosphine complex of the generic structure 8 or 9 (Scheme 2). This $\left({ }^{13} \mathrm{CH}_{3}\right)$ phosphine species was unambigously identified by X-ray diffraction analysis and NMR characterization of the collected X-ray quality crystals, which reveals that under polymerization conditions in the NMR tube $\left.\left[\kappa^{2} \text {-(anisyl) }\right)_{2} P, O\right] \mathrm{Pd}\left[\kappa^{2}\right.$-(anisyl) $\left.\left({ }^{13} \mathrm{CH}_{3}\right) \mathrm{P}, \mathrm{O}\right]$ (10) forms (Figure 4). The formation of 10 in NMR-tube polymerization and its isolation after thermolysis of $1{ }^{13} \mathrm{CH}_{3}$-dmso ultimately prove that (a) palladium-bound ${ }^{13} \mathrm{CH}_{3}$ groups can transfer to 


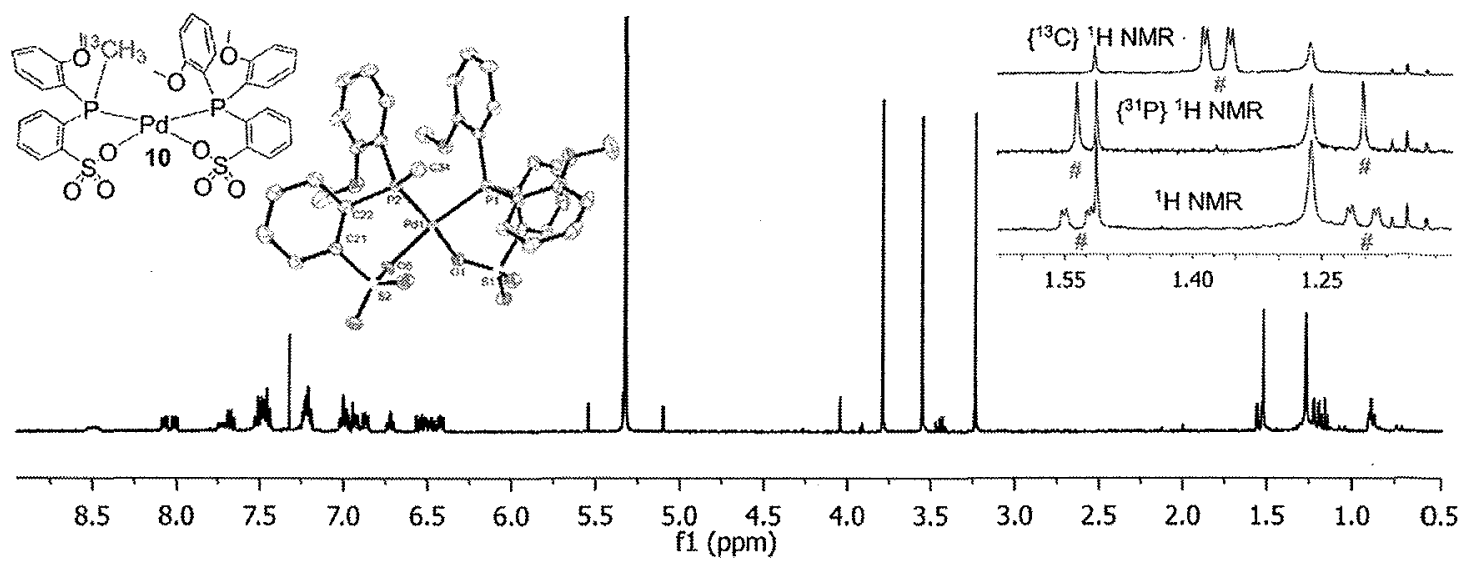

Figure 4. ${ }^{1} \mathrm{H}$ NMR spectrum $\left(298 \mathrm{~K}, 400 \mathrm{MHz}\right.$, methylene chloride- $\left.d_{2}\right)$ of isolated $\mathrm{X}$-ray quality crystals identified as $\left[\kappa^{2}-(\text { anisyl })_{2} P, O\right] P d\left[\left[\kappa^{2}\right.\right.$ (anisyl) $\left.\left({ }^{13} \mathrm{CH}_{3}\right) P, \mathrm{O}\right](\mathbf{1 0})$ with three characteristic methoxy singlets between 3.8 and $3.2 \mathrm{ppm}$ and the $\mathrm{P}-{ }^{13} \mathrm{CH}_{3}$ group at $1.37 \mathrm{ppm}$. The aliphatic inset shows ${ }^{1} \mathrm{H}$ (bottom line), $\left\{{ }^{31} \mathrm{P}\right\}^{1} \mathrm{H}$ (middle line), and $\left\{{ }^{13} \mathrm{C}{ }^{1} \mathrm{H}\right.$ NMR traces (top line), proving two ${ }^{31} \mathrm{P}$ and one ${ }^{13} \mathrm{C}$ coupling to the methyl protons marked (\#).

phosphorus under these conditions and that (b) part of the palladium-bound ${ }^{13} \mathrm{C}$-label therefore can be prevented from incorporation into the formed polymer. This is in accordance with the fractional incorporation of ${ }^{13} \mathrm{C}$-label determined by the NMR polymer analyses (vide supra, Table 1 ) and reveals that eq 1 (vide supra) is simplistic in describing the polymerization reaction catalyzed by $1-\mathrm{CH}_{3}-\mathrm{L}$, as the palladium-bound $\kappa^{2}-(P, O)$ ligand may be altered during the polymerization reaction. In addition to the isolation of 10 , poorly methanol-soluble material from these samples was identified as $\left[\kappa^{2} \text {-(anisyl) }{ }_{2} P, O\right]_{2} \mathrm{Pd}(11)$ by its characteristic ${ }^{1} \mathrm{H}$ and ${ }^{31} \mathrm{P}$ resonances in dmso- $d_{6}$ in comparison to independently prepared material.

These data fully corroborate the exchange of aryl substituents on phosphorus with methyl substituents on palladium (Scheme 3 ). Such exchange of substituents in transition metal complexes is not unprecedented and can be explained by consecutive reductive eliminations and oxidative additions of quaternary phosphonium salts followed, inter alia, by $[\mathrm{P}, \mathrm{O}]$-ligand exchange reactions with palladium- $\mathrm{CH}_{3}$ fragments. ${ }^{26}$ It also provides a mechanistic scheme for the aforementioned formation of 2-vinylanisole after ethylene insertion into a palladium-(2-anisyl) bond (Scheme 3 ).

While proven in NMR-tube experiments, the relevance of these reactions under preparative polymerization conditions remained questionable at this point. We have therefore conducted additional experiments under polymerization conditions at which the catalyst is highly active [ 5 bar ethylene pressure, $20-30 \mathrm{~min}$ polymerization time, resulting in formation of ca. $6 \mathrm{~g}$ of PE (from $20 \mu \mathrm{mol}$ of $1^{12} \mathrm{CH}_{3}$-dmso) and ca. $16 \mathrm{~g}$ of PE (from $40 \mu \mathrm{mol}$ of $1{ }^{12} \mathrm{CH}_{3}$ dmso), respectively]. The reaction mixture was precipitated by addition of methanol, the polymer was filtered off, and the methanol filtrate was concentrated. Part of this concentrated filtrate redissolves in methanol- $d_{4}$, while the methanol-insoluble part was dissolved in dmso- $d_{6}$ and identified as $\left[\kappa^{2}-(\text { anisyl })_{2} P, O\right]_{2} \mathrm{Pd}$ (11) by comparison to independently prepared material.

The methanol- $d_{4}$-soluble fraction does not contain detectable amounts of 11 by ${ }^{1} \mathrm{H}$ or ${ }^{31} \mathrm{P}$ NMR spectroscopy. However, several $\mathrm{CH}_{3}$ groups coupled to phosphorus were identified by analysis of the ${ }^{1} \mathrm{H},{ }^{3 \mathrm{l}} \mathrm{P},{ }^{1} \mathrm{H},{ }^{3 \mathrm{I}} \mathrm{P}-\mathrm{gHMBC}$, and ${ }^{1} \mathrm{H},{ }^{13} \mathrm{C}$-gHSQC NMR spectra, one of which were assigned to phosphonium salt 5 (Scheme 2) on the basis of a doublet at $\delta=3.05 \mathrm{ppm}$ with ${ }^{2} J_{\mathrm{PH}}=15.5 \mathrm{~Hz}$ in the ${ }^{1} \mathrm{H}$ NMR spectrum, which is correlated to one phosphorus at
$27.7 \mathrm{ppm}$ and agrees with the data of independently prepared 5 (for details, see SI). Furthermore, traces of 2-vinylanisole and one not fully identified styrene derivative were detected by ${ }^{1} \mathrm{H}$ NMR experiments. Most intriguing, one ethyl phosphine species was clearly identified by its characteristic splitting of the ethyl- $\mathrm{CH}_{3}$ group into a doublet of triplets at $\delta=1.05 \mathrm{ppm}$ with ${ }^{3} J_{\mathrm{PH}}=$ $20.5 \mathrm{~Hz}$, while the ethyl- $\mathrm{CH}_{2}$ group exhibits diastereotopic protons resonating at $\delta=1.89$ and $1.78 \mathrm{ppm}$ with couplings to two phosphorus nuclei (Figure 5 and SI). This ethyl phosphine species was identified as $\left.\left[\kappa^{2} \text {-(anisyl) }\right)_{2} P, O\right] \mathrm{Pd}\left[\kappa^{2}\right.$-(anisyl) (ethyl) $P, O](12)$ by $\mathrm{X}$-ray diffraction analysis. 12 cocrystallizes with $\left.\left[\kappa^{2} \text {-(anisyl) }\right)_{2} P, O\right] \mathrm{Pd}\left[\kappa^{2}\right.$-(anisyl)(butyl) $\left.P, O\right](13)$ as a methanol- $d_{4}$ solvate with identical positions in the unit cell (Figure 5).

In addition, ESI-MS analyses (negative mode) of the methanolic polymerization filtrate exhibit peaks that fit the resonances expected for (2-anisyl)(alkyl)phosphine benzenesulfonates (14) and their respective phosphine oxides (15) (Figure 6). These data ultimately prove that the exchange of palladium-bound alkyl groups with phosphorus-bound carbyl substituents is also relevant under preparative reactor polymerization experiments, even if turnover numbers of ethylene per palladium present exceed 10.000. The ESI-MS assignments, particurlarly those of (oddnumbered alkyl)phosphines, imply that under preparative (high productivity) reactor polymerization conditions chain growth is significantly faster than exchange of phosphorus- and palladiumbound carbon substituents, but that chain transfer and exchange of phosphorus- and palladium-bound carbon substituents occur on a similar time scale. While not supported by thermolysis experiments of ${ }^{-13)} \mathrm{CH}_{3}$-dmso in the absence of ethylene (which takes up to $24 \mathrm{~h}$ at $378-395 \mathrm{~K}$ ), this notion is clearly supported by the $\mathrm{X}$-ray diffraction analysis of $\mathbf{1 2}$ and 13 .

While $\left.\left[\kappa^{2} \text {-(anisyl) }{ }_{2} \mathrm{P}, \mathrm{O}\right]_{2} \mathrm{Pd}(11),\left[\kappa^{2} \text {-(anisyl) }\right)_{2} \mathrm{P}, \mathrm{O}\right] \mathrm{Pd}\left[\kappa^{2}-\right.$ (anisyl) (ethyl) $P, O](12)$, and $\left.\left[\kappa^{2} \text {-(anisyl }\right)_{2} P, O\right] P d\left[\kappa^{2}\right.$-(anisyl). (butyl) $P, O]$ (13) separated (by crystallization) from the polymerization filtrates are not polymerization active in NMRtube experiments, some of the species remaining in solution still enchain ethylene in thf- $d_{8}$ NMR experiments, whereby additional traces of 2-vinylanisole are formed apart from ethyleneoligomers/polymers. We therefore conclude that part of these complexes consist of palladium-anisyl complexes and that the transfer of palladium-bound alkyl groups to phosphorus does not 

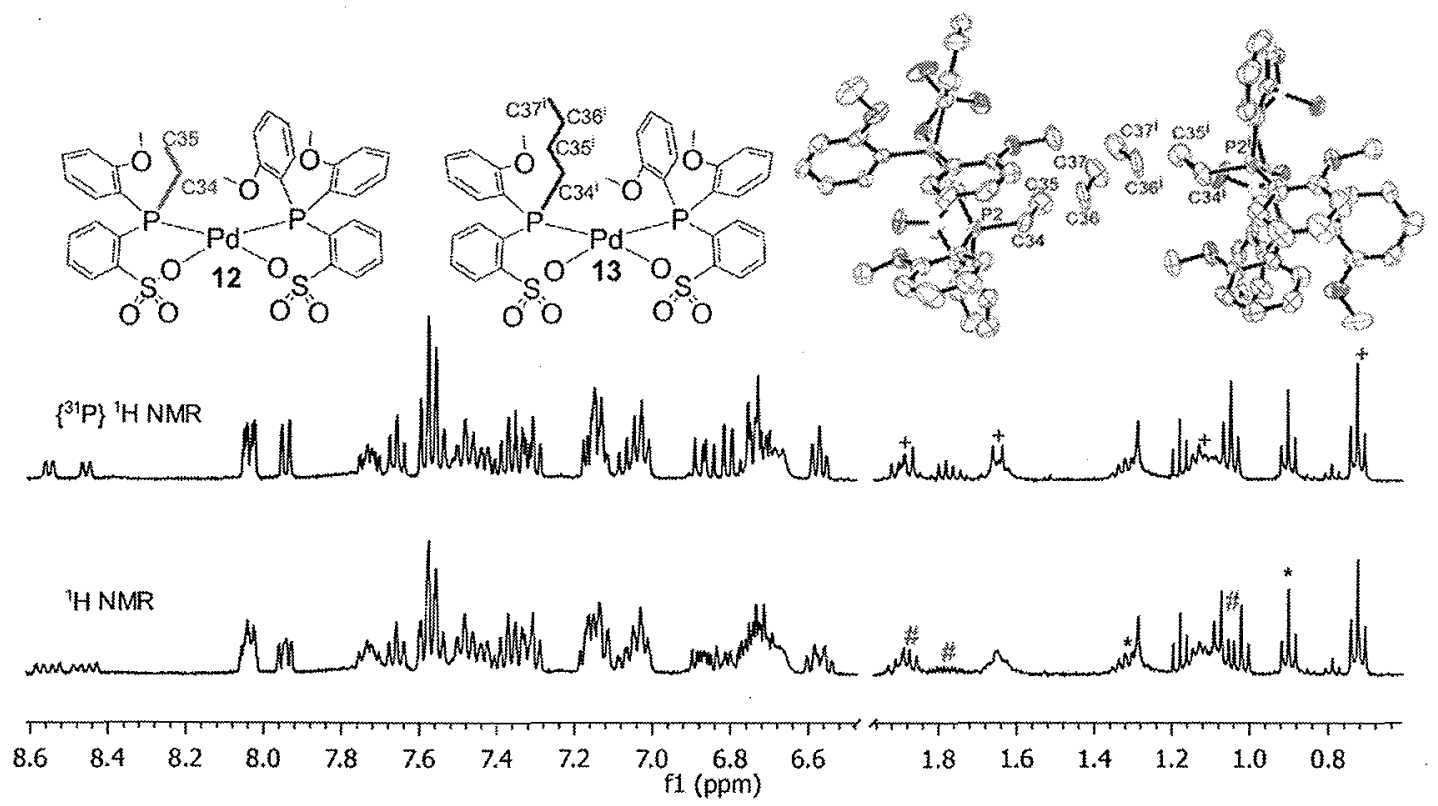

Figure 5. Aromatic and aliphatic region of the ${ }^{1} \mathrm{H}$ (bottom line) and $\left\{{ }^{31} \mathrm{P}\right\}^{1} \mathrm{H}$ NMR spectra $\left(298 \mathrm{~K}, 400 \mathrm{MHz}\right.$, methanol- $\left.d_{4}\right)$ of isolated X-ray quality crystals identified as a mixture of $\left.\left[\kappa^{2} \text {-(anisyl) }\right)_{2} P, O\right] \mathrm{Pd}\left[\left[\kappa^{2}\right.\right.$-(anisyl)(ethyl)P,O] (12) and $\left[\kappa^{2}\right.$-(anisyl) $\left.{ }_{2} P, \mathrm{O}\right] \mathrm{Pd}\left[\left[\kappa^{2}-(\right.\right.$ anisyl) $($ butyl $) P, \mathrm{O}](13)$. \#: $\mathrm{PCH}_{2} \mathrm{CH}_{3},+: \mathrm{P}\left(\mathrm{CH}_{2}\right)_{3} \mathrm{CH}_{3}$, * pentane. 12 and 13 have been isolated from the filtrate of preparative reactor polymerizations [20(9) $\mu \mathrm{mol}$ of ${ }_{1-12(13)} \mathrm{CH}_{3}$-dmso, 5 bar ethylene, $30 \mathrm{~min}$ polymerization time at $368 \mathrm{~K}$, ca. $10^{4}\left(10^{4}\right)$ turnovers ethylene per present palladium]. Also given: $X$-ray diffraction analysis of cocrystallized 12 and 13.12 and 13 occupy symmetry-equivalent positions in the unit cell. However, they likely form pairs, since the crystallographic void containing the $\mathrm{P}(2)-\mathrm{C} 34-\mathrm{C} 35$ (ethyl-)/ $\mathrm{P}\left(2^{\mathrm{i}}\right)-\mathrm{C} 34^{\mathrm{i}}-\mathrm{C} 35^{\mathrm{i}}-\mathrm{C} 36^{\mathrm{i}}-\mathrm{C} 37^{\mathrm{i}}$ (butyl-) group (and a center of symmetry) allows for an alignment of six carbon atoms, e.g., C34 $, \mathrm{C} 35^{\mathrm{i}}, \mathrm{C} 36^{\mathrm{i}}, \mathrm{C} 37^{\mathrm{i}}, \mathrm{C} 35$, and $\mathrm{C} 34$, while $\mathrm{C} 37$ and $\mathrm{C} 37^{\mathrm{i}}$ are separated by only $1.247 \AA$ This is in accordance with an occupancy of $\mathrm{C} 36, \mathrm{C} 37$, which refined to $50 \%$ (for details, see $\mathrm{SI}$ ).

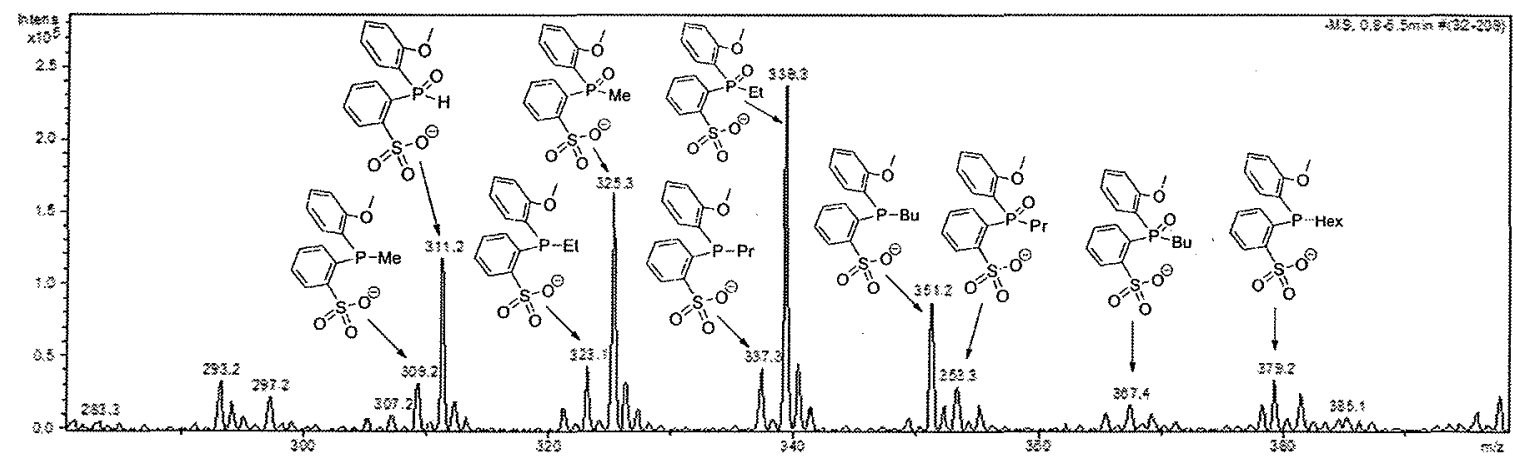

Figure 6. ESI-MS analysis (negative mode) of preparative reactor polymerization residue obtained from $1-^{12} \mathrm{CH}_{3}$-dmso after separation of the formed polymer, indicating the presence of several alkylphosphines (14) and their respective alkylphosphine oxides (15).

necessarily result in deactivation of polymerization-active palladium complexes in preparative reactor polymerizations.

DFT calculations of the reductive elimination and oxidative addition of methylphosphonium salts indicate that reductive elimination is kinetically accessible and thermodynamically favorable, while oxidative addition of the $\mathrm{P}^{-\mathrm{CH}_{3}}$ moiety is thermodynamically prohibitive (vide infra). Thus, the multiple methylation of phosphorus to form, for example, 2 starting from $1{ }^{13} \mathrm{CH}_{3}-\mathrm{L}$ and the formation of palladium anisyl complexes (and 2-vinylanisole in the presence of ethylene) likely reflect the thermodynamic stability of the palladium-aryl vs the palladiummethyl bond, which is supported by DFT calculations (vide infra).

Details of the Formation of Saturated Polymer Chains. In contrast to NMR-tube oligomerizations with $1-{ }^{13} \mathrm{CH}_{3}-\mathrm{pyr}$ and
${ }_{1-}{ }^{(13)} \mathrm{CH}_{3}$-dmso and to preparative reactor polymerizations with 1- $\mathrm{CH}_{3}$-dmso, these side reactions resulting in the formation of phosphonium salts, 2-vinylanisole, and methylphosphine (or more general: alkylphosphine) palladium complexes can be completely avoided by using the weaker coordinated and thus more reactive $1{ }^{13} \mathrm{CH}_{3}$-dmso $\left(5 \mathrm{mmol} \mathrm{L}{ }^{-1}\right.$, ca. $39 \mathrm{mmol} \mathrm{L}^{-1}$ ethylene, 8 equiv) in anhydrous thf $d_{8}$ at $298 \mathrm{~K}$ in NMR-tube experiments: Albeit slow, $1^{13}{ }^{13} \mathrm{CH}_{3}$-dmso already inserts ethylene at room temperature and ca. $95 \%$ of $1 .{ }^{13} \mathrm{CH}_{3}$-dmso is consumed within $165 \mathrm{~min}$ at $298 \mathrm{~K}$, while ca. 5.5 equiv of ethylene has been enchained. ${ }^{27}$ In these room-temperature studies, chain transfer by $\beta$-hydride elimination and chain-walking/isomerization is negligible, as concluded from the appearance of only traces of $\alpha$-olefins ( $<2 \%$ with respect to all palladium complexes present) 
and the absence of internal olefins. In addition, palladium propyl, pentyl, heptyl, and higher alkyl complexes were identified in the ${ }^{1} \mathrm{H}$ NMR spectra to contain ${ }^{13} \mathrm{C}$-labeled $\mathrm{CH}_{3}$ end groups exclusively on the basis of characteristic ${ }^{1} J_{\mathrm{CH}}=124-125 \mathrm{~Hz}$ and the absence of the respective ${ }^{12} \mathrm{CH}_{3}$ signals. These palladium alkyl complexes $1-\left(\mathrm{CH}_{2}\right)_{2 n}{ }^{13} \mathrm{CH}_{3}-\mathrm{L}$ constitute the only products formed from $1-{ }^{13} \mathrm{CH}_{3}$-dmso and indicate that true activation efficiencies of ca. $95 \%$ are already reached after ca. 5.5 turnovers of ethylene. They also indicate that at $298 \mathrm{~K}$ the polymerization of ethylene by ${ }^{1}-{ }^{13} \mathrm{CH}_{3}$-dmso has a living character in that the formed $1-\left(\mathrm{CH}_{2}\right)_{2 n}{ }^{13} \mathrm{CH}_{3}-\mathrm{L}$ complexes do not undergo decomposition or chain transfer even at very low ethylene concentration over prolonged periods of time: After an additional $12 \mathrm{~h}$ at $298 \mathrm{~K}$ ca. 7.3 of the initially 8 equiv of ethylene have been consumed. Simultaneously, trace amounts (ca. $5 \%$ vs palladium complexes) of 1 -olefins have formed by $\beta$-hydride elimination, while the formed palladium hydride complex reinserts ethylene, as concluded from the observation of palladium ethyl and butyl complexes 1-Et-L and 1-But-L. The stability of these complexes 1- $\left(\mathrm{CH}_{2}\right)_{2 n}{ }^{13} \mathrm{CH}_{3}-\mathrm{L}$ has allowed for a full characterization by $2 \mathrm{D}$ NMR techniques, which reveals that the most characteristic palladium-bound methylene group of a growing polymer chain resonates at $\delta\left({ }^{1} \mathrm{H}\right)=0.73 \mathrm{ppm}$ and $\delta\left({ }^{13} \mathrm{C}\right)=32.75 \mathrm{ppm}$ with ${ }^{2} J_{\mathrm{PC}}=5.8 \mathrm{~Hz}$ (for details, see $\mathrm{SI}$ ).

Heating this sample for $16 \mathrm{~h}$ to $313 \mathrm{~K}$ results in depletion of all signals corresponding to identified odd-numbered palladium alkyl complexes 1- $\left(\mathrm{CH}_{2}\right)_{2 n}{ }^{13} \mathrm{CH}_{3}-\mathrm{L}$, while ca. $2 \%$ of $1{ }^{1{ }^{13}} \mathrm{CH}_{3}$ dmso, 5\% of 1-Et, and traces of 1-But are still detectable. With respect to organic products we have unambiguously detected 1-alkenes, 2-alkenes, internal ( $x$-) alkenes with $x>2$ (4:4:1 ratio), and traces of ${ }^{13} \mathrm{CH}_{3}-\mathrm{CH}=\mathrm{CH}_{2}$ and $\mathrm{CH}_{3}-\mathrm{CH}={ }^{13} \mathrm{CH}_{2}$ (in a ca. 3:1 ratio), 2-methyl-1-alkenes, ${ }^{13} \mathrm{CH}_{3} \mathrm{CH}_{2} \mathrm{CH}_{3}$, and ${ }^{13} \mathrm{CH}_{4}$ in the 'H NMR spectra (for further details, see $\mathrm{SI}$ ).

The presence of ${ }^{13} \mathrm{CH}_{4}$ and ${ }^{13} \mathrm{CH}_{3} \mathrm{CH}_{2} \mathrm{CH}_{3}$ in all these NMR experiments with both $1-{ }^{13} \mathrm{CH}_{3}$-dmso and $1{ }^{13} \mathrm{CH}_{3}$-pyr suggests that also higher alkanes may form during ethylene polymerization. While the ratio of 1-olefins:2-olefins:internal olefins $(n>2)$ allows for an estimate of the expected ${ }^{13} \mathrm{CH}_{3}:{ }^{12} \mathrm{CH}_{3}$ end group ratio in these samples (internal olefins contain one ${ }^{12} \mathrm{CH}_{3}-$ $S 1$ end group even if initiated by $1{ }^{13} \mathrm{CH}_{3}-\mathrm{L}$ ), we find ${ }^{13} \mathrm{CH}_{3}:{ }^{12} \mathrm{CH}_{3}$ ratios that indicate the presence of additional saturated chains. However, since chain transfer as a source of ${ }^{12} \mathrm{CH}_{3}$ end groups is not quantified here, an accurate proof for the formation of fully saturated ethylene oligomers is hardly possible with these experiments. Therefore further experiments have been devised that circumvent the complicating issue of chain transfer and allow for the quantification of olefinic and aliphatic chains formed by $1-{ }^{13} \mathrm{CH}_{3}$-dmso and ethylene (vide infra).

On the basis of these data we conclude here that the formation of the catalytically active species $1-{ }^{13} \mathrm{CH}_{3}$-(ethylene) $\left(1-\mathrm{CH}_{3}\right.$ (ethylene), 1-( $\left(\mathrm{CH}_{2}\right)_{2 n}{ }^{13} \mathrm{CH}_{3}$-(ethylene), and 1-( $\left.\mathrm{CH}_{2}\right)_{2 n} \mathrm{CH}_{3}$ (ethylene), respectively) from $1{ }^{13} \mathrm{CH}_{3}-\mathrm{L}\left(1-\mathrm{CH}_{3}-\mathrm{L}\right.$, respectively) is indeed a rapid equilibrium reaction with respect to the following ethylene insertion, which justifies (a) the simplified reaction scheme given in eq 1 and (b) the assumption of a high activation efficiency. However, the reaction scheme of the overall polymerization according to eq 1 is simplistic in that it does not account for the observed exchange of palladium- and phosphorus-bound alkyl and aryl substituents and the polymerization activity of the species formed thereby. We also note that there is a strong indication that part of the formed ethylene oligomers in preparative (reactor) and analytical (NMR) experiments are fully saturated.
Deactivation of Catalytically Active Species by Endoand Exogenic Pathways. An exogenic (and thus avoidable) catalyst deactivation pathway at low ethylene concentration has been reported in the presence of chlorinated solvents, e.g., $\mathrm{C}_{2} \mathrm{D}_{2} \mathrm{Cl}_{4}$ or $\mathrm{CDCl}_{3}$, and resulted in isolation of $\left[\kappa^{2}-\mathrm{P}, \mathrm{O}\right] \mathrm{Pd}(\mathrm{Cl})$. (L) complexes. ${ }^{123}$ While the presence of water has been reported not to affect the stability of $1-\mathrm{CH}_{3}-\mathrm{L}$ at temperatures of 343 to $373 \mathrm{~K}^{25}$ we have now found that thermolysis of $1^{-13)} \mathbf{C H}_{3}-\mathrm{L}$ at 378-395 $\mathrm{K}$ apart from several phosphonium salts (vide supra) also yields ${ }^{(13)} \mathrm{CH}_{4}$ or ${ }^{(13)} \mathrm{CH}_{3} \mathrm{D}$ if the solvent is not rigorously dry. Complete consumption of $\mathbf{1}-\mathrm{CH}_{3}$-dmso in the presence of 30 equiv of $\mathrm{D}_{2} \mathrm{O}$ in tetrachloroethane- $d_{2}$ solution takes ca. $3 \mathrm{~h}$ at $368 \mathrm{~K}$, while a ca. 8:1 mixture of $\mathrm{CH}_{3} \mathrm{D}$ and $\mathrm{CH}_{4}$ forms (see SI). We therefore consider hydrolysis of palladium-methyl/alkyl species a further exogenic decomposition pathway. ${ }^{30}$

In contrast, reductive elimination of methyl/alkyl phosphonium salts, e.g., 2-7 (vide supra), as observed in the NMR-tube experiments and in preparative polymerizations, constitutes an endogenic (and unavoidable) deactivation pathway if the formed palladium $(0)$ does not completely reenter the catalytic cycle by oxidative addition of phosphonium salts, with, for example, formation of palladium-anisyl complexes (vide supra).

Additionally, we will present evidence that there is a second endogenic and totally irreversible catalyst deactivation pathway that is directly linked to the reactivity of palladium hydrides $\left[\kappa^{2}-\mathrm{P}, \mathrm{O}\right] \mathrm{Pd}(\mathrm{H})(\mathrm{L})$ formed by $\beta$-hydride elimination from a growing palladium polymeryl species and that these palladium hydrides are (directly or indirectly) responsible for the formation of fully saturated oligomers.

Considering the increased catalyst decomposition with increasing concentration of $1 .{ }^{13} \mathrm{CH}_{3}-\mathrm{L}$ in preparative ethylene polymerizations (vide supra, Table 1, entries $1-3$ and 9-11), the most straightforward hypothesis to rationalize the formation of saturated polymer chains and the decreasing activity over time is a bimolecular reaction of catalytically active palladium complexes, which is greater than first-order in active palladium and results in inactive palladium species according to eq 2 or eq 3 .

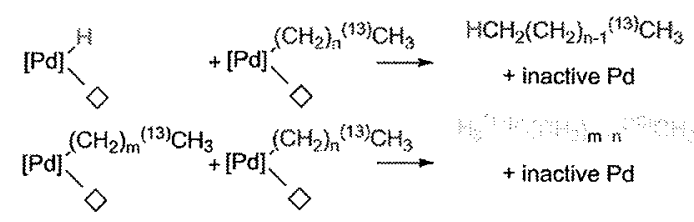

With respect to a coupling reaction of two palladium carbyl complexes according to eq 3 the experimental data do not support such a possibility: ${ }^{29}$ (a) $1-{ }^{13} \mathrm{CH}_{3}$-dmso $\left(1{ }^{13} \mathrm{CH}_{3}-\right.$ pyr, respectively) does not decompose to ${ }^{13} \mathrm{C}$-enriched/natural abundance ethane in anhydrous thf- $d_{8}$ solution up to $378 \mathrm{~K}, 8 \mathrm{~h}$, and (b) INADEQUATE, 2D ADEQUATE, or ${ }^{13} \mathrm{C},{ }^{13} \mathrm{C}$ - $J$-resolved experiments conducted with the oligomer sample obtained with $\left[1{ }^{13} \mathrm{CH}_{3}-\mathrm{pyr}\right]\left(6.6 \mathrm{mmol} \mathrm{L}{ }^{-1}\right)$ and [ethylene $]_{0}(50-55 \mathrm{mmol}$ $\mathrm{L}^{-1}$, ca. 8 equiv) in thf- $d_{8}$ under chain-walking conditions (vide supra) revealed no measurable ${ }^{13} \mathrm{C}-{ }^{13} \mathrm{C}$ connectivity between, for example, ${ }^{13} \mathrm{CH}_{3}$ - and ${ }^{13} \mathrm{CH}_{2}$-S3-(or backbone ${ }^{13} \mathrm{CH}_{2}$ groups), i.e., to form, for example, $1,2-\left({ }^{13} \mathrm{C}\right)$-butane from $1{ }^{13} \mathrm{CH}_{3}$ and $1-{ }^{13} \mathrm{CH}_{2} \mathrm{CH}_{2} \mathrm{CH}_{3}$ [or higher even-numbered $x,(x+1)-\left({ }^{13} \mathrm{C}\right)$ alkanes].

In contrast, the formation of ${ }^{13} \mathrm{C}$-labeled methane and propane as well as natural abundance ethane can likely be traced to a formal reaction of palladium hydride and palladium methyl, propyl, or ethyl complexes according to eq 2 . In order to provide 
hard evidence that also higher saturated alkanes can form, we have repeated the formation of $1-\left(\mathrm{CH}_{2}\right)_{2 n}{ }^{13} \mathrm{CH}_{3}-\mathrm{dmso}$ under conditions where $\beta$-hydride elimination/chain-walking is negligible $(298 \mathrm{~K})$, then removed excess ethylene, and finally heated the sample in order to induce $\beta$-hydride elimination and formation of palladium hydride complexes $\left[\kappa^{2}-\mathrm{P}, \mathrm{O}\right] \mathrm{Pd}(\mathrm{H})(\mathrm{L})$. Under these reaction conditions the overall number of oligomer chains will not increase after $\beta$-hydride elimination since initiation of a new chain requires ethylene to be present. Consequently, easily identified ${ }^{12} \mathrm{CH}_{3}-\mathrm{CH}_{2}$ end groups are expected only for internal $(n$-)olefins $(n>2)$ and for fully saturated polymer chains formed according to eq 2 . Furthermore, a quantification of fully saturated chains is possible since the amount of internal olefins is accessible (for details see $\mathrm{SI}$ ). After heating the ethylene-free sample of $1-\left(\mathrm{CH}_{2}\right)_{2 n}{ }^{13} \mathrm{CH}_{3}$-dmso for $3 \mathrm{~min}$ at $363 \mathrm{~K}$, more than $>90 \%$ of $1-\left(\mathrm{CH}_{2}\right)_{2 n}{ }^{13} \mathrm{CH}_{3}$-dmso is already decomposed, while a mixture of 1-olefins, 2-olefins, internal olefins, propane ${ }^{13} \mathrm{CH}_{4}$, and alkanes forms. The sample was heated for a further $22 \mathrm{~min}$ at $363 \mathrm{~K}$, after which time $1-\left(\mathrm{CH}_{2}\right)_{2 n}{ }^{13} \mathrm{CH}_{3}$-dmso is no longer detected, while palladium black deposited in the NMR tube and four new signals in the ${ }^{31} \mathrm{P}$ NMR spectrum at $\delta=30.03,22.81$, 3.83 , and $-24.06 \mathrm{ppm}$ in a $3: 25: 1: 1$ ratio were detected. The signals at 30.03 and $22.81 \mathrm{ppm}$ (accounting for more than $90 \%$ of all ${ }^{31} \mathrm{P}$ detected) were identical to those obtained when dissolving the bis(chelate) palladium complex $\left.\left.\left[\kappa^{2} \text {-(anisyl }\right)_{2} P, O\right)\right]_{2} \mathrm{Pd}(11)$ in thf- $d_{8}$ after prolonged heating. The other two phosphoruscontaining species at 3.83 and $-24.06 \mathrm{ppm}$ have not been identified.

Figure 7 shows the olefinic and aliphatic regions of the ${ }^{1} \mathrm{H}$ NMR spectrum obtained after heating the ethylene-free mixture

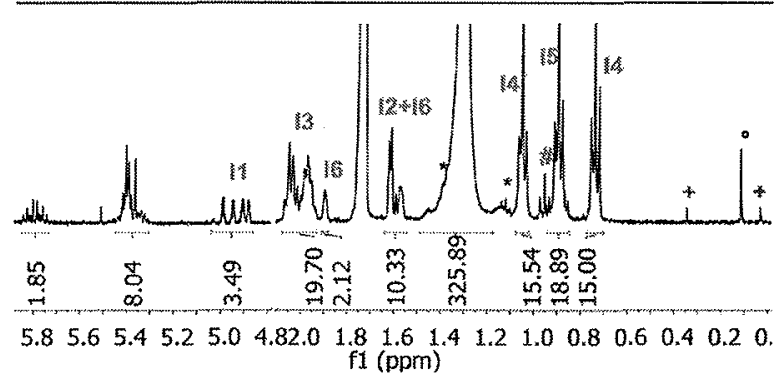

Figure 7. Olefinic and aliphatic region of the ${ }^{1} \mathrm{H}$ NMR spectrum of 1. $\left(\mathrm{CH}_{2}\right)_{2 n}{ }^{13} \mathrm{CH}_{3}$-dmso after $25 \mathrm{~min}$ at $363 \mathrm{~K}$ in the absence of additional ethylene. I1: integral of $=\mathrm{CH}_{2}$ of 1-olefins, 12 : integral of the allyic $\mathrm{CH}_{3}$ of cis- and trans-2-olefins, 13: integral of all allylic $\mathrm{CH}_{2}$ in 1-, 2-, and internal olefins, 14 : integral of all $\mathrm{CH}_{2}{ }^{13} \mathrm{CH}_{3}$ introduced by $1{ }^{13} \mathrm{CH}_{3}$ dmso, I5: integral of $\mathrm{CH}_{2}{ }^{12} \mathrm{CH}_{3}$ of $n$-olefins and fully saturated chains, 16: integral of the ${ }^{13} \mathrm{C}$-satellite of thf- $d_{8-x}[12$ is obtained by $(12+16)-$ 16]; *: propane, \#: $\mathrm{CH}_{2}{ }^{12} \mathrm{CH}_{3}$ group of 3 -olefins, $+{ }^{13} \mathrm{CH}_{4},{ }^{\circ}$ : grease.

of $1-\left(\mathrm{CH}_{2}\right)_{2 n}{ }^{13} \mathrm{CH}_{3}$-dmso for $25 \mathrm{~min}$ at $363 \mathrm{~K}$. Analysis of the integrals II (1-olefins), I2 (2-olefins), and $\mathbf{I} 3$ (allylic $\mathrm{CH}_{2}$ groups of all olefins) reveals a 25:38:37 ratio of 1-olefins:2-olefins:internal olefins. In combination with the integrals $14\left({ }^{13} \mathrm{CH}_{3} \mathrm{CH}_{2}\right.$ end groups) and $\mathrm{IS}\left({ }^{12} \mathrm{CH}_{3} \mathrm{CH}_{2}\right.$ end groups) a ratio of olefins:alkanes of 60:40 was determined (Scheme 4; for details, see SI).

Since formation of alkanes requires equimolar amounts of palladium hydride $\left[\kappa^{2}-\mathrm{P}, \mathrm{O}\right] \mathrm{Pd}(\mathrm{H})(\mathrm{L})$ (formed by $\beta$-hydride elimination and release of equimolar amounts of olefins) and palladium carbyl complexes 1-( $\left(\mathrm{CH}_{2}\right)_{2 n}{ }^{13} \mathrm{CH}_{3}$-dmso according to eq 2 , a quantitative reaction according to eq 2 will result in a 50:50 mixture of olefins and alkanes. Thus, the observed 60:40
Scheme 4. Formation of ${ }^{13} \mathrm{C}$-Labeled Olefins from 1- $\left(\mathrm{CH}_{2}\right)_{2 n}{ }^{13} \mathrm{CH}_{3}$-dmso and ${ }^{13} \mathrm{C}$-Labeled Alkanes by $\beta$-Hydride Elimination and Reaction of the Formed Palladium Hydride with 1 - $\left(\mathrm{CH}_{2}\right)_{2 n}{ }^{13} \mathrm{CH}_{3}$-dmso

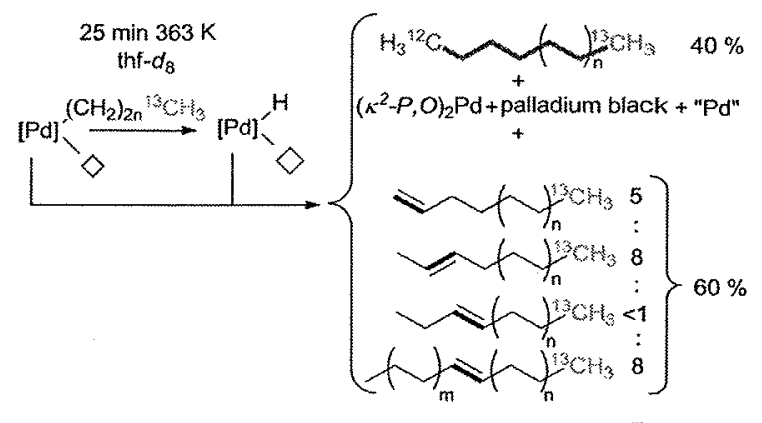

mixture corresponds to an $80 \%$ yield with respect to $1-\left(\mathrm{CH}_{2}\right)_{2 n}$ ${ }^{13} \mathrm{CH}_{3}$-dmso accessible for the formation of saturated chains (Scheme 4).

Palladium black, $\left.\left.\left[\kappa^{2} \text {-(anisyl }\right)_{2} P, O\right)\right]_{2} \mathrm{Pd}(11)$, and the two remaining phosphorus-containing species in this sample do not initiate new oligomer chains upon repeated addition of ethylene; that is, all polymerization-active species have been decomposed at this point. ${ }^{30}$ However, trace amounts of ethane are clearly detected already after $5 \mathrm{~min}$ at $298 \mathrm{~K}$ upon addition of ethylene. While we have not detected hydrogen directly after the thermolysis in the ${ }^{1} \mathrm{H}$ NMR spectrum (Figure 8 and SI), we

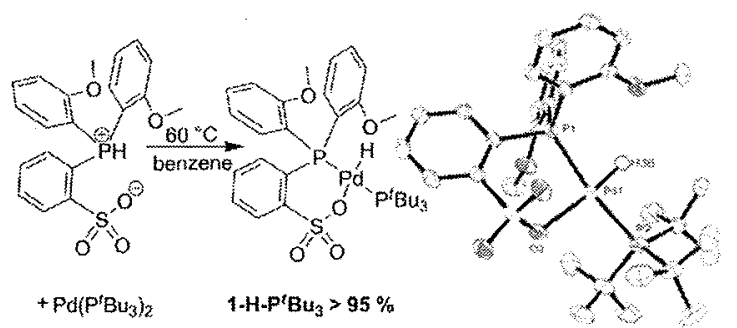

Figure 8. Synthesis of $1-\mathrm{H}-\mathrm{P}^{t} \mathrm{Bu}_{3}$ by oxidative addition of $\mathrm{P}$-protonated phosphonium salt $\mathrm{H}[\mathrm{P}, \mathrm{O}]$ to $\mathrm{Pd}\left(\mathrm{P}^{i} \mathrm{Bu}_{3}\right)_{2}$ and ORTEP plot of 1-H$\mathrm{P}^{t} \mathrm{Bu}_{3}$ at the $50 \%$ probability level. Hydrogen atoms (except for $\mathrm{Pd}$ $\mathrm{H} 36$ ) and one cocrystallized benzene molecule are omitted for clarity. The hydride bound to palladium was located in the electron density map and refined isotropically.

believe that the observed presence of ethane after ethylene addition results from palladium black catalyzed hydrogenation of ethylene; that is, hydrogen is also formed during the thermolysis of 1- $\left(\mathrm{CH}_{2}\right)_{2 n}{ }^{13} \mathrm{CH}_{3}$-dmso but not observable under these conditions. This assumption is supported by incremental addition of hydrogen $(1.2 \mathrm{bar})$ to the ethylene-containing reaction mixture, which results in rapid growth of the ethane singlet at $\delta=$ $0.851 \mathrm{ppm}$ in the ${ }^{1} \mathrm{H}$ NMR spectrum, while no hydrogen at $\delta=$ $4.545 \mathrm{ppm}$ is detectable until all ethylene has been hydrogenated. Notably, hydrogenation of the propene present is much slower $(12 \mathrm{~h}, 363 \mathrm{~K})$, as evidenced by its disappearance and the observed growth of the propane triplet at $\delta=1.118 \mathrm{ppm}$ in the ${ }^{1} \mathrm{H}$ NMR spectrum. In contrast to propene, I-olefins with $\mathrm{C}>3$ are mainly isomerized to internal olefins, which even after $20 \mathrm{~h}$ at $363 \mathrm{~K}$ are not hydrogenated.

The assumed presence of hydrogen after thermolysis of 1- $\left(\mathrm{CH}_{2}\right)_{2 n}{ }^{13} \mathrm{CH}_{3}$-dmso (which is responsible for ethane 
formation upon ethylene addition) indicates that formation of hydrogen is another reaction path by which palladium hydride complexes may be deactivated according to eq 4 .

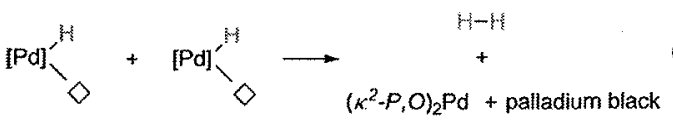

Thus, $1-\left(\mathrm{CH}_{2}\right)_{2 n}{ }^{13} \mathrm{CH}_{3}$-dmso at elevated temperature in part $\beta$-hydride eliminates olefins, while the formed palladium hydride $\left[\kappa^{2}-\mathrm{P}, \mathrm{O}\right] \mathrm{Pd}(\mathrm{H})$ decomposes by bimolecular reaction with 1-( $\left(\mathrm{CH}_{2}\right)_{2 n}{ }^{13} \mathrm{CH}_{3}$-dmso to form alkanes and with further palladium hydride $\left[\kappa^{2}-P, O\right] \mathrm{Pd}(\mathrm{H})$ to form hydrogen, which is finally responsible for the detection of ethane upon ethylene addition. The hydrogen formed likely also participates in further irreversible decomposition reactions with $1-\left(\mathrm{CH}_{2}\right)_{2 n}{ }^{(13)} \mathrm{CH}_{3}$ dmso, as $1 .{ }^{13} \mathrm{CH}_{3}$-dmso in the presence of hydrogen was found to decompose to ${ }^{13} \mathrm{CH}_{4}$, palladium black, and mainly $\left.\left.\left[\kappa^{2} \text {-(anisyl }\right)_{2} P, O\right)\right]_{2} \mathrm{Pd}(11)$ in thf- $d_{8}$ solution. However, the reaction takes $>8 \mathrm{~h}$ at $363 \mathrm{~K}$, which indicates that under polymerization conditions, i.e., in the presence of ethylene, (a) hydrogen present will hydrogenate ethylene to ethane once palladium black forms instead of cleaving growing polymer chains in 1-( $\left(\mathrm{CH}_{2}\right)_{2 n}{ }^{13} \mathrm{CH}_{3}$-dmso, and (b) therefore palladium hydride complexes $\left[\kappa^{2}-P, O\right] \mathrm{Pd}(\mathrm{H})$ are mostly responsible for deactivating polymerization-active species by cleaving polymer chains from 1- $\left(\mathrm{CH}_{2}\right)_{2 n}{ }^{13} \mathrm{CH}_{3}$-dmso.

Synthesis of the Model Hydride Complex $\left[\kappa^{2}-P, O-(O-\right.$ $\left.\left.\left.\mathrm{MeOC}_{6} \mathrm{H}_{4}\right)_{2} \mathrm{P}\left(\mathrm{C}_{6} \mathrm{H}_{4} \mathrm{SO}_{3}\right)\right) \mathrm{Pd}(\mathrm{H})\left(\mathrm{P}^{t} \mathrm{Bu}_{3}\right)\right]\left(1-\mathrm{H}-\mathrm{P}^{t} \mathrm{Bu}_{3}\right)$. As we did not directly observe palladium hydride complexes $\left[\kappa^{2}-P, O\right] \mathrm{Pd}$ $(\mathrm{H})$ in any of the above-mentioned experiments, we sought to synthesize a suitable palladium hydride complex 1-H-L that could model the decomposition reactions, e.g., of $\mathbf{1}-\mathrm{CH}_{3}$-dmso and 1-( $\left(\mathrm{CH}_{2}\right)_{2 n}{ }^{(13)} \mathrm{CH}_{3}$-dmso to form methane, alkanes, and hydrogen. Since the seminal work of Drent, Pugh, and coworkers, it is known that a combination of $\left[\mathrm{Pd}(0)(\mathrm{dba})_{2}\right]$ and zwitterionic, P-protonated phosphine benzenesulfonic acid $\left(0-\mathrm{MeOC}_{6} \mathrm{H}_{4}\right)_{2} \mathrm{PH}^{+}\left(\mathrm{C}_{6} \mathrm{H}_{4} \mathrm{SO}_{3}^{-}\right)(\mathrm{H}[\mathrm{P}, \mathrm{O}])$ generates active species for the copolymerization of ethylene and acrylates ( $\mathrm{dba}=1,5$-diphenylpenta-1,4-dien-3-one). While the nature of the active species has not been investigated in detail, it is likely a palladium hydride $\left[\kappa^{2}-P, O\right] \mathrm{Pd}(\mathrm{H})$ that forms upon formal oxidative addition of the protonated phosphine to palladium $(0)$.

In need for a suitable $\left[\kappa^{2}-P, O\right] P d(H)$ model complex we therefore explored the reaction of zwitterionic phosphine benzenesulfonic acid with palladium $(0)$ sources. While $[\mathrm{Pd}(0)$ $\left.(\mathrm{dba})_{2}\right]$ and $\left(o-\mathrm{MeOC}_{6} \mathrm{H}_{4}\right)_{2} \mathrm{PH}^{+}\left(\mathrm{C}_{6} \mathrm{H}_{4} \mathrm{SO}_{3}{ }^{-}\right)(\mathrm{H}[\mathrm{P}, \mathrm{O}])$ indeed forms a palladium hydride (even though in less than $5 \%$ yield as evidenced by in situ ${ }^{\mathrm{I}} \mathrm{H}$ NMR), this hydride is not stable and at room temperature eludes isolation. However, oxidative addition of $\mathrm{H}[\mathrm{P}, \mathrm{O}]$ to $\mathrm{Pd}\left(\mathrm{P}^{t} \mathrm{Bu}_{3}\right)_{2}$ generates $\left[\left(\kappa^{2}-\mathrm{P}, \mathrm{O}\right)-\left(\sigma-\mathrm{MeOC}_{6} \mathrm{H}_{4}\right)_{2} \mathrm{P}-\right.$ $\left.\left(\mathrm{C}_{6} \mathrm{H}_{4} \mathrm{SO}_{3}\right)\right] \mathrm{Pd}(\mathrm{H})\left(\mathrm{P}^{t} \mathrm{Bu}_{3}\right)\left(1-\mathrm{H}-\mathrm{P}^{t} \mathrm{Bu}_{3}\right)$ in virtually quantitative yield, which was isolated and fully characterized by NMR techniques and X-ray diffraction analysis (Figure 8 and Table 2). Notably, the palladium-bound hydride was located in the electron

Table 2. Selected Bond Distances $(\AA)$ and Angles (deg) for Complex 1-H-P ${ }^{t} \mathrm{Bu}_{3}$

$\begin{array}{lllr}\text { Pdl-H36 } & 1.48(4) & \mathrm{Pl}-\mathrm{Pdl}-\mathrm{P} 2 & 166.28(2) \\ \mathrm{Pdl}-\mathrm{O} 3 & 2.191(2) & \mathrm{P} 2-\mathrm{Pdl}-\mathrm{H} 36 & 85.8(14) \\ \mathrm{Pdl}-\mathrm{P} 1 & 2.3072(7) & \mathrm{O} 3-\mathrm{Pd} 1-\mathrm{H} 36 & 174.5(13) \\ \mathrm{Pd} 1-\mathrm{P} 2 & 2.3473(8) & \mathrm{O} 3-\mathrm{PdI}-\mathrm{P} 1 & 92.66(5)\end{array}$

density map with a distance to palladium of $1.48(4) \AA^{33}$ The coordination geometry of palladium in the solid state and in solution is corroborated by the ${ }^{1} \mathrm{H}$ and ${ }^{31} \mathrm{P}$ NMR solution data, which confirm the trans-disposition of both phosphorus atoms, as concluded from a ${ }^{2} J_{\mathrm{pp}, \text { trans }}=357.4 \mathrm{~Hz}$ and two ${ }^{2} J_{\mathrm{pH}, \text { cis }}=13.6$ and $1.9 \mathrm{~Hz}$, which split the hydridic resonance into a doublet of doublets at $\delta\left({ }^{1} \mathrm{H}\right)=-18.02 \mathrm{ppm}$.

Reactivity of the Model Palladium Hydride Complex. In order to understand the cross-reactivity of $1-\mathbf{H}-\mathrm{P}^{t} \mathbf{B u}_{3}$ with 1- $\mathrm{CH}_{3}-\mathrm{L}$ (vide infra), the reactivity of $1-\mathrm{H}-\mathrm{P}^{t} \mathrm{Bu}_{3}$ alone was also evaluated: 1-H-P ${ }^{t} \mathrm{Bu}_{3}$ slowly decomposes in tetrachloroethane$d_{2}$ solution within ca. $11 \mathrm{~h}$ at $373 \mathrm{~K}$ with concomitant evolution of hydrogen $(\delta=4.70 \mathrm{ppm})$. In addition, the bis(chelate) palladium complex $\left.\left.\left[\kappa^{2} \text {-(anisyl) }\right)_{2} P, O\right)\right]_{2} \mathrm{Pd}(11)$ crystallizes from these samples, as proven by single-crystal $X$-ray diffraction analysis (Figure 9$)^{32}$

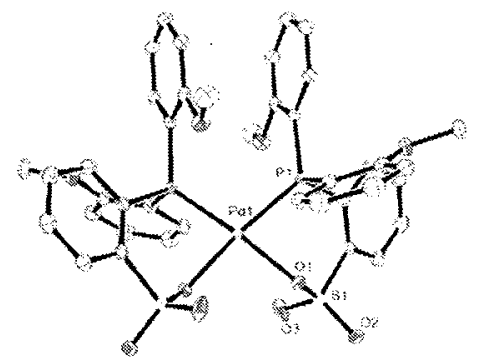

Figure 9. ORTEP plot of $\left.\left[\kappa^{2}-(\text { anisyl })_{2} P, O\right)\right]_{2} P d(11)$. Ellipsoids are shown at the $50 \%$ probability level. Hydrogen atoms and two cocrystallized $\mathrm{C}_{2} \mathrm{D}_{2} \mathrm{Cl}_{4}$ molecules are omitted for clarity.

With these observations in hand we monitored the reactivity of 1- $\mathrm{CH}_{3}$-dmso with 1-H-P $\mathbf{P}^{t} \mathrm{Bu}_{3}$ by ${ }^{1} \mathrm{H}$ NMR spectroscopy: 1- $\mathrm{CH}_{3-}$ dmso $(30 \mathrm{mM})$ disappears in the presence of $1-\mathrm{H}-\mathbf{P}^{t} \mathbf{B u}_{3}(1.2$ equiv) within $1.5 \mathrm{~h}$ at $373 \mathrm{~K}$ in tetrachloroethane- $d_{2}$ solution, while methane (characteristic singlet at $\delta=0.23 \mathrm{ppm}$ ) and traces of hydrogen $(\delta=4.71 \mathrm{ppm})$ were detected as decomposition products. ${ }^{33}$ The formation of methane may originate from adventious traces of water in the solvent (vide supra). However we note that upon reaction of partially deuterated $1-D-\mathbf{P}^{t} \mathbf{B u}_{3}$ (ca. $71 \%$ deuteride content) with $\mathbf{1} \cdot \mathbf{C H}_{3}$-dmso under otherwise identical reaction conditions (i.e., same solvent batch, temperature, concentration), methane- $d_{1}$ and methane are formed in a $66: 34$ ratio, as identified by the additional $1: 1: 1$ triplet at $\delta=$ $0.21 \mathrm{ppm}$ with a ${ }^{2} J_{\mathrm{HD}}=1.8 \mathrm{~Hz}$ in the ${ }^{1} \mathrm{H}$ NMR spectrum. That is, the solvent does not contain a significant amount of $\mathrm{H}_{2} \mathrm{O}$, as the amount of deuterium-label found in the methane is not signifcantly altered with respect to $\mathbf{1}-\mathbf{D}-\mathbf{p}^{t} \mathbf{B} \mathbf{u}_{3}$. While these data clearly indicate that methane (mainly) originates from a reaction of 1-H-Pt $\mathbf{B u}_{3}$ with $\mathbf{1}-\mathrm{CH}_{3}$-dmso, we note that in tetrachloroethane- $d_{2}$ solution only ca. 0.7 equiv of $1-\mathbf{H}-\mathbf{P}^{\prime} \mathrm{Bu}_{3}$ is necessary to decompose 1 equiv of $1-\mathrm{CH}_{3}$-dmso; that is, there is likely a second (and unidentified) decomposition reaction operative. In contrast, such an alternative decomposition pathway is not operative in thf- $d_{8}$ solution (ca. $24 \mathrm{~h}$ at $363 \mathrm{~K}$ ), as $1-\mathrm{CH}_{3}$-dmso and 1-H-P' $\mathbf{B u}_{3}$ ( 2 equiv) were consumed in a 1:1 ratio, while the remaining equivalent of $1-\mathrm{H}-\mathrm{P}^{t} \mathrm{Bu}_{3}$ only very slowly decomposes to hydrogen (additional $120 \mathrm{~h}, 383 \mathrm{~K}$ ).

While much slower than in the thermolysis of $1-\left(\mathrm{CH}_{2}\right)_{2 \pi}{ }^{13} \mathrm{CH}_{3}$ dmso, the formation of methane and particularly of methane- $d_{1}$ (from 1-D-P $\mathbf{P}^{t} \mathrm{Bu}_{3}$ ) and hydrogen clearly supports our assumption that palladium hydride complexes $\left[\kappa^{2}-\mathrm{P}, \mathrm{O}\right] \mathrm{Pd}(\mathrm{H})$ are responsible 
for the deactivation of polymerization-active palladium complexes and the formation of saturated hydrocarbons. Further evidence for this assumption also comes from the reaction of the isolated palladium ethyl complex 1-Et-PPh , which models the mixture of palladium alkyl complexes $1-\left(\mathrm{CH}_{2}\right)_{2 n}{ }^{13} \mathrm{CH}_{3}$-dmso obtained by in situ NMR experiments. Upon heating 1-Et- $\mathrm{PPh}_{3}$ in tetrachloroethane- $d_{2}$ solution, a mixture of ethylene, ethane, and hydrogen forms along with detectable amounts of $\mathbf{1}-\mathbf{H} \cdot \mathbf{P} \mathbf{P h}_{3}$ characterized by two ${ }^{31} \mathrm{P}$ nuclei resonating at $\delta=24.42$ and $7.92 \mathrm{ppm}$ with a ${ }^{2} J_{\text {PPtrans }}=395 \mathrm{~Hz}$ and one hydridic resonance at $\delta\left({ }^{1} \mathrm{H}\right)=$ $-17.36 \mathrm{ppm}$ with observable ${ }^{3} J_{\mathrm{PHC}}=16.5 \mathrm{~Hz}$ (for details, see SI).

Enhanced Decomposition in the Presence of Zwitterionic (o- $\left.\mathrm{MeOC}_{6} \mathrm{H}_{4}\right)_{2} \mathrm{PH}^{+}\left(\mathrm{C}_{6} \mathrm{H}_{4} \mathrm{SO}_{3}{ }^{-}\right), \mathrm{H}[\mathrm{P}, \mathrm{O}]$. All experimental data presented so far point to an inherent reactivity of palladium hydride complexes $\left[\kappa^{2}-P, O\right] P d(H)$, which results in a deactivation of polymerization-active species by formation of saturated hydrocarbons and hydrogen as well as palladium black and $\left[\kappa^{2}\right.$-(anisyl) $\left.\left.{ }_{2} P, O\right)\right]_{2} \mathrm{Pd}(11)$ (vide supra). However, as reductive elimination and oxidative addition of methylphosphonium salts were proven under NMR-tube conditions as well as in high. activity, high-pressure polymerization experiments (vide supra), and oxidative addition of $\left(0-\mathrm{MeOC}_{6} \mathrm{H}_{4}\right)_{2} \mathrm{PH}^{+}\left(\mathrm{C}_{6} \mathrm{H}_{4} \mathrm{SO}_{3}^{-}\right)$to palladium $(0)$ is obviously a viable strategy to generate polymerization-active palladium hydride species (vide supra and ref 3 ), we hypothesized that the microscopic reverse, i.e., reductive elimination of phosphonium salt $\left(o-\mathrm{MeOC}_{6} \mathrm{H}_{4}\right)_{2} \mathrm{PH}^{+}$$\left(\mathrm{C}_{6} \mathrm{H}_{4} \mathrm{SO}_{3}{ }^{-}\right)(\mathrm{H}[\mathrm{P}, \mathrm{O}])$ from palladium hydride complexes, may in principle be possible and that therefore $\mathrm{H}[\mathrm{P}, \mathrm{O}]$ may be responsible for the deactivation of polymerization-active palladium complexes and the formation of saturated polymer chains (Scheme 5) ${ }^{34}$ While thermodynamically the formation

Scheme 5. Reductive Elimination As a Source of $\mathrm{H}[\mathrm{P}, \mathrm{O}]$

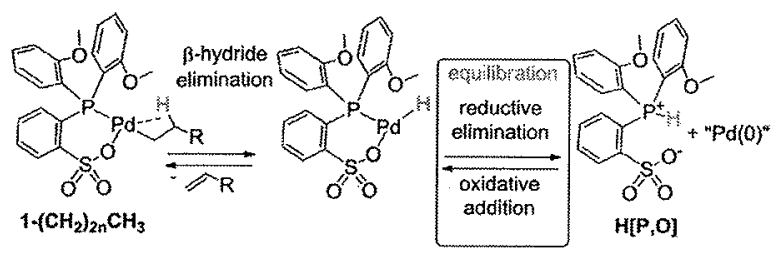

of $1-\mathrm{H}^{\prime} \mathrm{P}^{\prime} \mathrm{Bu}_{3}$ from stochiometric amounts of $\mathrm{H}[\mathrm{P}, \mathrm{O}]$ and $\mathrm{Pd}\left(\mathrm{P}^{t} \mathrm{Bu}_{3}\right)_{2}$ is preferred (Figure 8 ), heating of $1-\mathrm{H}-\mathrm{P}^{t} \mathrm{Bu} \mathbf{u}_{3}$ in dmso- $d_{6}$ solution in the presence of excess $\mathrm{P}\left({ }^{t} \mathrm{Bu}\right)_{3}$ results in the formation of $\left[\mathrm{HP}^{t} \mathrm{Bu}_{3}\right]^{+}[\mathrm{P}, \mathrm{O}]^{-}$, which thermodynamically likely reflects the higher basicity of $\mathrm{P}^{t} \mathrm{Bu}_{3}$ vs $[\mathrm{P}, \mathrm{O}](\mathrm{cf} . \mathrm{SI})$ and reduces the amount of $\mathrm{H}[\mathrm{P}, \mathrm{O}]$ accessible for oxidative addition to $\mathrm{Pd}(0)$. These experiments establish that oxidative addition and reductive elimination of $\mathrm{P}$-protonated phosphonium sulfonate $\mathrm{H}[\mathrm{P}, \mathrm{O}]$ to palladium $(0)$ are kinetically accessible and equilibrated.

Therefore, the reactivity of $\mathrm{H}[\mathrm{P}, \mathrm{O}]$ toward $1-\mathrm{CH}_{3}$-dmso, 1- $\mathrm{CH}_{3}-\mathrm{P}^{t} \mathrm{Bu}_{3}, \quad 1-\mathrm{CH}_{2} \mathrm{CH}_{3}-\mathbf{P P h}_{3}, 1-\mathrm{H}-\mathrm{P}^{t} \mathbf{B u}_{3}$, and 1- $\left(\mathrm{CH}_{2}\right)_{2 n^{-}}$ ${ }^{13} \mathrm{CH}_{3}-\mathrm{dmso}$ was studied. Intriguingly, the reaction of $1-\mathrm{CH}_{3}-$ dmso or ${ }^{1}-\mathrm{CH}_{3}-\mathrm{P}^{t} \mathrm{Bu}_{3}$ with 1.1 equiv of $\mathrm{H}[\mathrm{P}, \mathrm{O}]$ (instead of $1-\mathrm{H}-\mathrm{P}^{t} \mathrm{Bu}_{3}$ ) also yields methane, but the reaction is already complete within $5 \mathrm{~min}$ at $298 \mathrm{~K}$ in tetrachloroethane- $d_{2}$ solution, which contrasts with $\mathrm{ca} .1 .5 \mathrm{~h}$ at $373 \mathrm{~K}$ for the complete decomposition of $1-\mathrm{CH}_{3}$-dmso by $1-\mathrm{H}(\mathrm{D})-\mathrm{P}^{\prime} \mathrm{Bu}_{3}$ to form methane $\left(-d_{1}\right)$.

Decomposition of $\mathbf{1}-\mathbf{H}-\mathrm{P}^{t} \mathrm{Bu}_{3}$ by $\mathrm{H}[\mathrm{P}, \mathrm{O}]$ to form hydrogen is much slower than decomposition of $1-\mathrm{CH}_{3}$-dmso or $1-\mathrm{CH}_{3}$ $\mathbf{P}^{t} \mathbf{B u}_{3}$ by $\mathrm{H}[\mathrm{P}, \mathrm{O}](4 \mathrm{~h}, 373 \mathrm{~K}$ vs $<5 \mathrm{~min}, 298 \mathrm{~K})$ but faster than decomposition of $\mathbf{1 - H}-\mathrm{P}^{t} \mathrm{Bu}_{3}$ alone in the absence of $\mathrm{H}[\mathrm{P}, \mathrm{O}]$ $\left(11 \mathrm{~h}, 373 \mathrm{~K}\right.$, vide supra). Finally, $1-\mathrm{Et}_{-} \mathbf{P P h}_{3}$ decomposes to ethane, ethylene, butenes, and higher oligomers in the presence of $\mathrm{H}[\mathrm{P}, \mathrm{O}]$ at a similar rate as in the absence of $\mathrm{H}[\mathrm{P}, \mathrm{O}]$. While the relatively slow formation of ethane from $1-\mathrm{CH}_{2} \mathrm{CH}_{3}-\mathbf{P P h}_{3}$ and $\mathrm{H}[\mathrm{P}, \mathrm{O}]$ vis à vis the much faster formation of methane from 1- $\mathrm{CH}_{3}-\mathrm{dmso}$ or $1-\mathrm{CH}_{3}-\mathrm{P}^{t} \mathrm{Bu}_{3}$ and $\mathrm{H}[\mathrm{P}, \mathrm{O}]$ is intriguiging, we believe that it is caused by a much slower dissociation of $\mathrm{PPh}_{3}$ from 1-Et-PPh than the dissociation of bulky $\mathrm{P}^{t} \mathrm{Bu}_{3}$ or dmso from $1-\mathrm{CH}_{3}$-dmso or $\mathbf{1}-\mathrm{CH}_{3}-\mathrm{P}^{t} \mathrm{Bu}_{3}$ and that the reaction of 1-alkyl-PR ${ }_{3}$ complexes with $\mathrm{H}[\mathrm{P}, \mathrm{O}]$ only qualitatively models a catalyst decomposition during polymerization experiments with $1-\mathrm{CH}_{3}$-dmso or $1-\mathrm{CH}_{3}$-pyr. To verify this hypothesis, further ethylene oligomerizations were conducted in NMR-tube experiments. Thus, $1-{ }^{13} \mathrm{CH}$-dmso was reacted with ca. 7.5 equiv of ethylene for $90 \mathrm{~min}$ at $298 \mathrm{~K}$ in thf- $d_{8}$, while 5.5 equiv of ethylene was enchained to form a mixture of $1-\left(\mathrm{CH}_{2}\right)_{2 n}{ }^{-13} \mathrm{CH}_{3}$ dmso complexes in $74 \%$ NMR yield and $26 \% 1^{1-13} \mathrm{CH}$-dmso remained unreacted. At this point no signals indicating the presence of terminal or internal olefins were detectable by ${ }^{1} \mathrm{H}$ NMR spectroscopy. After addition of 1.5 equiv of $\mathrm{H}[\mathrm{P}, \mathrm{O}]$ (which is virtually insoluble in pure thf $-d_{8}$ ) the complete disappearance of $1-{ }^{13} \mathrm{CH}$-dmso and formation of ${ }^{13} \mathrm{CH}_{4}$ were evident within less than $5 \mathrm{~min}$ at $298 \mathrm{~K}$, while complete depletion of the aliphatic signals of $1-\left(\mathrm{CH}_{2}\right)_{2 n^{-1}}{ }^{13} \mathrm{CH}_{3}$ complexes was observed within $25 \mathrm{~min}$ at $298 \mathrm{~K}$. Simultaneously, characteristic signals of linear alkanes (internal methylene groups at $\delta=1.293$ ppm and of $\mathrm{CH}_{3}$ groups at $\delta=0.891 \mathrm{ppm}$ ) and traces of propane were detected. The ratio of ${ }^{13} \mathrm{CH}_{3}$ and ${ }^{12} \mathrm{CH}_{3}$ as well as $\left({ }^{13} \mathrm{C}\right) \mathrm{SI}$ $\mathrm{S} 2:\left({ }^{12} \mathrm{C}\right) \mathrm{S} 1-\mathrm{S} 2$ in these linear alkanes is virtually $1: 1$, while only trace amounts of olefins ( $<5 \%$, mainly 1 -olefins) were detected by means of ${ }^{1} \mathrm{H}$ and ${ }^{13} \mathrm{C}$ NMR spectroscopy. This experiment confirms that in the real catalytic system $\mathrm{H}[\mathrm{P}, \mathrm{O}]$ (if formed by reductive elimination from a palladium hydride according to Scheme 5) rapidly cleaves the palladium-polymeryl bond to form saturated hydrocarbons and that palladium-coordinated $\mathrm{PPh}_{3}$ may significantly reduce the rate of this decomposition reaction in the 1 $\mathrm{CH}_{2} \mathrm{CH}_{3}-\mathrm{PPh}_{3}$ model complex. ${ }^{31} \mathrm{P}$ NMR analysis of this sample indicates a virtually quantitative formation of $\left.\left[\kappa^{2}-(\text { anisyl })_{2} P, O\right)\right]_{2} \mathrm{Pd}$ (11), as concluded from two signals at $\delta=30.03$ and $22.81 \mathrm{ppm}$ in a 1:8 ratio, also observed with independently prepared material in thf- $d_{8}:$ dmso- $d_{6} 4: 1$ (vide supra).

At this point it remains unresolved whether palladium hydride complexes $\left[\kappa^{2} \cdot \mathrm{P}, \mathrm{O}\right] \mathrm{Pd}(\mathrm{H})$ or $\mathrm{H}[\mathrm{P}, \mathrm{O}]$ are directly responsible for the deactivation of polymerization-active palladium complexes and the formation of saturated hydrocarbons. However, DFT calculations have been conducted in order to clarify this issue (vide infra).

Implications for Copolymerizations of Ethylene with Polar Vinyl Monomers. The tendency of 1 -alkyl-L for $\beta$-hydride elimination under preparative reactor polymerization conditions ultimately opens a catalyst decomposition pathway by the inherent reactivity of formed $\left[\kappa^{2}-\mathrm{P}, \mathrm{O}\right] \mathrm{Pd}(\mathrm{H})$ or the reductive elimination product $\mathrm{H}[\mathrm{P}, \mathrm{O}]$ formed thereof. In general in copolymerizations of ethylene with polar vinyl monomers catalyzed by $1-\mathrm{CH}_{3}-\mathrm{L}$ polymer molecular weights tend to be lower vs ethylene homopolymerizations, due to an enhanced propensity for $\beta$-hydride elimination after enchainment of polar monomer. That is, the issue of irreversible catalyst deactivation initiated by palladium hydride complexes becomes increasingly important. As the decomposition reaction of $1-\left(\mathrm{CH}_{2}\right)_{21 t^{-}}{ }^{(13)} \mathrm{CH}_{3}$ with $\left[\kappa^{2}-\mathrm{P}, \mathrm{O}\right] \mathrm{Pd}(\mathrm{H})$ or $\mathrm{H}[\mathrm{P}, \mathrm{O}]$ will be greater than first-order in palladium $\left\{\right.$ due to $\left.\mathrm{d}[\mathrm{H}[\mathrm{P}, \mathrm{O}]] / \mathrm{d} t=-k \times\left[\left[\kappa^{2}-\mathrm{P}, \mathrm{O}\right] \mathrm{Pd}(\mathrm{H})\right]\right\}$, the 
most promising strategy to suppress this decomposition without changing the nature of the catalyst will be (a) to reduce the catalyst concentration in (co)polymerization experiments and (b) to lower the reaction temperature, thereby reducing the tendency for $\beta$-hydride elimination. While lowering the reaction temperature, e.g., to $298 \mathrm{~K}$, already was proven to reduce the tendency for $\beta$-hydride elimination due to the living character of ethylene enchainment (vide supra), the viability of this strategy is limited for preparative polymerizations due to decreased polymerization rates. We have therefore focused on the effect of catalyst concentration in ethylene-methyl acrylate (MA) copolymerization experiments.

Copolymerizations of ethylene and MA were performed with varying concentrations of $1-\mathrm{CH}_{3}$-dmso (from 0.2 to $1.0 \mathrm{mM}$ under otherwise identical conditions). In these experiments, clearly a decreasing productivity was found with increasing catalyst loading (i.e., with increasing [Pd]). Furthermore, although methyl acrylate incorporation did not change significantly, molecular weights of the obtained copolymers decreased with increasing [Pd], which indicates that growing copolymer chains may be terminated not only by $\beta$-hydride elimination but on a similar time scale also by reaction with $\left[\kappa^{2}-\mathrm{P}, \mathrm{O}\right] \mathrm{Pd}(\mathrm{H})$ or $[\mathrm{P}, \mathrm{O}] \mathrm{H}$, with formation of saturated copolymer chains (Table 3 ).

Table 3. Ethylene-Methyl Acrylate Copolymerizations at Variable Concentrations of the Catalyst Precursor ${ }^{a}$

\begin{tabular}{|c|c|c|c|c|c|c|c|}
\hline try. & $\begin{array}{l}\text { conc } \\
\text { pd(u) } \\
\text { (nM) }\end{array}$ & yield & $\begin{array}{l}\mathrm{TON}_{2} \\
\mathrm{C}_{2} \mathrm{H}_{4}\end{array}$ & $\begin{array}{l}\text { ToN } \\
\text { Mr }\end{array}$ & $\lambda_{X i}$ & {$\left[10^{3} \mathrm{~g} \mathrm{~mol}^{+}\right]$} & $M_{w} / M_{i}{ }^{d}$ \\
\hline 1 & 0.2 & 0.47 & 603 & 77 & 11.3 & 8000 & 1.4 \\
\hline 2 & 0.5 & 0.97 & 486 & 67 & 12.2 & 7100 & 1.4 \\
\hline 3 & 1.0 & 1.61 & 414 & 53 & 11.3 & 5800 & 1.5 \\
\hline
\end{tabular}

${ }^{a}$ Reaction conditions: $100 \mathrm{~mL} 0.6 \mathrm{M} \mathrm{MA}$ in toluene, 5 bar $\left[\mathrm{C}_{2} \mathrm{H}_{4}\right]$; $95{ }^{\circ} \mathrm{C} ; 30 \mathrm{~min}$ polymerization time, catalyst $\left(\mathbf{1}-\mathrm{CH}_{3}\right.$-dmso) added as methylene chloride solution. ${ }^{b}$ Turnover number per palladium. ${ }^{\circ}$ From ${ }^{\mathrm{l}} \mathrm{H}$ NMR in $\mathrm{C}_{2} \mathrm{D}_{2} \mathrm{Cl}_{4}$ at $100{ }^{\circ} \mathrm{C}$. ${ }^{\mathrm{A}} \mathrm{From} \mathrm{GPC}$ at $40{ }^{\circ} \mathrm{C}$ vs polystyrene standards.

The reactivity of the methyl acrylate diinsertion product 16 , which is isolable upon reaction of $1-\mathrm{CH}_{3}-\mathrm{L}$ with methyl acrylate, ${ }^{12 \mathrm{~b}}$ was studied. Complex 16 is a suitable model for catalyst deactivation in ethylene-methyl acrylate copolymerizations, as $\beta$-hydride elimination after acrylate insertion can be modeled. Thus, heating 16 in tetrachloroethane- $d_{2}$ solution to $373 \mathrm{~K}$ for $8 \mathrm{~h}$ results in formation of a ca. 60:40 mixture of unsaturated 4-ethylpent-2-enedioic acid dimethyl ester (17) and saturated 2-ethylpentanedioic acid dimethyl ester (18) (Scheme 6; for details, see SI). This experiment proves that in ethyleneacrylate copolymerizations palladium hydride $\left[\kappa^{2}-\mathrm{P}, \mathrm{O}\right] \mathrm{Pd}(\mathrm{H})$ or P-protonated phosphonium salt $\mathrm{H}[\mathrm{P}, \mathrm{O}]$ is capable of cleaving palladium polymeryl species formed after an acrylate insertion.

Scheme 6. Formation of Unsaturated 17 and Saturated 18 by Thermolysis of Complex 16 in the Absence or Presence of $\mathrm{H}[\mathrm{P}, \mathrm{O}]$

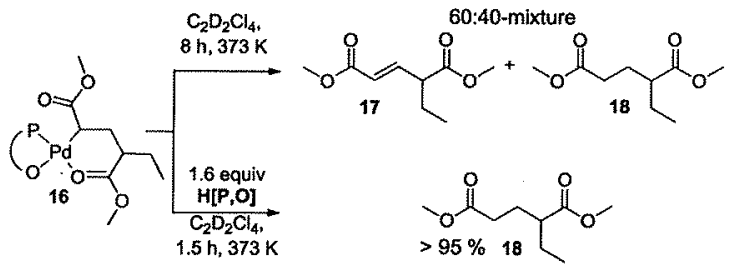

Furthermore, upon addition of 1.6 equiv of $\mathrm{H}[\mathrm{P}, \mathrm{O}]$ to complex 16 the saturated product 18 is formed in nearly quantitative NMR yield within $1.5 \mathrm{~h}$ under otherwise identical reaction conditions.

Theoretical Investigations on Reversible and Irreversible Catalyst Deactivation Reactions. DFT calculations were performed with Gaussian $09^{35}$ using the $B P 86^{36-38}$ functional and the LANL2DZ ECP C5 ${ }^{39}$ with the associated valence basis set on the Pd atom and the 6-31G (d) basis set on all the other atoms. All geometries were localized in the gas phase at the BP86 level. Minima were localized by full optimization of the starting structures, while transition states were approached through a linear transit procedure and then located by a full transition-state search. All structures were confirmed as minimum or transition state through frequency calculations. The natural bond orbital analyses were performed by using NBO version $3^{40-47}$ The reported energies were obtained through single-point energy calculations on the BP86 geometries using the M06 functional, the SDD ECP with the associated valence basis set on the Pd atom, and the TZVP basis set on all other atoms. Dichloroethane solvent effects were induded with the continuum solvation model PCM. ${ }^{48}$

Since products obtained after reductive elimination of phosphonium salts (aryl) ${ }_{3-x} \mathrm{P}^{+} \mathrm{R}_{x+1}(x=0,1)$ from $\left[\left(\kappa^{2}-\mathrm{P}, \mathrm{O}\right)\right.$ $\left.\left(o-\mathrm{MeOC}_{6} \mathrm{H}_{4}\right)_{2} \mathrm{P}\left(\mathrm{C}_{6} \mathrm{H}_{4} \mathrm{SO}_{3}\right)\right] \mathrm{Pd}(\mathrm{R})(\mathrm{L})$ (1-R-L) were formed during preparative reactor polymerizations, NMR in situ polymerizations, and thermolysis of complexes 1-R-L (vide supra), mechanistic pathways for these reductive elimination reactions were investigated. Due to the potential participation of P-protonated phosphonium salt $\left(0-\mathrm{MeOC}_{6} \mathrm{H}_{4}\right)_{2}\left(\mathrm{C}_{6} \mathrm{H}_{4} \mathrm{SO}_{3}\right)$ $\mathrm{P}^{+}(\mathrm{H})(\mathrm{H}[\mathrm{P}, \mathrm{O}])$ in an irreversible catalyst deactivation (vide supra), we first investigated the formation of $\mathrm{H}[\mathrm{P}, \mathrm{O}]$ starting from the synthesized model complex $\mathbf{1}-\mathrm{H}-\mathrm{P}^{t} \mathrm{Bu}_{3}$ and $\mathrm{P}^{t} \mathrm{Bu}_{3}$ (note that $1-\mathrm{H}-\mathrm{P}^{\prime} \mathrm{Bu}_{3}$ was synthesized by oxidative addition of $\mathrm{H}[\mathrm{P}, \mathrm{O}]$ to $\left.\left[\mathrm{Pd}\left(\mathrm{P}^{t} \mathrm{Bu}_{3}\right)_{2}\right]\right)$.

These calculations indicate that the reductive elimination of $\mathrm{H}[\mathrm{P}, \mathrm{O}]$ occurs through a transition state (TS) lying $124 \mathrm{~kJ} \mathrm{~mol}^{-1}$ higher in energy than $1-\mathrm{H} \cdot \mathrm{P}^{t} \mathrm{Bu}_{3}$, with the $\mathrm{P}^{t} \mathrm{Bu}_{3}$ ligand still coordinated to the $\mathrm{Pd}$ (see Scheme 7). The transition-state geometry 1-H-TS1 (Scheme 7 and Figure 10) exhibits a still short palladium-hydride and palladium-oxygen bonds $(\mathrm{Pd}-\mathrm{H}$ : 1.58 vs $1.48 \AA$ and 2.28 vs $2.19 \AA$ in $1-\mathbf{H}-\mathbf{P}^{t} \mathrm{Bu}_{3}$, see Figure 8 and Table 2), while the cleaving palladium-phosphine bond is

Scheme 7. Energetics $\left(\mathrm{kJ} \mathrm{mol}^{-1}\right)$ of the Reductive Elimination of $\mathrm{H}[\mathrm{P}, \mathrm{O}]$ from $\mathbf{1}-\mathrm{H}-\mathrm{P}^{t} \mathrm{Bu}_{3}$.
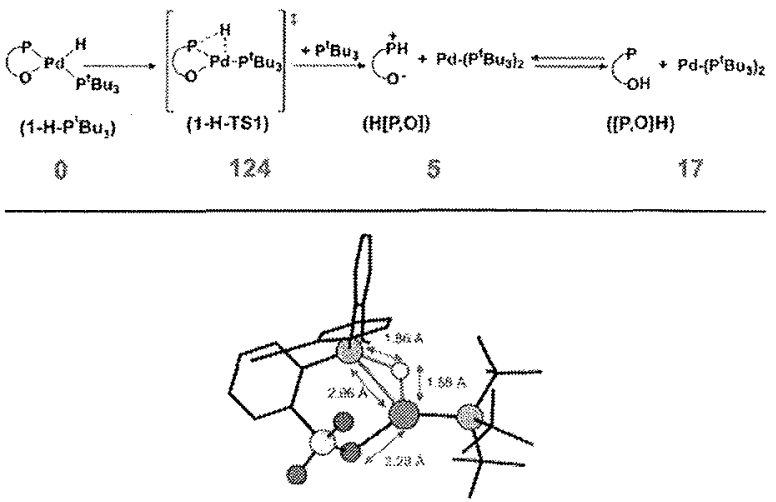

Figure 10. Transition-state geometry for the reductive elimination reaction of $\mathrm{H}[\mathrm{P}, \mathrm{O}]$ from $1-\mathrm{H} \cdot \mathrm{P}^{t} \mathrm{Bu}_{3}$ 
already $2.96 \AA$ long, as compared to $2.31 \AA \AA$ in $\mathbf{1}-\mathrm{H}-\mathbf{P}^{t} \mathbf{B u}_{3}$. Finally the evolving phosphine-hydrogen bond is still $1.86 \AA$ long, as compared to ca. $1.33-1.40 \AA$ in reported P-protonated phosphonium salts. ${ }^{51}$ After reductive elimination of $\mathrm{H}[\mathrm{P}, \mathrm{O}]$ the departing $\mathrm{Pd}-\mathrm{P}^{t} \mathrm{Bu}_{3}$ fragment is stabilized by incoming $\mathrm{P}^{t} \mathrm{Bu}_{3}$ to form $\left[\mathrm{Pd}\left(\mathrm{P}^{t} \mathrm{Bu}_{3}\right)_{2}\right]$. The overall reaction is essentially thermoneutral, with $1-\mathrm{H}-\mathrm{P}^{t} \mathrm{Bu}_{3}+\mathrm{P}^{t} \mathrm{Bu}_{3}$ favored by $5 \mathrm{~kJ} \mathrm{~mol}{ }^{-1}$ over $\mathrm{H}[\mathrm{P}, \mathrm{O}]+\left[\mathrm{Pd}\left(\mathrm{P}^{t} \mathrm{Bu}_{3}\right)_{2}\right]$, which is in qualitative agreement with the synthesis of $\mathbf{1}-\mathbf{H}-\mathrm{P}^{t} \mathrm{Bu}_{3}$ from $\mathrm{H}[\mathrm{P}, \mathrm{O}]+\left[\mathrm{Pd}\left(\mathrm{P}^{t} \mathrm{Bu}_{3}\right)_{2}\right]$. Considering the principle of microscopic reversibility and the calculated energies of educts, products, and the transition state 1-H-TS1, these results indicate a fully reversible formation of 1-H-P. ${ }^{t} \mathrm{Bu}_{3}+\mathrm{P}^{t} \mathrm{Bu}_{3}$ from $\mathrm{H}[\mathrm{P}, \mathrm{O}]+\left[\mathrm{Pd}\left(\mathrm{P}^{t} \mathrm{Bu}_{3}\right)_{2}\right]$.

A similar reaction profile was also found for the reductive elimination of $\mathrm{P}$-methylated and P-ethylated phosphonium salts $\mathrm{Me}[\mathrm{P}, \mathrm{O}]$, and $\mathrm{Et}[\mathrm{P}, \mathrm{O}]$ from $1-\mathrm{CH}_{3}-\mathrm{P}^{t} \mathbf{B u}_{3}$ and $1-\mathrm{CH}_{2} \mathbf{C H}_{3}-$ $\mathrm{P}^{t} \mathrm{Bu}_{3}+\mathrm{P}^{t} \mathrm{Bu}_{3}$. However, the formed products $\mathrm{Me}[\mathrm{P}, \mathrm{O}]$ $(\mathrm{Et}[\mathrm{P}, \mathrm{O}]$, respectively $)+\left[\mathrm{Pd}\left(\mathrm{P}^{t} \mathrm{Bu}_{3}\right)_{2}\right]$ are much more stable than the educts by $65\left(66\right.$, respectively) $\mathrm{kJ} \mathrm{mol}^{-1}$, while the transition states $1-\mathrm{CH}_{3}-\mathrm{TS1}$ (1- $\mathrm{CH}_{2} \mathrm{CH}_{3}-\mathrm{TS1}$, respectively) lie 164 (171) $\mathrm{kJ} \mathrm{mol}^{-1}$ higher than the educts (Scheme 8).

Scheme 8. Energetics $\left(\mathrm{kJ} \mathrm{mol}^{-1}\right)$ of the Reductive Elimination of $\mathrm{Me}[\mathrm{P}, \mathrm{O}]$ from $1-\mathrm{CH}_{3}-\mathrm{P}^{\mathrm{t}} \mathrm{Bu}_{3}$ (a) and of the Elimination of $\mathrm{Et}[\mathrm{P}, \mathrm{O}]$ from $1-\mathrm{CH}_{2} \mathrm{CH}_{3}-\mathrm{P}^{t} \mathrm{Bu}_{3}$ (b)

(a)

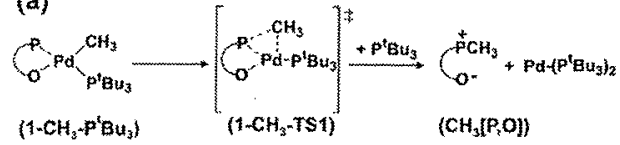

0

19

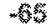

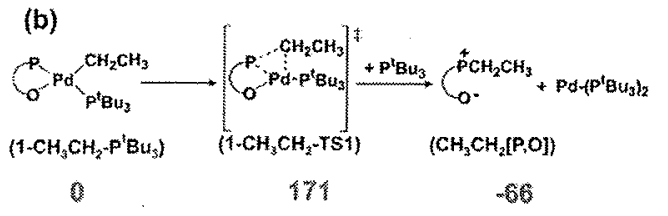

Thus, although thermodynamically much more favorable than reductive elimination of $\mathrm{H}[\mathrm{P}, \mathrm{O}]$, the reductive elimination of $\mathrm{Me}[\mathrm{P}, \mathrm{O}](\mathrm{Et}[\mathrm{P}, \mathrm{O}]$, respectively) requires a 40 (47, respectively) $\mathrm{kJ} \mathrm{mol}^{-1}$ higher activation energy than reductive elimination of $\mathrm{H}[\mathrm{P}, \mathrm{O}]$. These significantly increased activation energies also manifest in the transition-state geometries $1-\mathrm{CH}_{3}-\mathrm{TS} 1$ (1- $\mathrm{CH}_{2} \mathrm{CH}_{3}-\mathrm{TS} 1$, respectively, Figure 11) with already short $\mathrm{P}-\mathrm{CH}_{3}\left(\mathrm{P}-\mathrm{CH}_{2} \mathrm{CH}_{3}\right.$, respectively) distances of 1.92 (1.95, respectively) $\AA$ for the evolving $\mathrm{P}-\mathrm{C}$ bond as compared, for example, with $1.80 \AA \AA$ in P-methylated complex 10 or $1.84 \AA$ in
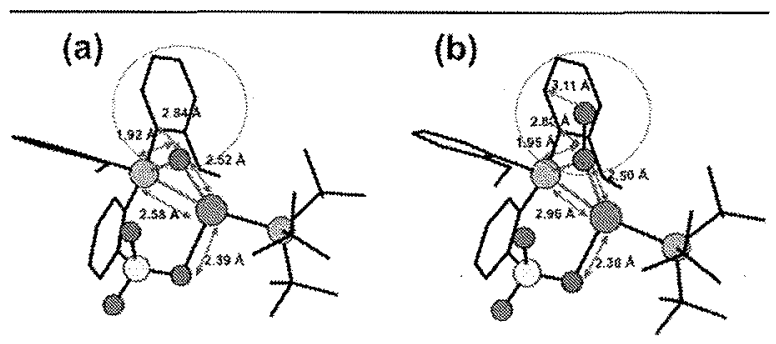

Figure 11. Transition states $1-\mathrm{CH}_{3}-\mathrm{TS} 1$ and $1-\mathrm{CH}_{2} \mathrm{CH}_{3}-\mathrm{TS} 1$ for the reductive elimination of $\mathrm{H}[\mathrm{P}, \mathrm{O}]$ from $1-\mathrm{CH}_{3}-\mathrm{P}^{t} \mathrm{Bu}_{3}$ (a) and from 1- $\mathrm{CH}_{2} \mathrm{CH}_{3}-\mathrm{P}^{t} \mathrm{Bu}_{3}$ (b).
P-ethylated complex 12 or with a calculated ground-state distance of $1.84(1.86) \AA$ in $\mathrm{Me}[\mathrm{P}, \mathrm{O}](\mathrm{Et}[\mathrm{P}, \mathrm{O}])$.

To rationalize the remarkable thermodynamic difference between reductive eliminations from the $\mathrm{Pd}-\mathrm{H}$ complex on one hand and the Pd-Me and Pd-Et complexes on the other hand, we compare the homolytic bond dissociation energy (BDE) of the $\mathrm{Pd}-\mathrm{R}$ bond in the $\mathrm{Pd}-\mathrm{H}, \mathrm{Pd}-\mathrm{Me}$, and $\mathrm{Pd}-\mathrm{Et}$ complexes. The calculated BDEs indicate that the $\mathrm{Pd}-\mathrm{H}$ bond is roughly $100 \mathrm{~kJ} \mathrm{~mol}^{-1}$ stronger than the $\mathrm{Pd}-\mathrm{C}$ bonds. On the other hand, the $\mathrm{BDE}$ of the $\mathrm{P}-\mathrm{H}, \mathrm{P}-\mathrm{Me}$, and $\mathrm{P}-\mathrm{Et}$ bonds in the corresponding $\mathrm{R}[\mathrm{P}, \mathrm{O}]$ zwitterions indicates that the $\mathrm{P}-\mathrm{H}$ bond is only ca. $30 \mathrm{~kJ} \mathrm{~mol}^{-1}$ stronger than the $\mathrm{P}-\mathrm{C}$ bonds. Thus, the main difference in the thermodynamics of the reductive elimination is caused by the difference in the strength of the $\mathrm{Pd}-\mathrm{H}$ and $\mathrm{Pd}-\mathrm{C}$ bonds and can be reasonably approximated by the calculated differences of the BDE of the Pd-R and $\mathrm{P}-\mathrm{R}$ bonds.

Furthermore, the transition-state energy differences seem to have a steric term. As indicated in Figure 11, steric interactions between the migrating $\mathrm{Me}$ or Et group and one of the anisyl rings of the ligand with close contacts of ca. $2.8 \AA$ to the ipso-anisyl carbon atom may be responsible for the higher energy of $1-\mathrm{CH}_{3}$ TS1-Pt ${ }^{t} \mathbf{u}_{3}$ and $1-\mathrm{CH}_{2} \mathrm{CH}_{3}-\mathrm{TS} 1-\mathrm{P}^{t} \mathbf{B u}_{3}$ compared with the TS calculated for the less encumbered 1-H-TS1 (Figure 10).

Given the strong thermodynamic preference for the reductive elimination to form P-alkylated phosphonium salts, the microscopic reverse, i.e., oxidative addition of $\mathrm{Me}[\mathrm{P}, \mathrm{O}]$ to $\left[\mathrm{Pd}\left(\mathrm{P}^{t} \mathrm{Bu} \mathrm{u}_{3}\right)_{2}\right]$ with an activation energy of $229 \mathrm{~kJ} \mathrm{~mol}^{-1}\left(237 \mathrm{~kJ} \mathrm{~mol}^{-1}\right.$ for $\mathrm{Et}[\mathrm{P}, \mathrm{O}]$, respectively), seems highly unlikely based on these calculations. However, since mass spectrometric and NMR data prove the formation of double-methylated phosphonium salts, e.g., 2, and in addition 2-(vinyl)anisole was detected by NMR experiments (vide supra and $\mathrm{SI}$ ), the oxidative addition of a $\mathrm{P}$-anisyl bond of $\mathrm{Me}[\mathrm{P}, \mathrm{O}]$ to $\left[\mathrm{Pd}\left(\mathrm{P}^{\prime} \mathrm{Bu}_{3}\right)_{2}\right]$ was investigated. Remarkably, a transition-state geometry 1-anisyl-TS1 was found, which lies $157 \mathrm{~kJ} \mathrm{~mol}^{-1}$ higher than $\mathrm{Me}[\mathrm{P}, \mathrm{O}]+\left[\mathrm{Pd}\left(\mathrm{P}^{t} \mathrm{Bu} \mathrm{u}_{3}\right)_{2}\right]$. This barrier is similar to that of reductive elimination of $\mathrm{Me}[\mathrm{P}, \mathrm{O}]$ from $1-\mathrm{CH}_{3}-\mathrm{P}^{\prime} \mathrm{Bu}_{3}\left(164 \mathrm{~kJ} \mathrm{~mol}^{-1}\right)$ and is therefore kinetically accessible considering that formation of $\mathrm{Me}[\mathrm{P}, \mathrm{O}]$ takes place under experimental conditions. The transition state 1-anisyl-TS1 evolves into the palladium anisyl complex 19 -(anisyl)- $\mathbf{P}^{t} \mathrm{Bu}_{3}$, which, though thermodynamically $15 \mathrm{~kJ} \mathrm{~mol}^{-1}$ less stable than $\mathrm{Me}[\mathrm{P}, \mathrm{O}]+\left[\mathrm{Pd}\left(\mathrm{P}^{t} \mathrm{Bu}_{3}\right)_{2}\right]$, is $50 \mathrm{~kJ} \mathrm{~mol}^{-1}$ more stable than $1-\mathrm{CH}_{3^{-}}$ $\mathbf{P}^{t} \mathbf{B u}_{3}$ (Scheme 9a). These results are in accordance with the

Scheme 9. Energetics $\left(\mathrm{kJ} \mathrm{mol}^{-1}\right)$ of the Reductive Elimination of $\mathrm{Me}[\mathrm{P}, \mathrm{O}]$ from 1- $\mathrm{CH}_{3}-\mathrm{P}^{t} \mathrm{Bu}_{3}$ and of the P-Anisyl Oxidative Addition of $\mathrm{Me}[\mathbf{P}, \mathrm{O}]$ to $\left[\mathbf{P d}\left(\mathbf{P}^{t} \mathbf{B u}_{3}\right)_{2}\right](\mathbf{a})$ and to $\left[\mathbf{P d}\left(\mathbf{P}^{t} \mathbf{B u}_{3}\right)\right](\mathrm{b})$

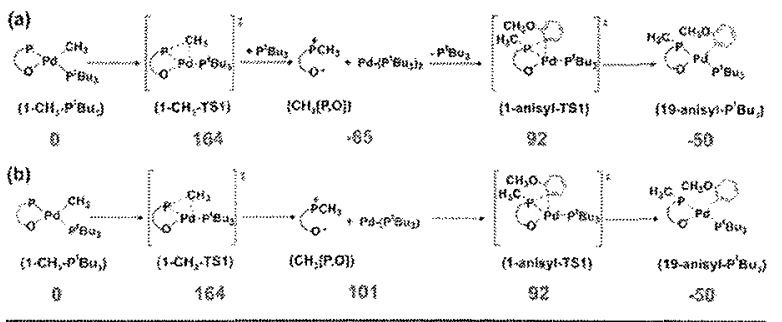

more general trend observed in metal-carbon bond energies experimentally determined by Wolczanski et al. for titanium carbyl complexes $^{50 \mathrm{a}}$ and by Jones et al. for rhodium carbyl complexes. ${ }^{50 \mathrm{~b}}$ They indicate that the respective metal-methyl bonds tend to be ca. $30 \mathrm{~kJ} \mathrm{~mol}^{-1}(\mathrm{Ti})$ or ca. $65 \mathrm{~kJ} \mathrm{~mol}^{-1}(\mathrm{Rh})$ less stable than the respective metal-phenyl bonds. They are also in accordance 
with DFT calculations of the Wolczanski and Jones series at the B3PW91 and BP86 levels of theory, which clearly support the higher stability of metal-phenyl vs metal-methyl bonds. ${ }^{50 c}$

In the absence of free $\mathrm{P}^{t} \mathrm{Bu}_{3}$ the $\mathrm{Pd}\left(\mathrm{P}^{t} \mathrm{Bu}_{3}\right)$ fragment evolving from 1- $\mathrm{CH}_{3}-\mathrm{TSI}-\mathrm{P}^{t} \mathrm{Bu}_{3}$ will not be stabilized by formation of $\left[\operatorname{Pd}\left(\mathrm{P}^{t} \mathrm{Bu}_{3}\right)_{2}\right]$, and reaction of $\mathrm{Me}[\mathrm{P}, \mathrm{O}]+\operatorname{Pd}\left(\mathrm{P}^{t} \mathrm{Bu}_{3}\right) \rightarrow$ 19-anisyl- $\mathrm{P}^{t} \mathrm{Bu}_{3}$ becomes energetically barrierless (Scheme $9 \mathrm{~b}$ ). Simultaneously, the absence of free $\mathrm{P}^{t} \mathrm{Bu}_{3}$ makes 19 -anisyl- $\mathrm{P}^{t} \mathrm{Bu}_{3}$ a global and not just a local thermodynamical minimum when compared to the reaction shown in Scheme 9a. ${ }^{51}$

These results indicate that reductive elimination of methyl/ alkylphosphonium salts $\mathrm{Me}[\mathrm{P}, \mathrm{O}] /($ alkyl $)[\mathrm{P}, \mathrm{O}]$ in the real catalytic system constitutes a reversible deactivation pathway of polymerization-active palladium complexes to form palladium $(0)$ species. Reactivation of palladium( 0 ) species, however, proceeds by oxidative addition of a $P$-anisyl bond as supported by experimental results and DFT calculations.

In contrast, the formation of fully saturated alkanes under polymerization conditions and the additional formation of dihydrogen in model reactions result in an irreversible catalyst deactivation. The experimental data, however, do not allow for a precise mechanistic scheme, since palladium hydride complexes $\left[\left(\kappa^{2}-P, O\right] P d(H)(L)\right.$ or reductively eliminated P-protonated phosphonium salts $\mathrm{H}[\mathrm{P}, \mathrm{O}]$ may be responsible for the formation of inactive palladium and saturated alkanes. Therefore several mechanistic schemes were investigated by DFT methods: (a) the reactions of $\mathrm{P}$-protonated phosphonium salt $\mathrm{H}[\mathrm{P}, \mathrm{O}]$ with synthetically accessible $1-\mathbf{H}-\mathrm{P}^{t} \mathrm{Bu}_{3}, \quad \mathbf{1}-\mathrm{CH}_{3}-\mathrm{P}^{t} \mathrm{Bu}_{3}$, and 1- $\mathrm{CH}_{2} \mathrm{CH}_{3}-\mathrm{PPh}_{3}$, (b) the reaction of $1-\mathrm{CH}_{3}-\mathrm{P}^{t} \mathrm{Bu}_{3}$ with $1-\mathrm{H}$ $\mathbf{P}^{t} \mathrm{Bu}_{3}$, and finally (c) the reaction $\mathbf{1}-\mathrm{CH}_{3}$-dmso with $\mathbf{1}-\mathbf{H}-\mathbf{P}^{t} \mathbf{B u}_{3}$.

With respect to the reactions of $\mathrm{P}$-protonated phosphonium salt $H[P, O]$, we note that low-lying transition states were formed only after tautomerization into the O-protonated sulfonic acid form $[\mathrm{P}, \mathrm{O}] \mathrm{H}$, which is $12 \mathrm{~kJ} \mathrm{~mol}^{-1}$ less stable than the P-protonated $\mathrm{H}[\mathrm{P}, \mathrm{O}]$ form (Scheme 7). ${ }^{52}$ The reaction of 1-H$\mathrm{P}^{t} \mathrm{Bu}_{3}$ with $[\mathrm{P}, \mathrm{O}] \mathrm{H}$ is then initiated by substitution of the $\mathrm{P}^{t} \mathrm{Bu}_{3}$ ligand for the phosphine $[\mathrm{P}, \mathrm{O}] \mathrm{H}$ to form $\mathbf{I}-\mathbf{H}-[\mathbf{P}, \mathrm{O}] \mathbf{H}$, which is $20 \mathrm{~kJ} \mathrm{~mol}^{-1}$ higher in energy than 1-H. $\mathbf{P}^{t} \mathbf{B u}_{3}+\mathrm{O}$-protonated $[\mathrm{P}, \mathrm{O}] \mathrm{H}$. 1-H- $[\mathrm{P}, \mathrm{O}] \mathrm{H}$ directly evolves to the transition state 1H-TS2 lying $124 \mathrm{~kJ} \mathrm{~mol}^{-1}$ higher than $1-\mathrm{H}^{\prime} \mathrm{P}^{t} \mathrm{Bu}_{3}+\mathrm{O}$-protonated sulfonic acid (Scheme 10). Considering the tautomerization of

Scheme 10. Energetics $\left(\mathrm{kJ} \mathrm{mol}^{-1}\right)$ of the Reaction of $[\mathrm{P}, \mathrm{O}] \mathrm{H}$ with $1-\mathrm{H} \cdot \mathrm{P}^{t} \mathrm{Bu}_{3}$

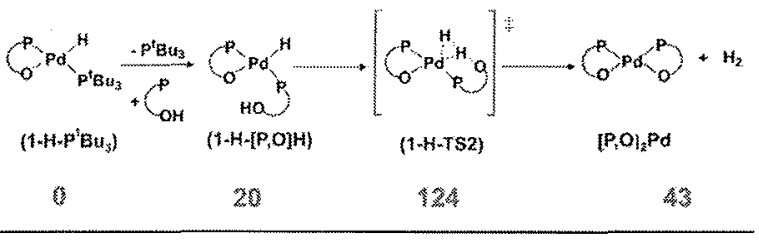

P-protonated $\mathrm{H}[\mathrm{P}, \mathrm{O}]$ into O-protonated $[\mathrm{P}, \mathrm{O}] \mathrm{H}$, which costs $12 \mathrm{~kJ} \mathrm{~mol}^{-1}$, the overall barrier amounts to $136 \mathrm{~kJ} \mathrm{~mol}^{-1}$ to reach 1-H-TS2. 1-H-TS2 then decomposes to form dihydrogen and $\left.\left.\left[\kappa^{2} \text {-(anisyl }\right)_{2} P, O\right)\right]_{2} \mathrm{Pd}(11)$, which lie $43 \mathrm{~kJ} \mathrm{~mol}^{-1}$ higher in energy than $\mathbf{1}-\mathrm{H}-\mathrm{P}^{t} \mathrm{Bu}_{3}+\mathrm{O}$-protonated $[\mathrm{P}, \mathrm{O}] \mathrm{H}$. The endoergicity of the overall reaction is in accordance with a late transition state in which the hydrogen-hydrogen distance is only $0.80 \AA$ (Figure 12 ), i.e., very close to the distance in free $\mathrm{H}_{2}(0.74 \AA)$ and certainly at the lower limit even of dihydrogen complexes $(0.8-1.0 \AA) .^{55}$

Comparison of the energy profile of the three reactions involved in the deactivation process (i.e., reductive elimination of

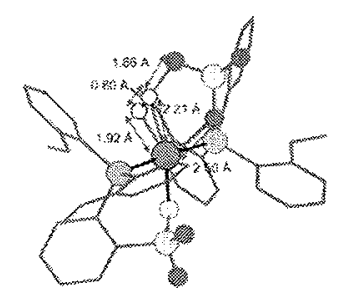

Figure 12. Transition-state geometry of 1-H-TS2 for the reaction leading to $[\mathrm{P}, \mathrm{O}]_{2} \mathrm{Pd}(11)+\mathrm{H}_{2}$.

$\mathrm{H}[\mathrm{P}, \mathrm{O}]$, tautomerization of $\mathrm{H}[\mathrm{P}, \mathrm{O}]$ into $[\mathrm{P}, \mathrm{O}] \mathrm{H}$, and reaction of $[\mathrm{P}, \mathrm{O}] \mathrm{H}$ with $\left.1-\mathrm{H}-\mathrm{P}^{t} \mathrm{Bu}_{3}\right)$ shows that the reactions $1-\mathbf{H}-\mathrm{P}^{t} \mathrm{Bu}_{3}$ $+\mathrm{P}^{t} \mathrm{Bu}_{3} \rightarrow\left[\mathrm{Pd}\left(\mathrm{P}^{t} \mathrm{Bu}_{3}\right)_{2}\right]+\mathrm{H}[\mathrm{P}, \mathrm{O}]$ and 1-H-Pt $\mathrm{Bu}_{3}+\mathrm{H}[\mathrm{P}, \mathrm{O}] \rightarrow$ $\mathbf{1}-\mathrm{H}-\mathrm{P}^{\prime} \mathrm{Bu}_{3}+[\mathrm{P}, \mathrm{O}] \mathrm{H} \rightarrow\left[\kappa^{2}\right.$-(anisyl) $\left.\left.{ }_{2} \mathrm{P}, \mathrm{O}\right)\right]_{2} \mathrm{Pd}(\mathbf{1 1})+\mathrm{H}_{2}$ have very similar energy barriers, i.e., 124 and $12+124=136 \mathrm{~kJ} \mathrm{~mol}^{-1}$ (Scheme 10). The energy balance of the overall decomposition reaction, shown in Scheme 11, is endoergic by ca. $60 \mathrm{~kJ} \mathrm{~mol}^{-1}$,

Scheme 11. Energetics $\left(\mathrm{kJ} \mathrm{mol}^{-1}\right)$ of the Overall

Decomposition Reaction of $1-\mathrm{H}-\mathrm{P}^{t} \mathrm{Bu}_{3}$

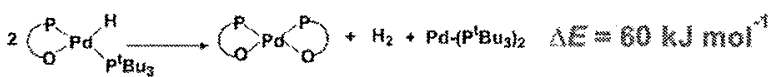

which is mostly caused by the formation of 11 and $\mathrm{H}_{2}$ from 1-HTS2. However, despite the endoergicity, release and irreversible removal of $\mathrm{H}_{2}$ from the reaction mixture is a plausible driving force for this reaction to proceed.

The reaction of O-protonated $[\mathrm{P}, \mathrm{O}] \mathrm{H}$ with $\mathbf{1}-\mathrm{CH}_{3}-\mathbf{P}^{t} \mathbf{B u} 3$ to form complex 11 and methane proceeds along a similar reaction coordinate to the reaction of $[\mathrm{P}, \mathrm{O}] \mathrm{H}$ with $\mathbf{1}-\mathrm{H}-\mathrm{P}^{t} \mathbf{B} \mathbf{u}_{3}$. However, substitution of $\mathrm{P}^{t} \mathrm{Bu}_{3}$ by $[\mathrm{P}, \mathrm{O}] \mathrm{H}$ leads to intermediate $1-\mathrm{CH}_{3}$ $[\mathrm{P}, \mathrm{O}] \mathrm{H}+\mathrm{P}^{\prime} \mathrm{Bu}_{3}$, which lie $2 \mathrm{~kJ} \mathrm{~mol}^{-1}$ higher than the educts and evolve to transition state $\mathbf{1}-\mathrm{CH}_{3}-\mathrm{TS} 2$ for the formation of methane and 11 , which lies $84 \mathrm{~kJ} \mathrm{~mol}^{-1}$ higher than the educts (as compared to $124 \mathrm{~kJ} \mathrm{~mol}^{-1}$ for the formation of $\mathrm{H}_{2}$ and 11) (Scheme 12, line (a)). The overall formation of methane and 11

Scheme 12. Energetics $\left(\mathrm{kJ} \mathrm{mol}^{-1}\right)$ of the Reaction of $[\mathrm{P}, \mathrm{O}] \mathrm{H}$ with $1-\mathrm{CH}_{3}-\mathrm{P}^{t} \mathrm{Bu}_{3}$ (line (a)) and with 1-CH $-\mathrm{CH}_{3}$ dmo (line (b))

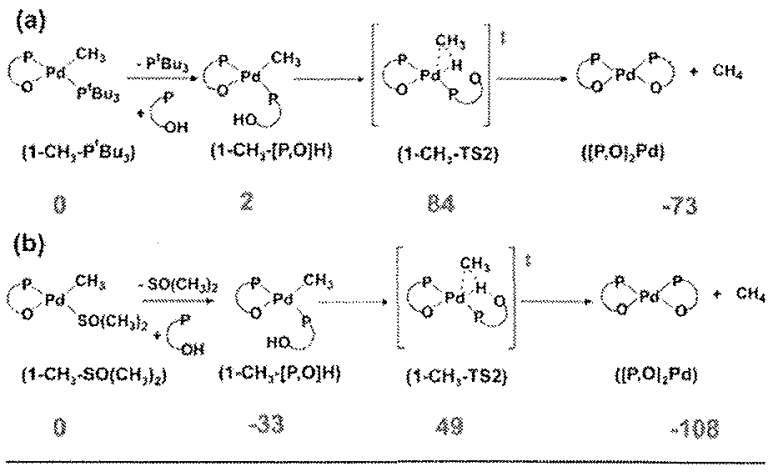

is exoergic (and therefore thermodynamically favorable) by $73 \mathrm{~kJ}$ $\mathrm{mol}^{-1}$ starting from O-protonated $[\mathrm{P}, \mathrm{O}] \mathrm{H}$ and $\mathbf{1}-\mathrm{CH}_{3}-\mathrm{P}^{t} \mathbf{B u}$. When $[\mathrm{P}, \mathrm{O}] \mathrm{H}$ is reacted with $\mathbf{1}-\mathrm{CH}_{3}$-dmso, substitution of dmso for $[\mathrm{P}, \mathrm{O}] \mathrm{H}$ to form the new ground state $1 \mathrm{CH}_{3}[\mathbf{P}, \mathrm{O}] \mathrm{H}+$ dmso is exoergic by $33 \mathrm{~kJ} \mathrm{~mol}^{-1}$ and evolves into the transition state $1-\mathrm{CH}_{3}-\mathrm{TS} 2$, which now lies $49 \mathrm{~kJ} \mathrm{~mol}^{-1}$ above $[\mathrm{P}, \mathrm{O}] \mathrm{H}+$ 1- $\mathrm{CH}_{3}$-dmso. ${ }^{56}$ The rate-limiting step to reach $1-\mathrm{CH}_{3}-\mathrm{TS} 2$, 
however, is $82 \mathrm{~kJ} \mathrm{~mol}^{-1}$ in energy for the transformation of 1- $\mathrm{CH}_{3}-[\mathrm{P}, \mathrm{O}] \mathrm{H}+\mathrm{dmso}$ into $1-\mathrm{CH}_{3}-\mathrm{TS} 2+$ dmso (Scheme 12, line (b)) and therefore very similar to the overall barrier of $84 \mathrm{~kJ} \mathrm{~mol}^{-1}$ calculated for the reaction of $[\mathrm{P}, \mathrm{O}] \mathrm{H}$ with $1-\mathrm{CH}_{3}$ $\mathbf{P B u}_{3}$ (compare lines (a) and (b) in Scheme 12).

The overall formation of methane and 11 is also exoergic by $56 \mathrm{~kJ} \mathrm{~mol}{ }^{-1}$ starting from $1-\mathrm{H}-\mathrm{P}^{t} \mathrm{Bu}_{3}$ and $1-\mathrm{CH}_{3}-\mathrm{P}^{t} \mathrm{Bu}_{3}$ and $23 \mathrm{~kJ} \mathrm{~mol}^{-1}$ starting from $1-\mathrm{H}-\mathrm{P}^{t} \mathrm{Bu}_{3}$ and $\mathbf{1}-\mathrm{CH}_{3}$-dmso by following a reaction sequence composed of reductive elimination of $\mathrm{H}[\mathrm{P}, \mathrm{O}]$ from $1-\mathrm{H}-\mathrm{P}^{t} \mathrm{Bu}_{3}$, tautomerization of $\mathrm{H}[\mathrm{P}, \mathrm{O}]$ into $[\mathrm{P}, \mathrm{O}] \mathrm{H}$, and reaction of $[\mathrm{P}, \mathrm{O}] \mathrm{H}$ with $\mathbf{1}-\mathrm{CH}_{3}-\mathrm{P}^{t} \mathrm{Bu}_{3}$ or $\mathbf{1}-\mathrm{CH}_{3}-$ dmso (Scheme 13).

Scheme 13. Energetics $\left(\mathrm{kJ} \mathrm{mol}^{-1}\right)$ for the Overall Formation of Methane and 11 from the Reaction of $1-\mathrm{CH}_{3}-\mathrm{P}^{t} \mathrm{Bu}_{3}$ with 1$\mathrm{H}-\mathrm{P}^{t} \mathrm{Bu}_{3}$ (line (a)) and from the Reaction of $1-\mathrm{CH}_{3}$-dmso with 1-H-Pt $\mathrm{Bu}_{3}$ (line (b))

(a)

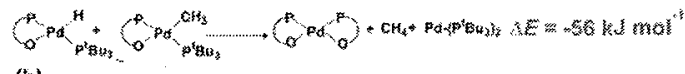

(b)

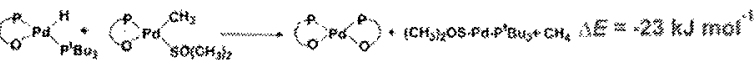

However, the rate-limiting step for the formation of methane and 11 starting from $\mathbf{1}-\mathrm{H}-\mathrm{P}^{t} \mathrm{Bu}_{3}$ and $\mathbf{1}-\mathrm{CH}_{3}-\mathrm{P}^{t} \mathrm{Bu}_{3}$ or $\mathbf{1}-\mathrm{CH}_{3}$ dmso is now reductive elimination of $\mathrm{H}[\mathrm{P}, \mathrm{O}]$ with a barrier of $124 \mathrm{~kJ} \mathrm{~mol}^{-1}$, as compared to the $84 \mathrm{~kJ} \mathrm{~mol}^{-1}$ barrier calculated for the reaction of $\mathrm{O}$-protonated $[\mathrm{P}, \mathrm{O}] \mathrm{H}$ with $\mathbf{1}-\mathrm{CH}_{3}-\mathrm{P}^{t} \mathrm{Bu}_{3}$ and compared to the $82 \mathrm{~kJ} \mathrm{~mol}^{-1}$ calculated barrier for the reaction of $[\mathrm{P}, \mathrm{O}] \mathrm{H}$ with $\mathbf{1}-\mathrm{CH}_{3}-\mathrm{dmso}$ (compare Schemes 7 and 12 ).

A rate-limiting reductive elimination of $\mathrm{H}[\mathrm{P}, \mathrm{O}]$ is in accordance with the experimental finding that upon addition of $\mathrm{H}[\mathrm{P}, \mathrm{O}]$ to $\mathbf{1}-\mathrm{CH}_{3}-\mathbf{P}^{t} \mathbf{B u}_{3}$ or $\mathbf{1}-\mathrm{CH}_{3}$-dmso, formation of methane and 11 takes place within $<5 \mathrm{~min}$ at $298 \mathrm{~K}$, while complete formation of methane and 11 takes $1.5 \mathrm{~h}$ at $373 \mathrm{~K}$ starting from $1-\mathrm{CH}_{3}-\mathrm{dmso}+1-\mathrm{H}(\mathrm{D})$ $\mathbf{P}^{t} \mathrm{Bu}_{3}$ in tetrachloroethane- $d_{2}$ (vide supra).

While formation of $\mathrm{H}_{2}$ and 11 from $1-\mathrm{H}-\mathrm{P}^{t} \mathrm{Bu}_{3}$ is thermodynamically disfavored by $60 \mathrm{~kJ} \mathrm{~mol}^{-1}$, but due to removal of $\mathrm{H}_{2}$ still observable in the experimental system, formation of methane and 11 from $1-\mathrm{H}-\mathrm{P}^{t} \mathrm{Bu}_{3}$ and $1-\mathrm{CH}_{3} \cdot \mathrm{P}^{t} \mathrm{Bu}_{3}$ is favored by $56 \mathrm{~kJ}$ $\mathrm{mol}^{-1}$. This huge calculated energy difference of $116 \mathrm{~kJ} \mathrm{~mol}^{-1}$ for the formation of $\mathrm{H}_{2}$ and methane seems odd at first glance. However, it is in accordance with calculated homolytic bond dissociation energies of the $\mathrm{Pd}-\mathrm{CH}_{3}$ bond and the $\mathrm{Pd}-\mathrm{H}$ bond in $\mathbf{1}-\mathrm{CH}_{3}-\mathbf{P}^{t} \mathbf{B u}_{3}$ and $\mathbf{1}-\mathbf{H}-\mathbf{P}^{t} \mathbf{B u}_{3}$, which indicates that the $\mathrm{Pd}-$ $\mathrm{CH}_{3}$ bond is $\mathrm{ca} .100 \mathrm{~kJ} \mathrm{~mol}^{-1}$ weaker than the $\mathrm{Pd}-\mathrm{H}$ bond (see SI) ${ }_{37}$ while the respective $\mathrm{H}_{3} \mathrm{C}-\mathrm{H}$ and $\mathrm{H}-\mathrm{H}$ bonds are reported to be ca. $440\left(\mathrm{H}_{3} \mathrm{C}-\mathrm{H}\right)$ and $436 \mathrm{~kJ} \mathrm{~mol}^{-1}\left(\mathrm{H}_{2}\right):^{56}$ Thus the calculated difference of $116 \mathrm{~kJ} \mathrm{~mol}^{-1}$ for the formation of a H-H bond as compared to a $\mathrm{H}_{3} \mathrm{C}-\mathrm{H}$ bond starting from $1-\mathrm{CH}_{3}-\mathrm{P}^{t} \mathrm{Bu}_{3}$ and $\mathbf{1 - H}-\mathrm{P}^{t} \mathrm{Bu}_{3}$ originates mainly from the differences in bond dissociation energies of the respective $\mathrm{Pd}-\mathrm{H}$ and $\mathrm{Pd}-\mathrm{CH}_{3}$ bonds.

We move now to the decomposition of $\mathbf{1}-\mathrm{CH}_{2} \mathrm{CH}_{3}-\mathbf{P}^{t} \mathbf{B u}$ promoted by reaction with the protonated ligand $[\mathrm{P}, \mathrm{O}] \mathrm{H}$; see Scheme 14. Overall, the energy profile is rather similar to that of the corresponding methyl complex 1- $\mathrm{CH}_{3}-\mathrm{P}^{\prime} \mathrm{Bu}_{3}$ (Scheme 12); the main difference is in the energy barrier for ethane elimination, which is roughly $25 \mathrm{~kJ} \mathrm{~mol}^{-1}$ higher than the barrier for methane elimination.

A rather similar energy profile is also calculated when the experimentally employed ethyl complex with a $\mathrm{PPh}_{3}$ ligand in
Scheme 14. Energetics $\left(\mathrm{kJ} \mathrm{mol}^{-1}\right)$ of the Decomposition Reaction of $1-\mathrm{CH}_{2} \mathrm{CH}_{3}-\mathrm{P}^{t} \mathrm{Bu}_{3}$ with 1-H-P ${ }^{t} \mathrm{Bu}_{3}$

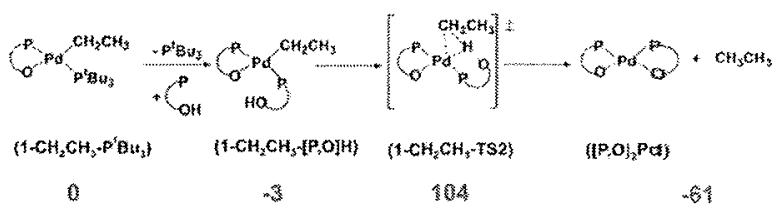

place of $\mathrm{P}^{t} \mathrm{Bu}_{3}$ is considered. The main difference is in the energy of $\mathrm{PPh}_{3}$ substitution by $[\mathrm{P}, \mathrm{O}] \mathrm{H}$, which is disfavored by $18 \mathrm{~kJ} \mathrm{~mol}^{-1}$; see Scheme 15 . This is related to the lower steric

Scheme 15. Energetics $\left(\mathrm{kJ} \mathrm{mol}^{-1}\right)$ of the Reaction of $[\mathrm{P}, \mathrm{O}] \mathrm{H}$ with $1-\mathrm{CH}_{2} \mathrm{CH}_{3}-\mathrm{PPh}_{3}$

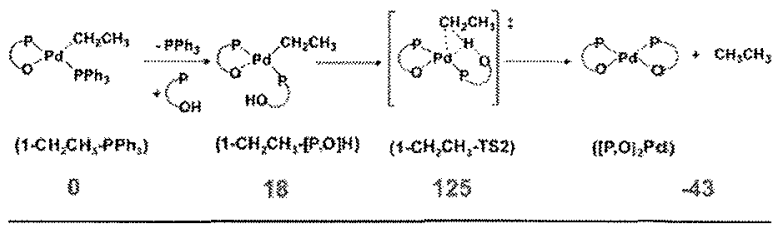

bulkiness of $\mathrm{PPh}_{3}$ compared to $\mathrm{P}^{t} \mathrm{Bu}_{3}$. The stronger binding of $\mathrm{PPh}_{3}$ compared to $\mathrm{P}^{t} \mathrm{Bu}_{3}$ translates into a decomposition pathway shifted about $20 \mathrm{~kJ} \mathrm{~mol}^{-1}$ higher in energy; compare Schemes 14 and $15 .^{57}$ The reasonable energy barrier we found for the decomposition of $1-\mathrm{CH}_{2} \mathbf{C H}_{3}-\mathbf{P P h}_{3}$ promoted by the protonated ligand $[\mathrm{P}, \mathrm{O}] \mathrm{H}$ is in agreement with the experimental evidence: (a) $1-\mathrm{CH}_{2} \mathrm{CH}_{3}-\mathbf{P P h}_{3}$ decomposes with formation of ethane and trace amounts of hydrogen at $343 \mathrm{~K}$, (b) the reaction of $\mathrm{H}[\mathrm{P}, \mathrm{O}]$ with $\mathbf{1}-\mathrm{CH}_{2} \mathrm{CH}_{3}-\mathrm{PPh}_{3}$ is slower than the reaction with $1-\mathrm{CH}_{3}-\mathrm{P}^{t} \mathbf{B u}_{3}$, and (c) the reaction of $\mathrm{H}[\mathrm{P}, \mathrm{O}]$ with $1-\left(\mathrm{CH}_{2}\right)_{2 n}{ }^{13} \mathrm{CH}_{3}$-dmso at $298 \mathrm{~K}$ is slower than with $1{ }^{13} \mathrm{CH}_{3-}$ dmso (vide supra).

In conclusion, the experimentally observed reactivity differences are largely not due to the different binding strengths of the monodentate phosphine or dmso. While the substitution of monodentate phosphines for $[\mathrm{P}, \mathrm{O}] \mathrm{H}$ in 1-alkyl-PR $\mathrm{PR}_{3}$ is essentially thermoneutral or slightly endoergic, replacement of dmso in 1- $\mathrm{CH}_{3}$-dmso by $[\mathrm{P}, \mathrm{O}] \mathrm{H}$ is exoergic (Schemes 12,14 , and 15). However, all these substitution reactions lead to $1-\mathrm{CH}_{3}$ / $\mathrm{CH}_{2} \mathrm{CH}_{3}-[\mathrm{P}, \mathrm{O}] \mathrm{H}$, which eliminates methane with a barrier of $82 \mathrm{~kJ} \mathrm{~mol}^{-1}$ or ethane with a barrier of $107 \mathrm{~kJ} \mathrm{~mol}^{-1}$. Thus, the experimentally observed finding, that $1{ }^{13} \mathrm{CH}_{3}$-dmso reacts faster with $[\mathrm{P}, \mathrm{O}] \mathrm{H}$ to form methane than with $1-\left(\mathrm{CH}_{2}\right)_{2 n}{ }^{13} \mathrm{CH}_{3}$-dmso to form alkanes (vide supra) is mainly due to the difference in the respective barriers for methane vs ethane elimination. However, as shown for the model compound $\mathrm{I}-\mathrm{H}-\mathrm{P}^{\mathrm{t}} \mathrm{Bu}_{3}$, reductive elimination of $\mathrm{H}[\mathrm{P}, \mathrm{O}]$ with a barrier of $124 \mathrm{~kJ} \mathrm{~mol}^{-1}$ seems rate limiting for the formation of alkanes whenever $\mathrm{H}[\mathrm{P}, \mathrm{O}]$ is not deliberately added to catalytically active species.

Finally we have investigated two reaction schemes in which 1-H-P $\mathbf{P}^{t} \mathbf{B u}_{3}$ directly reacts with $1-\mathrm{CH}_{3}-\mathrm{P}^{t} \mathrm{Bu}_{3}$ or with $1-\mathrm{CH}_{3}$ dmso (i.e., without prior reductive elimination of $\mathrm{H}[\mathrm{P}, \mathrm{O}]$ ). The first reaction coordinate we investigated comprises the reaction of $\mathbf{1 - H}$ and $1-\mathrm{CH}_{3}$ formed after $\mathrm{P}^{l} \mathrm{Bu}_{3}$ dissociation from $\mathbf{1 - H}$ $\mathbf{P}^{t} \mathrm{Bu}_{3}$ and $\mathbf{1}-\mathrm{CH}_{3}-\mathbf{P}^{t} \mathbf{B u}_{3}$. The formed intermediate $\mathbf{1}-\mathrm{H}-\mathbf{1}-\mathrm{CH}_{3}$ exhibits a bridging hydride and methyl group with short $\mathrm{Pd}(1)-\mathrm{H}(1.877 \AA), \mathrm{Pd}(2)-\mathrm{H}(1.646 \AA), \mathrm{Pd}(\mathrm{l})-\mathrm{CH}_{3}$ $(2.044 \AA)$, and $\mathrm{Pd}(2)-\mathrm{CH}_{3}(2.538 \AA)$ distances, which evolves into transition state $\mathbf{1}-\mathrm{H}-\mathbf{1}-\mathrm{CH}_{3}$ - TS1, in which the two palladium atoms, the hydrogen atom, and the carbon atom adopt a 
distorted four-membered ring. However, 1-H-1-CH $\mathrm{CH}_{3}+2 \mathrm{P}^{t} \mathrm{Bu}_{3}$ and $1-\mathrm{H}-1-\mathrm{CH}_{3}-\mathrm{TS1}+2 \mathrm{P}^{t} \mathrm{Bu}_{3}$ are 225 and $278 \mathrm{~kJ} \mathrm{~mol}^{-1}$ higher in energy than $1-\mathrm{H}-\mathrm{P}^{t} \mathrm{Bu}_{3}+1-\mathrm{CH}_{3}-\mathrm{P}^{t} \mathrm{Bu}_{3}$ and thus prohibitively high for the reaction to proceed (Scheme 16). The reason for

Scheme 16. Energetics $\left(\mathrm{kJ} \mathrm{mol}^{-1}\right)$ of the Decomposition Reaction of $1-\mathrm{CH}_{3}-\mathrm{P}^{t} \mathrm{Bu}_{3}$ with 1-H-P ${ }^{t} \mathrm{Bu}_{3}$ Initiated by $\mathrm{P}^{t} \mathrm{Bu}_{3}$ Dissociation from $1-\mathrm{CH}_{3}-\mathrm{P}^{t} \mathrm{Bu}_{3}$ and $1-\mathrm{H}-\mathrm{P}^{t} \mathrm{Bu}_{3}$

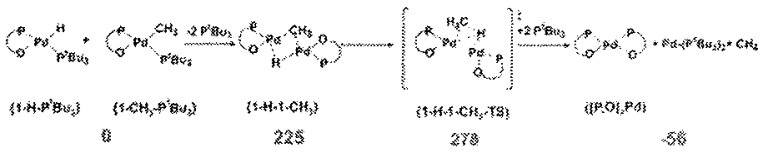

these high energies of $\mathbf{1}-\mathrm{H}-\mathbf{1}-\mathrm{CH}_{3}+2 \mathrm{P}^{t} \mathrm{Bu}_{3}$ and $\mathbf{1}-\mathrm{H}-\mathbf{1}-\mathrm{CH}_{3}-\mathrm{TS}+$ $2 \mathrm{PBu}_{3}$ is likely a huge energetic penalty for the dissociation of $\mathrm{P}^{i} \mathrm{Bu}_{3}$ in both educt complexes, which cannot be compensated for by the bridging interaction of hydride and the methyl group in 1-H-1- $\mathrm{CH}_{3}$.

In order to avoid such high energetic penalties due to ligand dissociations, we have investigated a second reaction coordinate, which comprises the reactions of two four-coordinate palladium complexes, namely, $\mathbf{1}-\mathbf{H}-\mathbf{P}^{t} \mathbf{B u}_{3}+\mathbf{1}-\mathrm{CH}_{3}-\mathbf{P}^{t} \mathbf{B u}_{3}$ and $\mathbf{1}-\mathbf{H}-\mathbf{P}^{t} \mathbf{B u}_{3}+$ 1- $\mathrm{CH}_{3}$-dmso, i.e., without dissociation of $\mathrm{P}^{t} \mathrm{Bu}_{3}$ or dmso.

Intriguingly, transition state $\mathbf{1}-\mathbf{H}-\mathbf{P}^{t} \mathbf{B u}_{3}-\mathbf{I}-\mathbf{C H}_{3}-\mathbf{p}^{t} \mathbf{B u}_{3}$ - TS was located lying only $131 \mathrm{~kJ} \mathrm{~mol}^{-1}$ higher than $\mathbf{1}-\mathbf{H} \cdot \mathbf{P}^{t} \mathrm{Bu}_{3}+1-\mathrm{CH}_{3}-$ $\mathbf{P}^{t} \mathrm{Bu}_{3}$ (Scheme 17, line (a)). An even lower transition state,

Scheme 17. Energetics $\left(\mathrm{kJ} \mathrm{mol}^{-1}\right)$ of the reaction of 1-H-P $\mathrm{P}^{t} \mathrm{Bu}$ with 1- $\mathrm{CH}_{3}-\mathrm{P}^{t} \mathrm{Bu}_{3}$ Leading to $1-\mathrm{H}-\mathrm{P}^{t} \mathrm{Bu}_{3}-1-\mathrm{CH}_{3}-\mathrm{P}^{t} \mathrm{Bu}_{3}$-TS (line (a)) and of 1-H-P ${ }^{t} \mathrm{Bu}_{3}$ with $1-\mathrm{CH}_{3}$-dmso Leading to 1-H-P $\mathrm{P}^{t} \mathrm{Bu}_{3}-1-\mathrm{CH}_{3}$-dmso-TS (line (b))

(a)

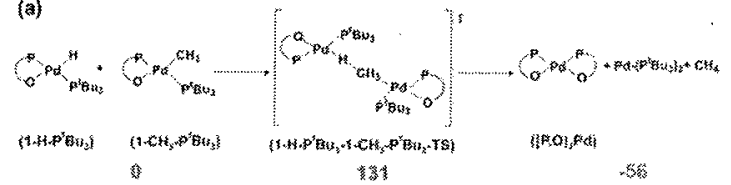

(b)

1-H-P ${ }^{t} \mathrm{Bu}_{3}-1-\mathrm{CH}_{3}$-dmso-TS, was located for the reaction of 1-H-Pt $\mathbf{B u}_{3}+1-\mathrm{CH}_{3}$-dmso with a barrier of $95 \mathrm{~kJ} \mathrm{~mol} \mathbf{m}^{-1}$ (Scheme 17, line (b)). Characteristic geometric features of these two transition state evolving into the elimination of methane comprise a nearly linear alignment of the reacting $\mathrm{H}-\mathrm{CH}_{3}-\mathrm{Pd} 2$ moieties of ca. $165^{\circ}$ and a substantial planarization of the central $\mathrm{CH}_{3}$ group (Figure 13), which are highly reminiscent of bimolecular substitution reactions. While it has been suggested in theoretical studies that evolution of hydrogen from homoleptic manganese hydride complexes may proceed through a similar, fully linear $\mathrm{Mn}-\mathrm{H}-\mathrm{H}-\mathrm{Mn}$ transition-state geometry, ${ }^{60}$ to our knowledge a linear hydride-alkyl-metal transition state for the reductive elimination of alkane has not been proposed or investigated for transition metal complexes. However, the reduction of haloalkanes by complex hydrides, e.g., $\mathrm{LiBEt}_{3} \mathrm{H}$ or $\mathrm{LiAlH}_{4}$, was found to exhibit typical characteristics of an $\mathrm{S}_{\mathrm{N}} 2$ reaction. ${ }^{61}$ We note, however, that the barriers
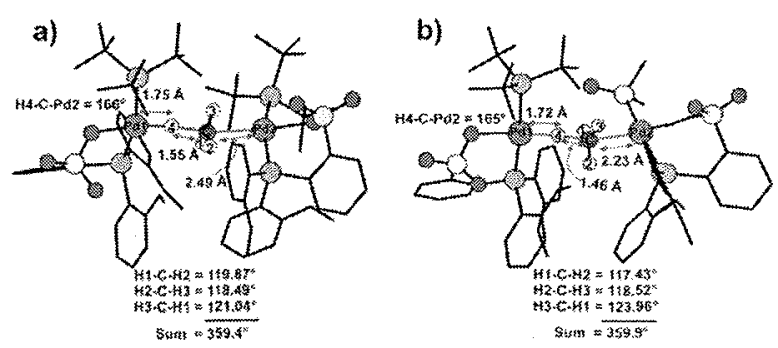

Figure 13. Geometry of 1-H- $\left(\mathrm{P}^{t} \mathrm{Bu}_{3}\right)-1-\mathrm{CH}_{3}-\mathrm{P}^{t} \mathrm{Bu}_{3}$-TS (left) and 1-H$\left(\mathrm{P}^{\prime} \mathrm{Bu}_{3}\right)-1-\mathrm{CH}_{3}$-dmso-TS (right) for the methane elimination starting from $\mathbf{1}-\mathrm{H}-\mathrm{P}^{t} \mathrm{Bu}_{3}$ and $\mathbf{1}-\mathrm{CH}_{3}-\mathrm{P}^{t} \mathrm{Bu}_{3}$ or $\mathbf{1}-\mathrm{CH}_{3}$-dmso.

associated with 1-H-P ${ }^{t} \mathrm{Bu}_{3}-\mathbf{1}-\mathrm{CH}_{3}-\mathbf{P}^{t} \mathbf{B u}_{3}-\mathrm{TS}$ and 1-H-P $\mathbf{B u}_{3}-\mathbf{1 -}$ $\mathrm{CH}_{3}$-dmso-TS (Scheme 17 and Figure 13) are prone to systematic errors caused by the self-interaction error of $\mathrm{DFT},{ }^{60}$ which results in a potentially overestimated stability of these transition states due to artificially stabilized delocalized states. Consequently, the real barriers might be higher than determined here.

The calculated reaction coordinate for the overall reaction of $1-\mathrm{H}-\mathrm{P}^{t} \mathrm{Bu}_{3}$ and $1-\mathrm{CH}_{3}-\mathrm{P}^{t} \mathrm{Bu}_{3}$ with a barrier of $131 \mathrm{~kJ} \mathrm{~mol}^{-1}$ according to Scheme $17 \mathrm{a}$ indicates that it may contribute to the formation of methane since it is very similar to the rate-limiting barrier $\left(124 \mathrm{~kJ} \mathrm{~mol}^{-1}\right)$ of reductive elimination of $\mathrm{H}[\mathrm{P}, \mathrm{O}]$ in the reaction sequence composed of reductive elimination of $\mathrm{H}[\mathrm{P}, \mathrm{O}]$ from 1-H-P ${ }^{t} \mathrm{Bu}_{3}$, tautomerization of $\mathrm{H}[\mathrm{P}, \mathrm{O}]$ into $[\mathrm{P}, \mathrm{O}] \mathrm{H}$, and reaction of $[\mathrm{P}, \mathrm{O}] \mathrm{H}$ with $1-\mathrm{CH}_{3}-\mathrm{P}^{t} \mathrm{Bu}_{3}$ according to Schemes 7 and $12 \mathrm{a}$. For the formation of methane from $1-\mathrm{H}-\mathrm{P}^{t} \mathrm{Bu}_{3}$ and 1- $\mathrm{CH}_{3}$-dmso a $\mathrm{S}_{\mathrm{N}}$ 2-like reaction with an activation barrier of $95 \mathrm{~kJ} \mathrm{~mol}^{-1}$ according to Scheme $17 \mathrm{~b}$ is favored over reductive elimination of $\mathrm{H}[\mathrm{P}, \mathrm{O}]$ from $\mathrm{I}-\mathrm{H}-\mathrm{P}^{\mathrm{t}} \mathrm{Bu}_{3}$, tautomerization of $\mathrm{H}[\mathrm{P}, \mathrm{O}]$ into $[\mathrm{P}, \mathrm{O}] \mathrm{H}$, and reaction of $[\mathrm{P}, \mathrm{O}] \mathrm{H}$ with $1-\mathrm{CH}_{3}$-dmso with a rate-limiting barrier of $124 \mathrm{~kJ} \mathrm{~mol}^{-1}$ (Scheme 7 and $12 \mathrm{~b}$ ).

In summary, two viable reaction coordinates for the irreversible deactivation of polymerization-active 1-(alkyl)-L/1-H-L and formation of saturated hydrocarbons have been disclosed: (a) A reaction sequence comprising reductive elimination of the P-protonated $\mathrm{H}[\mathrm{P}, \mathrm{O}]$ from $1-\mathrm{H}-\mathrm{P}^{t} \mathrm{Bu}_{3}$, followed by tautomerization of $\mathrm{H}[\mathrm{P}, \mathrm{O}]$ into O-protonated $[\mathrm{P}, \mathrm{O}] \mathrm{H}$ (Scheme 7), substitution of $\mathrm{P}^{t} \mathrm{Bu}_{3}$ in 1 -(alkyl)- $\mathrm{P}^{t} \mathrm{Bu} \mathbf{u}_{3}$ by $[\mathrm{P}, \mathrm{O}] \mathrm{H}$, and finally formation of alkane and $[\mathrm{P}, \mathrm{O}]_{2} \mathrm{Pd}(11)$ (Schemes 12, 14, and 15). The rate-limiting step in this sequence is reductive elimination of $\mathrm{H}[\mathrm{P}, \mathrm{O}]$ with a barrier of $124 \mathrm{~kJ} \mathrm{~mol}^{-1}$. (b) A bimolecular reaction of fully intact $1-\mathrm{H} \cdot \mathrm{P}^{t} \mathrm{Bu}_{3}$ with $1-\mathrm{CH}_{3}-\mathrm{L}$ according to Scheme 17 in which the transition-state geometries resemble a bimolecular substitution at a $\mathrm{sp}^{3}$-carbon atom. The energy barrier found for the reaction of $\mathbf{1}-\mathbf{H}-\mathbf{P}^{t} \mathrm{Bu}_{3}$ with $\mathbf{1}-\mathrm{CH}_{3}-\mathbf{P}^{t} \mathbf{B u}_{3}$ along this reaction coordinate is $131 \mathrm{~kJ} \mathrm{~mol}^{-1}$, whereas it is $95 \mathrm{~kJ} \mathrm{~mol}^{-1}$ for the reaction of $\mathbf{1}-\mathbf{H}-\mathbf{P}^{t} \mathrm{Bu}_{3}$ with $\mathbf{1}-\mathrm{CH}_{3}-\mathrm{dmso}$.

On the basis of these results, both reaction channels starting with reductive elimination of $\mathrm{H}[\mathrm{P}, \mathrm{O}]$ and starting with direct evolution into a bimetallic $S_{N}$ 2-like substitution can contribute to the overall deactivation of $\mathbf{1 - H}-\mathbf{P}^{t} \mathbf{B u}_{3}$ and 1 -(alkyl)- $\mathbf{P}^{t} \mathbf{B} \mathbf{u}_{3}$. However, when modeling the reaction of $1-\mathrm{H}-\mathrm{P}^{t} \mathrm{Bu}_{3}$ with 1 $\mathrm{CH}_{3}$-dmso, which is closer to the real catalytic system 1-H-L and 1-(alkyl)-L ( $\mathrm{L}=$ olefin, dmso), the bimetallic substitution pathway appears favorable.

\section{CONCLUSIONS}

These studies involving (a) direct monitoring of the polymerization reaction by NMR spectroscopy with isotope-labeled catalyst precursors, (b) analysis of end groups and distribution of 
catalyst precursor-derived labeled carbon atoms in polymers obtained under preparative polymerization conditions, (c) direct isolation and full identification of catalyst decomposition products from typical polymerization mixtures, (d) clean preparation, isolation, and full characterization of relevant intermediates of the polymerization reaction, namely, different palladium alkys as well as a palladium hydride, and (e) theoretical and experimental elucidation of the reactivity of these intermediates reveal the following reaction and decomposition pathways:

(1) Under typical polymerization conditions, extensive formation of mixed tetraaryl/alkyl phosphonium salts occurs by their reductive elimination from the polymerization-active Pd(II) alkyl species. That is, the growing polymeryl chain is transferred to the $\mathrm{P}$ atom of the phosphinesulfonato ligand. The reaction is in principle reversible as long as palladium black does not precipitate. It can afford $\mathrm{Pd}(\mathrm{II})$ aryl complexes with a P-alkyl phosphinesulfonato ligand by net scrambling of the growing polymeryl chain and the aryl moieties introduced with the catalyst precursor between the metal center and the phosphorus atom of the ligand. Such a species inserts ethylene, suggesting that it is polymerization-active. In fact, di(alkyl)phosphinesulfonate and (aryl)(alkyl)phosphinesulfonato $\mathrm{Pd}(\mathrm{II})$ complexes are precursors to active catalysts. ${ }^{61}$ This implies that in polymerizations with this class of catalysts for a given catalyst precursor actually a range of active species with different chelating $P, O$ ligands including P-polymeryl- and P-dipolymeryl-substituted ligands may be involved. The overall productivity and selectivity will be the sum of all their contributions. Thus, the catalytic properties observed for a given phosphinesulfonato catalyst precursor may actually reflect its propensity for the aforementioned net scrambling reactions.

(2) Also the $\mathrm{Pd}(\mathrm{II})$ hydride, which is an ubiquitious intermediate in polymerization resulting from $\beta$-hydride elimination as the key chain transfer step, undergoes reductive elimination to form the free neutral (zwitterionic, P-protonated) phosphoniumsulfonate $\mathrm{H}[\mathrm{P}, \mathrm{O}]$ and palladium $(0)$. This reaction again is reversible. However, once formed, the prevailing reaction of $\mathrm{H}[\mathrm{P}, \mathrm{O}]$ is a rapid irreversible reaction with the active growing polymeryl species to yield an alkane and the bis-chelated $\left[\kappa^{2}-(\mathrm{P}, \mathrm{O})\right]_{2} \mathrm{Pd}$. This stable compound is the final product of decomposition. Also, hydrogen can be formed from two equivalents of hydride, $2\left[\kappa^{2}-(P, O)\right] \mathrm{Pd}(\mathrm{H}) \rightarrow \mathrm{H}_{2}+\left[\kappa^{2}-(\mathrm{P}, \mathrm{O})\right]_{2} \mathrm{Pd}+$ $\mathrm{Pd}(0)$. This reaction again occurs most likely via reaction of the $\mathrm{Pd}$ hydride with free ligand, $\mathrm{H}[\mathrm{P}, \mathrm{O}]$, formed by reductive elimination from another equivalent of $\mathrm{Pd}$ hydride. A second irreversible catalyst deactivation pathway yielding alkanes, $\left[\kappa^{2}-(P, O)\right]_{2} \mathrm{Pd}$, and palladium $(0)$ was identified comprising the direct reaction of $\mathrm{Pd}(\mathrm{II})$ hydride with growing polymeryl species without reductive elimination of $\mathrm{H}[\mathrm{P}, \mathrm{O}]$.

These irreversible decomposition pathways originating from Pd hydrides will be particularly pronounced in (co)polymerization reactions of polar vinyl monomers. The metal carbyl insertion products of vinyl monomers, such as methyl acrylate, are more prone to chain transfer by $\beta$-hydride elimination than unsubstituted metal alkyls from ethylene incorporation. This is reflected in an overproportional number of unsaturated end groups based on the polar monomer in ethylene copolymers.

These reactions not only limit catalyst lifetime but also result in the formation of relevant amounts of fully saturated polymer chains. This can falsify molecular weight analysis substantially in NMR determination of $M_{n}$ under the common assumption that each chain will carry an unsaturated end group (from $\beta-\mathrm{H}$ elimination) whenever chain transfer numbers are small.
(3) Concerning the efficiency of activation of the catalyst precursor for polymerization, a weakly coordinated $(\mathrm{L}=\mathrm{dmso})$ complex $[(\mathrm{P}, \mathrm{O}) \mathrm{PdMe}(\mathrm{L})]$ is activated rapidly and completely even at room temperature and low ethylene concentrations. Under these mild conditions, polymerization is living, which allows for clean observation of the activation reaction. For less labile coordinated catalyst precursors, activation typically will also be complete, but at the elevated temperatures required not only will the aforementioned irreversible deactivation reactions complicate studies of activation and chain growth but also scrambling of the isotope label from the $\mathrm{Pd}^{13} \mathrm{CH}_{3}$ initiator into the polymer backbone by propene elimination and reinsertion can simulate a seemingly incomplete inactivation.

These findings suggest strategies for improving catalyst stability. As key reactions are bimolecular, low catalyst concentrations reduce deactivation rates, as illustrated in this study. Site isolation, by appropriate bulky and repulsive ligand environments, multidentate ligands, or ultimately binding to soluble or solid supports, is the further elucidation of this concept. While the aforementioned reductive eliminations to phosphonium sulfonates and $\mathrm{Pd}(0)$ are reversible, an agglomeration to palladium black will render this step irreversible. Colloidal stabilization toward further aggregation of $[\operatorname{Pd}(0)]_{n}$ at the stage of nanoparticles or addition of further tetraalkyl/aryl phosphonium sulfonates $\mathrm{R}[\mathrm{P}, \mathrm{O}]$ to the reaction mixture may be advantageous.

\section{ASSOCIATED CONTENT}

\section{Supporting Information}

Preparative procedures for the synthesis of complexes $1-{ }^{13} \mathrm{CH}_{3}-\mathrm{L}$, 1-H(D) $-\mathrm{P}^{t} \mathrm{Bu}_{3}$, and 1-Et-PPh , experimental procedures for preparative and NMR-tube polymerizations of ethylene, algorithms for the quantification of ${ }^{13} \mathrm{C}$-label incorporation and for the quantification of unsaturated and saturated oligomers, $X$-ray diffraction data of complexes $10,11,12$ cocrystallized with 13, and 1-H-P ${ }^{t} \mathrm{Bu}_{3}$ (CCDD nos. 897155-897158), NMR spectra of key experiments, ESI-MS data, and DFT data. This material is available free of charge via the Internet at http://pubs.acs.org.

\section{AUTHOR INFORMATION}

\section{Corresponding Author}

*E-mail: stefan.mecking@uni-konstanz.de; lcaporaso@unisa.it. Notes

The authors declare no competing financial interest.

\section{ACKNOWLEDGMENTS}

Financial support by the DFG (Me1388/10-1) is gratefully acknowledged. P.R. thanks the Carl Zeiss Foundation for a research stipend. The authors thank the HPC team of ENEA (www.enea.it) for using the ENEA-GRID and the HPC facilities CRESCO (www.cresco.enea.it) in Portici, Italy.

\section{REFERENCES}

(1) (a) Domski, G. J.; Rose, J. M.; Coates, G. M.; Bolig, A. D. Brookhart, M. Prog. Polym. Sci. 2007, 32, 30-92. (b) Berkefeld, A. Mecking, S. Angew. Chem., Int. Ed. 2008, 47, 2538-2542. (c) Nakamura, A.; Ito, S.; Nozaki, K Chem. Rev. 2009, 109, 5215-5244. (d) Chen, E. Y.X. Chem. Rev. 2009, 109, 5157-5214.

(2) (a) Johnson, L. K.; Mecking, S.; Brookhart, M. J. Am. Chem. Soc 1996, 118, 267-268. (b) Mecking, S.; Johnson, L. K.; Wang, L.; Brookhart, M. J. Am. Chem. Soc. 1998, 120, 888-899.

(3) Drent, E; van Dijk, R; van Ginkel, R; van Oort, B.; Pugh, R. I. Chem. Commun. 2002, 744-745. 
(4) (a) Kochi, T.; Noda, S.; Yoshimura, K; Nozaki, K. J.Am. Chem. Soc 2007, 129, 8948-8949. (b) Nozaki, K.; Kusumoto, S.; Noda, S.; Kochi, T.; Chung, L. W.; Morokuma, K J. Am. Chem. Soc. 2010, 132, 1603016042.

(5) Ito, S.; Munakata, K.; Nakamura, A.; Nozaki, K. J. Am. Chem. Soc. 2009, 131, 14606-14607.

(6) (a) Weng, W.; Shen, Z.; Jordan, R. F. J. Am. Chem. Soc. 2007, 129 , 15450-15451. (b) Shen, Z.; Jordan, R. F. Macromolecules 2010, 43, $8706-8708$

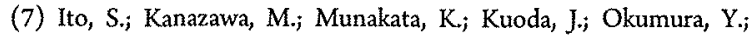
Nozaki, K. J. Am. Chem. Soc. 2011, 133, 1232-1235.

(8) (a) Riinzi, T.; Fröhlich, D.; Mecking, S. J. Am. Chem. Soc. 2010, 132, 17690-17691. (b) Daigle, J.C.; Piche, L; Claverie, J. P. J. P. Macromolecules 2011, 44, 1760-1762.

(9) (a) Skupov, K. M.; Piche, L.; Claverie, J. P. Macromolecules 2008 , 41, 2390-2310. (b) Friedberger, T.; Wucher, P.; Mecking, S. J. Am. Chem. Soc. 2012, 134, 1010-1018.

(10) Guironnet, D.; Roesle, P.; Rünzi, T.; Göttker-Schnetmann, L.; Mecking, S. J. Am. Chem. Soc. 2009, 131, 422-423.

(11) A broad scope of polar monomers can be incorporated in ethylene copolymers with cationic phosphine-phosphineoxide Pd(II) complexes: Carrow, B. P.; Nozaki, K. J. Am. Chem. Soc. 2012, 134, 8802-8805.

(12) Ethylene homopolymerization: (a) Noda, S.j Nakamura, A.j Kochi, T.; Wa Chung, L.; Morokuma, K.; Nozaki, K. J. Am. Chem. Soc. 2009, 131, 14088-14100. Acrylate copolymerizations and homooligomerization: (b) Guironnet, D.; Caporaso, L.; Neuwald, B.; Göttker-Schnetmann, I.; Cavallo, L; Mecking, S. J. Am. Chem. Soc. 2010, $132,4418-4426$.

(13) The ratio, e.g., of $\left[1^{13} \mathrm{CH}_{3}\right.$-dmso]:[ethylene], in these experiments is ca, 4-12 times higher than in comparable ethylene polymerizations catalyzed by $1-{ }^{12} \mathrm{CH}_{3}$-dmso at an identical ethylene pressure of 5 bar; cf. ref 10.

(14) On exemplified polyethylene samples we have determined $T_{1}$. relaxation times in the range of $1-1.5 \mathrm{~s}$ for all aliphatic carbon atoms. Based on these $T_{1}$-values, quantitative ${ }^{13} \mathrm{C}$ NMR analyses were conducted with a relaxation delay of $7 \mathrm{~s}$ using inverse gated decoupling techniques.

(15) We note that at lower [precatalyst], e.g., $\left[10^{13} \mathrm{CH}_{3}-\mathrm{L}\right]=20-50$ $\mu / \mathrm{mol} \mathrm{L}^{-1}$, under saturation kinetic behavior $(>10$ bar ethylene for 1 $\mathrm{CH}_{3}$-dmso and $>15$ bar for $1-\mathrm{CH}_{3}$-pyr), negligible catalyst deactivation is observed over 30 and $60 \mathrm{~min}$ polymerization experiments by mass flow monitoring, resulting in nearly polymerization time-independent turnover numbers; cf. ref 10 .

(16) Note that the respective ${ }^{13} \mathrm{C}$ NMR experiments do not allow for an accurate quantification, since the relaxation delay was set to $1 \mathrm{~s}$, and magnetization transfer from ${ }^{\mathrm{I}} \mathrm{H}$ was not suppressed during the relaxation delay.

(17) ${ }^{13} \mathrm{C},{ }^{13} \mathrm{C}$-J-resolved NMR experiments and INADEQUATE experiments did not support the existence of measurable quantities of ${ }^{13} \mathrm{C}-{ }^{13} \mathrm{C}$ connections for these signals under discussion, while a ${ }^{13} \mathrm{C}-{ }^{13} \mathrm{C}$ connection was established for the $\mathrm{S} 1-\mathrm{S} 2$ end group couple of formed oligomers.

(18) $\beta$-Hydride elimination after such 1,2-insertion of 1 -olefins would yield vinylidene end groups, which were indeed observed to form by ${ }^{1} \mathrm{H}$ NMR experiments in the late stage of the oligomerization, i.e., when most of the added ethylene was consumed.

(19) (a) Kanazawa, M.j Ito, S.j Nozaki, K. Organometallics 2011, 30, 6049-6052. (b) Vela, J.; Lief, G. R; Shen, Z.j Jordan, R F. Organometallics 2007, 26, 6624-6635.

(20) The ${ }^{13} \mathrm{C}$-labeled $\mathrm{SI}$ end group of $\mathrm{P}$-capped polymer chains is likely indistinguishable from $\mathrm{S} 1$ end groups in pure hydrocarbon polymer chains by ${ }^{13} \mathrm{C}$ NMR spectroscopy and qualifies as "polymer" despite the P-capping. However, short-chain alkylphosphine species, e.g., methyland propylphosphine species, containing ${ }^{13} \mathrm{CH}_{3}$-label are expected to exhibit different chemical ${ }^{13} \mathrm{C}$ NMR shifts as compared to $S 1$ end groups and do not qualify as "polymer". Consequently, some ${ }^{13} \mathrm{C}$-label will not at all be incorporated into the "polymer".

(21) While formation of ${ }^{\left({ }^{13}\right)} \mathrm{CH}_{4}$ may in principle result from hydrolysis with adventious traces of water in the reaction medium, we note that $1{ }^{13} \mathrm{CH}_{3}$ - $\mathrm{L}$ does not form ${ }^{13} \mathrm{CH}_{4}$ or ${ }^{13} \mathrm{CH}_{3} \mathrm{D}$ in rigorously dry (sodium-potassium alloy) thf- $d_{8}$ up to $378 \mathrm{~K}$ for $>5 \mathrm{~h}$ and that the same thf- $d_{8}$ batch was used for these ethylene oligomerizations in J. Young tubes.

(22) Carbon-phosphorus bond cleavage is not unprecedented: (a) MacGregor, S. Chem. Soc. Rev. 2007, 36, 67-76. (b) Garrou, P. E. Chem. Rev. 1985, 85, 171-185. (c) Morita, D. K.; Stille, J. K.; Norton, R K. J. Am. Chem. Soc. 1995, 117, 8576-8581. (d) Herrmann, W. A.; Broßmer, C.; Öfele, K.; Beller, M.; Fischer, H. J. Organomet. Chem. 1995, 491, C1-C4. (e) Wakioka, M.; Ozawa, F. Organometallics 2010, 29, $5570-5578$.

(23) See, for example: (a) de Graaf, W.; Boersma, J.; Smeets, W. J. J.; Spek, A. L.; van Koten, G. Organometallics 1989, 8, 2907-2917. (b) Ledford, J.; Shultz, C. S.; Gates, D. P.; White, P. S.; DeSimone, J. M.; Brookhart, M. Organometallics 2001, 20, 5266-5276.

(24) See, for example: (a) Ref 19b. (b) Zhang, D.; Guironnet, D.; Göttker-Schnetmann, I.; Mecking, S. Organometallics 2009, 28, 40724078.

(25) (a) Skupov, K. M.; Hobbs, J.; Marella, P.; Conner, D.; Golisz, S.; Goodall, B. L.; Claverie, J. P. Macromolecules 2009, 42, 6953-6963. (b) Ref $24 \mathrm{~b}$

(26) The mechanistic diversity for the exchange of phosphorus- and metal-bound carbyls has been reviewed: see ref $22 \mathrm{a}$.

(27) A similar formation of $1-\left(\mathrm{CH}_{2}\right)_{2 n} \mathrm{CH}_{3}$-(lutidine) characterized by ${ }^{1} \mathrm{H},{ }^{31} \mathrm{P}$, and ${ }^{1} \mathrm{H},{ }^{1} \mathrm{H}-\mathrm{gCOSY} \mathrm{NMR}$ experiments has already been reported: ref $12 \mathrm{a}$

(28) (a) Hristov, H. I.; DeKock, R. L.; Anderson, G. D. W.; GöttkerSchnetmann, I.; Mecking, S.; Ziegler, T. Inorg. Chem. 2005, 44, 78067818. (b) DeKock, R. L.; Hristov, I. H.; Anderson, G. D. W.; GöttkerSchnetmann, I.; Mecking, S.; Ziegler, T. Organometallics 2005, 24, 2679-2687.

(29) An unidentified chain coupling reaction of palladium carbyl complexes has been proposed to account for the increased polydispersity due to a bimodal distribution in living ethylene polymerization by palladium diimine complexes. Cleavage of palladium polymeryl species by triethylsilane after polymerization yields fully saturated polymer chains and avoids bimodal molecular weight distribution, thus narrowing polydispersities: Gottfried, A. C.; Brookhart, M. Macromolecules 2001, 34, 1140-1142.

(30) Complete inactivity of $\left.\left.\left[\kappa^{2} \text {-(anisyl) }\right)_{2} P, O\right)\right]_{2} \mathrm{Pd}(11)$ in ethylene polymerizations was also proven on a preparative scale with $10 \mu \mathrm{mol}$ of 11 under 5 bar ethylene pressure, $60 \mathrm{~min}$ polymerization time, in toluene at $363 \mathrm{~K}$

(31) X-ray diffraction analyses of five different palladium hydride complexes with a trans-disposition of oxygen and hydride at the palladium center have been deposited in the Cambrigde Crystallographic Database. In all these analyses the hydride was located in the electron density map and the palladium hydride bond distances range from $1.46 \AA$ for electron-deficient oxygen donors (pentafluorophenolate) to $1.57 \AA$ (phenolate, $\mathrm{H}_{2} \mathrm{O}$, arene carboxylate): (a) Braga, D.; Sabatino, P.; Di Bugno, C.; Leoni, P.j Pasquali, M. J. Organomet. Chem. 1987, 334, C46-C48. (b) Di Bugno, C.; Pasquali, M.; Sabatino, P.; Braga, D. Inorg. Chem. 1989, 28, 1390-1394. (c) Leoni, P.; Sommovigo, M.; Pasquali, M.; Midollini, S.; Braga, D.; Sabatino, P. Organometallics 1991, 10, 1038-1044. (d) Konnick, M. M.; Gandhi, B. A.; Guzei, I. A.; Stahl, S. S. Angew. Chem., Int. Ed. 2006, 45, 2904-2907. (e) Konnick, M. M.; Decharin, N.; Popp, B. V.; Stahl, S. S. Chem. Sci. 2011, 2, 326-330.

(32) The parent complex bis[ $\left[\left(\kappa^{2}-P, O\right)\right.$-diphenylphosphine benzenesulfonato]palladium has been analyzed by X-ray crystallography: (a) CCDC no. 246480: Schultz, T.; Pfaltz, A. Synthesis 2005, 1005-1011. (b) CCDC no. 274818: Hearley, A. K.; Nowack, R. J.; Rieger, B. Organometallics 2005, 24, 2755-2763.

(33) The NMR yield is likely underestimated, as some of the formed methane and $\mathrm{H}_{2}$ will be present in the headspace of the NMR tube.

(34) Note that for related anilidotropone nickel polymerization catalysts reductive elimination of anilinotropone from nickel hydride intermediates has been convincingly proposed to account for the formation of analogous, polymerization-inactive $[\mathrm{N}, \mathrm{O}]_{2} \mathrm{Ni}$ complexes: Jenkins, J. C.; Brookhart, M. J. Am. Chem. Soc. 2004, 126, 5827-5842. 
(35) Frisch, M.J.; Trucks, G. W.; Schlegel, H. B.; Scuseria, G. E.; Robb, M. A; Cheeseman, J. R.; Scalmani, G.; Barone, V.; Mennucci, B.; Petersson, G. A.; Nakatsuji, H.; Caricato, M.; Li, X; Hratchian, H. P.; Izmaylov, A. F.; Bloino, J.; Zheng, G.; Sonnenberg, J. L.; Hada, M.; Ehara, M.; Toyota, K.; Fukuda, R.; Hasegawa, J.; Ishida, M.; Nakajima, T.; Honda, Y.; Kitao, O.; Nakai, H.; Vreven, T.; Montgomery, J. A., Jr.; Peralta, J. E.; Ogliaro, F.; Bearpark, M.; Heyd, J. J.; Brothers, E.; Kudin, K. N.; Staroverov, V. N.; Kobayashi, R.; Normand, J.; Raghavachari, K; Rendell, A.; Burant, J. C.; Iyengar, S. S.; Tomasi, J.; Cossi, M.j Rega, N.; Millam, J. M.; Klene, M.; Knox, J. E.; Cross, J. B.; Bakken, V.; Adamo, C.; Jaramillo, J.; Gomperts, R; Stratmann, R. E.; Yazyev, O.; Austin, A. J.; Cammi, R.; Pomelli, C.; Ochterski, J. W.; Martin, R L.; Morokuma, K.; Zakrzewski, V. G.; Voth, G. A.; Salvador, P.; Dannenberg,J.J.; Dapprich, S.; Daniels, A. D.j Farkas, Ö.; Foresman, J. B.; Ortiz, J. V.; Cioslowski, J.; Fox, D. J. Gaussian 09, Revision A.1; Gaussian, Inc.: Wallingford, CT, 2009.

(36) Becke, A. D. Phys. Rev. A 1988, 38, 3098-3100

(37) Perdew, J. P. Phys. Rev. B 1986, 34, 7406-7406.

(38) Perdew, J. P. Phys. Rev. B 1986, 33, 8822-8824.

(39) (a) Dunning, T. H., Jr.; Hay, P.J. In Modern Theoretical Chemistry, Schaefer, H. F., III, Ed.; Plenum: New York, 1976; Vol. 3, pp 1-28. (b) Hay, P. J.; Wadt, W. R J. Chem. Phys. 1985, 82, 270-283.

(40) Reed, A. E.j Weinhold, F. J. Chem. Phys. 1983, 78, 4066-4073.

(41) Foster, J. P; Weinhold, F. J. Am. Chem. Soc. 1980, 102, 72117218.

(42) Reed, A. E.; Weinstock, R. B.; Weinhold, F. J. Chem. Phys. 1985, $83,735-746$.

(43) Reed, A. E.; Weinhold, F. J. Chem. Phys. 1985, 83, 1736-1740.

(44) Carpenter, J. E. Extension of Lewis structure concepts to openshell and excited-state molecular species, Ph.D. thesis, University of Wisconsin, Madison, WL, 1987.

(45) Carpenter, J. E.; Weinhold, F. J. Mol. Struct. (THEOCHEM) 1988, $46,41-62$.

(46) Reed, A. E.; Curtiss, L. A.; Weinhold, F. Chem. Rev. 1988, 88, $899-926$.

(47) Weinhold, F, Carpenter, J. E In The Structure of Small Molecules and Ions; Naaman, R. Vager, Z., Eds.; Plenum: New York, 1988; pp 227-

(48) Tomasi, J.; Mennucci, B.; Cammi, R. Chem. Rev. 2005, 10S, 2999-3094.

(49) For some crystallographically determined $\mathrm{P}-\mathrm{H}$ distances (isotropically refined) in $\mathrm{R}_{3} \mathrm{P}^{+} \mathrm{H}$, see, for example: Dureen, $M$. A.; Brown, C. C; Stephan, D. W. Organometallics 2010, 29, 6594-6607.

(50) For experimentally determined $\mathrm{M}-\mathrm{C}$ bond strengths: (a) Bennett, J. L.; Wolczanski, P. T. J. Am. Chem. Soc. 1997, 119, 10696-10719. (b) Wick, D. D; Jones, W. D. Organometallics 1999, 18, 495-505. For calculated $\mathrm{M}-\mathrm{C}$ bond strengths experimentally determined in refs (a) and (b): (c) Clot, E.; Mégret, C.; Eisenstein, O.; Perutz, R. N. J. Am. Chem. Soc. 2006, 128, 8350-8357.

(5I) This description holds true considering that a ca. $-40 \mathrm{~kJ} \mathrm{~mol}^{-1}$ entropic contribution to the formation of $\mathrm{Me}[\mathrm{P}, \mathrm{O}]+\mathrm{Pd}\left(\mathrm{P}^{t} \mathrm{Bu}_{3}\right)$ from one molecule 1- $\mathrm{CH}_{3}-\mathrm{P}^{t} \mathrm{Bu}_{3}$ makes $\mathrm{Me}[\mathrm{P}, \mathrm{O}]+\mathrm{Pd}\left(\mathrm{P}^{t} \mathrm{Bu}_{3}\right)$ ca. $60 \mathrm{~kJ}$ $\mathrm{mol}^{-1}$ less stable than $1-\mathrm{CH}_{3}-\mathrm{P}^{t} \mathrm{Bu}_{3}$, and ca. $110 \mathrm{~kJ} \mathrm{~mol}^{-1}$ less stable than 19-anisyl- $\mathrm{P}^{t} \mathrm{Bu}_{3}$.

(52) The reaction between $\mathbf{1}-\mathbf{H}-\mathbf{P}^{\prime} \mathbf{B u}_{3}$ and the zwitterionic $\mathrm{H}[\mathrm{P}, \mathrm{O}]$ ligand leads to an intermediate substitution product with the oxygen atom of $\mathrm{H}[\mathrm{P}, \mathrm{O}]$ coordinated to $\mathrm{Pd}$ that is about $40 \mathrm{~kJ} \mathrm{~mol}^{-1}$ higher in energy than $1-\mathrm{H}-[\mathrm{P}, \mathrm{O}] \mathrm{H}$. The related $\mathrm{TS}$ is about $60 \mathrm{~kJ} \mathrm{~mol}^{-1}$ less favored than TS 1-H-TS2.

(53) Heinekey, D. M.; Oldham, W. J., Jr. Chem. Rev. 1993, 93, 913926.

(54) We note that we also calculated the energetic profile for the reaction of $1-\mathrm{CH}_{3}-\left(\kappa-O\right.$-dmso) with $1-\mathrm{H}-\mathrm{P}^{\prime} \mathrm{Bu}_{3}$. The energy difference between the two coordination modes ( $\kappa-O$-dmso and $\kappa-S$-dmso) is only $4 \mathrm{~kJ} \mathrm{~mol}^{-1}$ in favor of $\kappa-O$-dmso coordination. However, due to the experimentally determined $\kappa-S$-dmso coordination mode (X-ray diffraction analysis) in the related [di( 2 '-methoxybiphen-2-yl)phosphine]benzensulfonato palladium methyl dmso complex (ref 10) and the only small difference in ground-state energies of $1-\mathrm{CH}_{3}-(\boldsymbol{\kappa}-\mathrm{O}-\mathrm{dmso})$ and $1-\mathrm{CH}_{3}-(\kappa-S$-dmso), we prefer to present the calculation starting from $1-\mathrm{CH}_{3}$ - $(\kappa-S$-dmso).

(55) For comparison see also: Zlegler, T.; Cheng, W.; Baerends, E. J.; Ravenek, W. Inorg. Chem. 1988, 27, 3458-3464.

(56) Blanksby, S. J.; Ellison, G. B. Acc. Chem. Res. 2003, 36, 255-263.

(57) The different behavior of $1-\mathrm{CH}_{2} \mathrm{CH}_{3}-\mathrm{PPh}_{3}$ and $1-\mathrm{CH}_{2} \mathrm{CH}_{3}$ $\mathrm{P}^{t} \mathrm{Bu}_{3}$ in the reaction with the protonated ligand $[\mathrm{P}, \mathrm{O}] \mathrm{H}$ is due to a

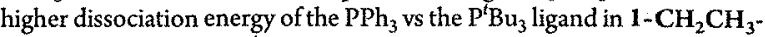
$\mathrm{PPh}_{3}$ and $1-\mathrm{CH}_{2} \mathrm{CH}_{3}-\mathbf{P}^{t} \mathrm{Bu}_{3}$. Steric interactions between the more bulky $\mathrm{P}^{t} \mathrm{Bu}_{3}$ and the ethyl group are responsible for the weaker coordination of $\mathrm{P}^{\prime} \mathrm{Bu}_{3}$ in $\mathbf{1}-\mathrm{CH}_{2} \mathrm{CH}_{3}-\mathrm{PH}^{\prime} \mathrm{Bu}_{3}$ as compared to $\mathrm{PPh}_{3}$ in $\mathbf{1}-\mathrm{CH}_{2} \mathrm{CH}_{3}-\mathrm{PPh}_{3}$.

(58) Trinquier, G.j Hoffmann, R Organometallics 1984, 3, 370-380.

(59) (a) Krishnamurthy, S.; Brown, H. C. J. Org. Chem. 1983, 48, 3085-3091. (b) Krishnamurthy, S.; Brown, H. C. J. Org. Chem. 1982, 47, 276-280. (c) Newcomb, M.; Curran, D. P. Acc. Chem. Res. 1988, 21, 206-214.

(60) (a) Cohen, A. J.; Mori-Sánchez, P.; Yang, W. Science 2008, 321, 792-794. (b) Lundberg, M.; Siegbahn, P. E. M. J. Chem. Phys. 2005, 122, 224103-224109.

(61) (a) Ito, S.; Manukata, K, Nakamura, A.; Nozaki, K. J. Am. Chem. Soc. 2009, 131, 14606-14607. (b) Piche, L.; Daigle, J.-C.; Rehse, G.; Claverie, J. P. Chem.-Eur. J. 2012, 18, 3277-3285. 